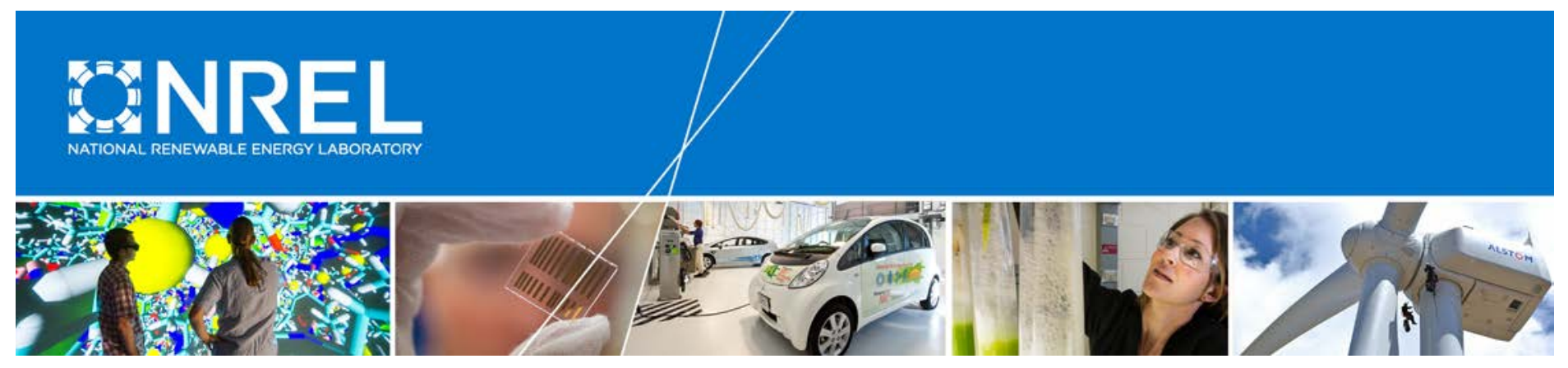

\title{
Analysis of Installed Measures and Energy Savings for Single- Family Residential Better Buildings Projects
}

M. Heaney and B. Polly National Renewable Energy Laboratory

NREL is a national laboratory of the U.S. Department of Energy Office of Energy Efficiency \& Renewable Energy Operated by the Alliance for Sustainable Energy, LLC

This report is available at no cost from the National Renewable Energy Laboratory (NREL) at www.nrel.gov/publications.

Technical Report

NREL/TP-5500-64091

April 2015

Contract No. DE-AC36-08GO28308 


\title{
Analysis of Installed Measures and Energy Savings for Single- Family Residential Better Buildings Projects
}

\author{
M. Heaney and B. Polly \\ National Renewable Energy Laboratory \\ Prepared under Task No. BE4R.0212
}

NREL is a national laboratory of the U.S. Department of Energy Office of Energy Efficiency \& Renewable Energy Operated by the Alliance for Sustainable Energy, LLC

This report is available at no cost from the National Renewable Energy Laboratory (NREL) at www.nrel.gov/publications.

National Renewable Energy Laboratory 15013 Denver West Parkway Golden, CO 80401

303-275-3000 • www.nrel.gov
Technical Report

NREL/TP-5500-64091

April 2015

Contract No. DE-AC36-08GO28308 


\title{
NOTICE
}

This report was prepared as an account of work sponsored by an agency of the United States government. Neither the United States government nor any agency thereof, nor any of their employees, makes any warranty, express or implied, or assumes any legal liability or responsibility for the accuracy, completeness, or usefulness of any information, apparatus, product, or process disclosed, or represents that its use would not infringe privately owned rights. Reference herein to any specific commercial product, process, or service by trade name, trademark, manufacturer, or otherwise does not necessarily constitute or imply its endorsement, recommendation, or favoring by the United States government or any agency thereof. The views and opinions of authors expressed herein do not necessarily state or reflect those of the United States government or any agency thereof.

This report is available at no cost from the National Renewable Energy Laboratory (NREL) at www.nrel.gov/publications.

Available electronically at SciTech Connect http:/www.osti.gov/scitech

Available for a processing fee to U.S. Department of Energy and its contractors, in paper, from:

\author{
U.S. Department of Energy \\ Office of Scientific and Technical Information \\ P.O. Box 62 \\ Oak Ridge, TN 37831-0062 \\ OSTI http://www.osti.gov \\ Phone: 865.576.8401 \\ Fax: 865.576.5728 \\ Email: reports@osti.gov
}

Available for sale to the public, in paper, from:

\author{
U.S. Department of Commerce \\ National Technical Information Service \\ 5301 Shawnee Road \\ Alexandra, VA 22312 \\ NTIS http://www.ntis.gov \\ Phone: 800.553 .6847 or 703.605 .6000 \\ Fax: 703.605.6900 \\ Email: orders@ntis.gov
}




\section{Acknowledgments}

The authors would like to thank Dale Hoffmeyer and David Lee of the U.S. Department of Energy Buildings Technology Program and Dave Roberts of the National Renewable Energy Laboratory for their support and guidance. The authors would also like to thank Noel Merket and Joseph Robertson of the National Renewable Energy Laboratory for their work to normalize Better Buildings utility billing data (major contributions to Appendix A), as well as Rebecca Ciraulo and Aayush Daftari of Navigant for their efforts in the collection of Better Buildings Program data. 


$\begin{array}{ll}\begin{array}{l}\text { List of Acronyms } \\ \text { BBNIS }\end{array} & \text { Better Buildings Neighborhood Information System } \\ \text { BBNP } & \text { Better Buildings Neighborhood Program } \\ \text { CV-RMSE } & \text { Coefficient of variation of the root mean squared error } \\ \text { EEM } & \text { Energy-Efficiency Measure } \\ \text { IMT } & \text { Inverse Modeling Toolkit } \\ \text { HVAC } & \text { Heating, Ventilating, and Air Conditioning } \\ \text { MLR } & \text { Multiple Linear Regression } \\ \text { NYSERDA } & \text { New York State Energy Research and Development Authority } \\ \text { PV } & \text { Photovoltaic } \\ \text { RECS } & \text { Residential Energy Consumption Survey } \\ \text { SD } & \text { Standard Deviation } \\ \text { TMY } & \text { Typical Meteorological Year }\end{array}$

iv 


\section{Executive Summary}

This report presents an analysis of data for residential single-family projects reported by 37 organizations that were awarded federal financial assistance (cooperative agreements or grants) by the U.S. Department of Energy's Better Buildings Neighborhood Program. ${ }^{1}$ The report characterizes the energy-efficiency measures installed for single-family residential projects and analyzes energy savings and savings prediction accuracy for measures installed in a subset of those projects.

The analysis documented in this report yielded the following conclusions:

- Air sealing and attic insulation were the most common installed measures ${ }^{2}$; both were present in five of the top ten most frequent combinations of measures.

- The percentage of projects having certain installed measures varied by:

○ Region of the country (e.g., houses in the South had the highest percentage of air conditioner replacement measures)

○ Vintage of the home (e.g., houses built in the 1990s had the highest percentage of air conditioner replacement measures)

- Simulations were used more often than deemed savings methods to estimate overall energy savings on projects. However, the multiple linear regression (MLR) analysis of total energy savings estimated by grantees indicated no significant differences in estimated savings between the deemed method and simulations.

- The five measures ${ }^{3}$ with the highest estimated energy savings, based on the MLR analysis, are solar photovoltaics, heat pumps, solar thermal, boilers, and wall insulation.

- The five measures with the lowest estimated energy savings, based on the MLR analysis, are low-flow aerators, thermostatic expansion valves, air conditioner tune-ups, dishwashers, and fireplace inserts.

- For the top ten energy-efficiency measure combinations (excluding medium-frequency measures), those with air sealing and attic insulation appear to have the greatest variation in estimated energy savings across all projects. Combinations with lighting and water heater installations have the least variation in estimated energy savings.

- There were significant differences in estimated energy savings per project by geographic region. The South had the lowest estimated average savings compared to three other standard census regions. There was not a significant correlation between estimated savings per project and regional energy consumption determined from Residential Energy

\footnotetext{
${ }^{1}$ There were actually 41 organizations that were awarded assistance, but four completed only multifamily projects or commercial projects or both.

${ }^{2}$ DOE has made available project data for 75,110 single-family projects. More information about the individual measures that were installed for those projects can be found in DOE (2015a) and the associated data files, which are available in DOE (2015b).

${ }^{3}$ For this analysis, measures included traditional energy-efficiency measures (e.g., insulation, equipment upgrades) as well as measures involving renewable energy (e.g., solar photovoltaics). Grantees estimated the reduction in net energy use that would result from solar installations. This was treated as the associated energy savings.
} 
Consumption Survey 2009 data, meaning that regions with higher average household energy consumption - according to RECS — did not necessarily have higher estimated savings values.

- MLR models of estimated energy savings using grantees as categories gave better fits than models using census region. The grantee categories captured location-dependent differences (e.g., climate, typical fuel types) as well as programmatic differences between grantees not captured by other regression variables.

- Based on the MLR analysis, the vintage ${ }^{4}$ of homes showed significant differences in estimated energy savings. Homes built before 1950 had the highest estimated savings compared to homes built in other years.

- Based on the MLR analysis, projects with loans had approximately 5 to 8 MMBtu greater estimated annual source energy savings than projects without loans. The mean retrofit invoiced cost on projects with loans was more than double the mean retrofit invoiced cost on projects without loans.

- Estimated energy savings were generally greater than the savings derived from utility data for the small subset of projects that had sufficient utility data:

- For natural gas, $68 \%$ of projects in the subset (data from 9 grantees, representing only $2 \%$ of single-family projects) had estimates greater than 1.5 times the normalized utility savings.

- For electricity, $53 \%$ of projects in the subset (data from 17 grantees, representing only $3 \%$ of single-family projects) had estimates greater than 1.5 times the normalized utility savings.

- Although savings were generally overestimated for homes in the small subset, the average savings derived from utility data were positive. According to these utility data, the average annual source electricity savings was $17.1 \mathrm{MMBtu}$ and the average annual source natural gas savings was 13.2 MMBtu.

Some ideas for future work follow:

- Conduct focused studies within subsets of data (e.g., data for a particular grantee) that present unique opportunities for insights.

- Investigate the potential benefit of calibrating savings prediction models to pre-retrofit billing data to improve the accuracy of savings predictions.

\footnotetext{
${ }^{4}$ The vintage of the home could be a proxy for many things, including the construction practices and energy codes at the time the house was built.
} 


\section{Table of Contents}

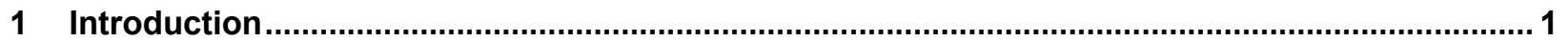

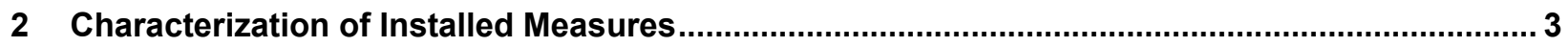

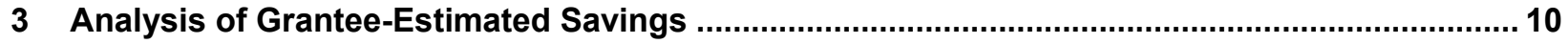

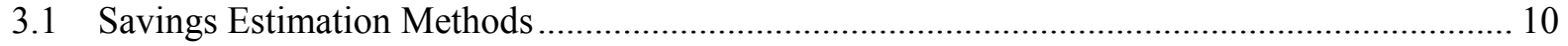

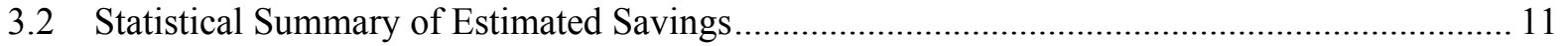

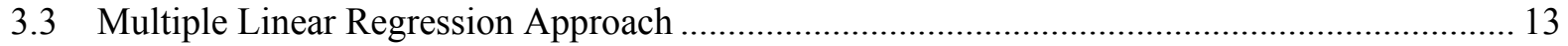

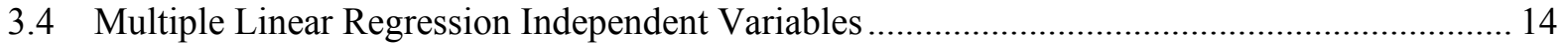

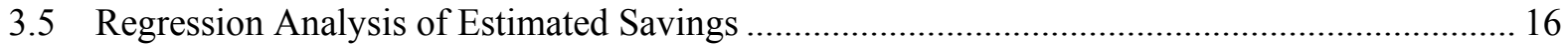

3.6 Regional and Vintage Comparisons to the Residential Energy Consumption Survey................ 28

4 Comparing Utility-Bill-Calculated Savings to Grantee-Estimated Savings .............................. 31

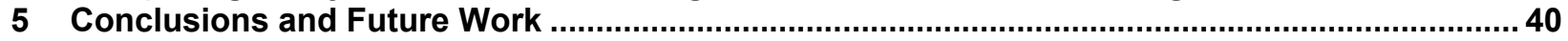

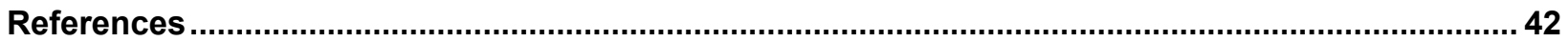

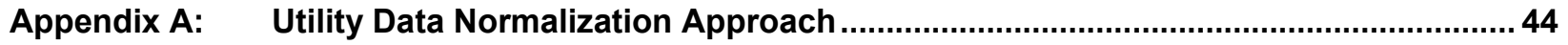

Extracting and Merging BBNIS Project Data and Utility Data.................................................... 44

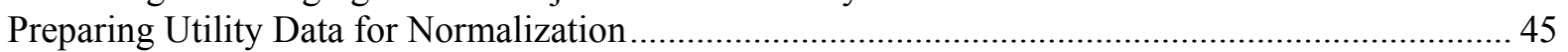

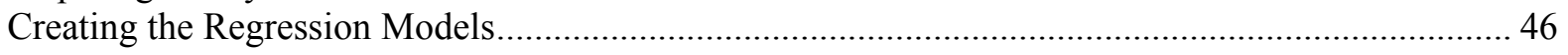

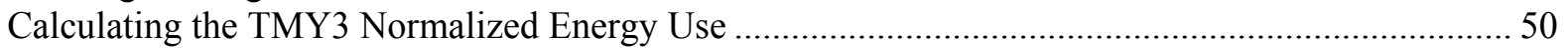

Appendix B: Energy-Efficiency Measure Tables ...................................................................... 51

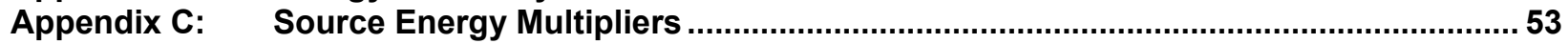

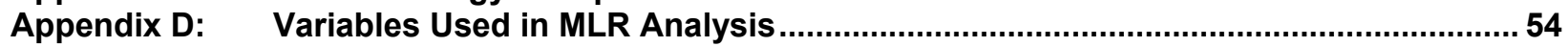

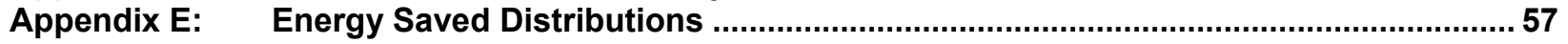




\section{List of Figures}

Figure 1. Number of each measure type installed for single-family homes, excluding projects from NYSERDA and Town of Bedford

Figure 2. Number of each measure type installed for single-family homes for NYSERDA and Town of Bedford

Figure 3. Percent of single-family projects that include specific measure types, excluding projects from NYSERDA and Town of Bedford

Figure 4. Percent of single-family projects that include specific measure types for NYSERDA and Town

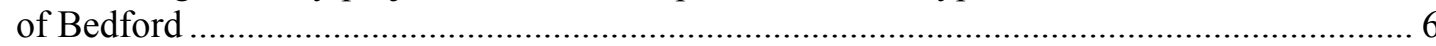

Figure 5. Percent of single-family projects that include specific measure types broken out by region of the country, excluding projects from NYSERDA and Town of Bedford .................................... 7

Figure 6. Percent of single-family projects that include specific measure types broken out by year of construction, excluding projects from NYSERDA and Town of Bedford.............................. 8

Figure 7. Percentage of single-family projects using particular estimation methods ............................... 11

Figure 8. Percentage of single-family projects using particular prediction methods after adjustments...... 11

Figure 9. Estimated energy saved versus MLR model predictions for initial MLR model and residuals versus MLR model predictions. Energy saved has units of source MMBtu/year.................. 17

Figure 10. Log of estimated energy saved versus MLR model predictions and residuals versus regression model predictions. Energy saved has units of source MMBtu/year......................................... 18

Figure 11. Log of estimated energy saved versus MLR model predictions and residuals versus MLR model predictions using the test data set. Energy saved has units of source MMBtu/year.... 19

Figure 12. Comparison of baseline energy used (from RECS) to estimated energy saved attributable to

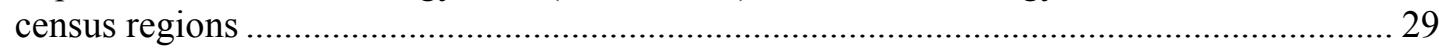

Figure 13. Comparison of baseline energy used (from RECS) to estimated energy saved attributable to vintage of homes

Figure 14. Normalized pre-retrofit natural gas energy uses ("Normalized") versus estimated pre-retrofit natural gas use ("Estimated"). All estimates are in source MMBtu. $\mathrm{N}=5,349$...

Figure 15. Normalized pre-retrofit electricity energy use ("Normalized") versus estimated electricity use

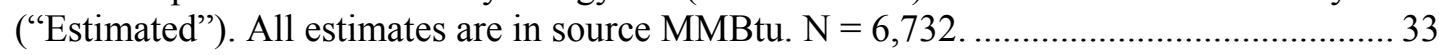

Figure 16. Normalized natural gas savings ("normalized") versus grantee estimated natural gas savings ("estimated"). All estimates are in source MMBtu. $\mathrm{N}=1,408$..

Figure 17. Normalized electricity savings ("normalized") versus grantee estimated electricity savings

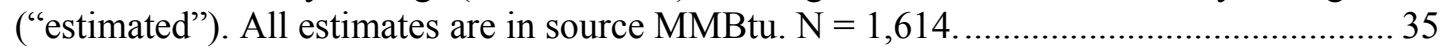

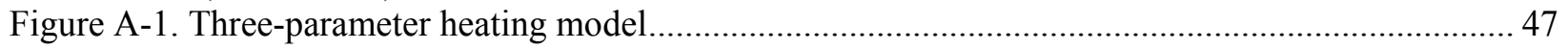

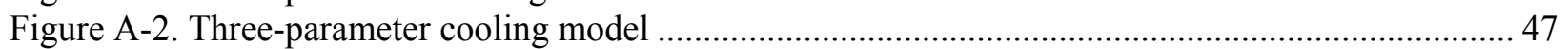

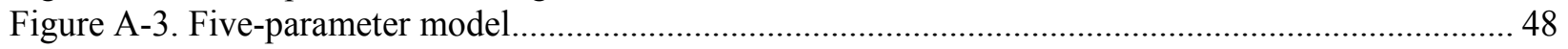

Figure E-1. Distributions of estimated energy saved for EEM combinations. Savings units are in source MMBtu. 


\section{List of Tables}

Table 1. Ten Most Frequent Combinations of Measures ...................................................................... 8

Table 2. Statistics on EEM Counts and Proportion of Projects That Include Specific Measures Broken Out by Quartiles of Estimated Source Energy Savings (MMBtu/year) ..................... 12

Table 3. Variability of Estimated Source Energy Savings (MMBtu/year) by Ten Most Frequent Combinations

Table 4. MLR Regression Model for Log (Estimated Energy Saved): R-Squared = 0.437, Adjusted $\mathrm{R}-$ Squared $=0.435$, Degrees of Freedom $=33389$.

Table 5. MLR Regression Model for Estimated Energy Saved: R-Squared = 0.370, Adjusted R-Squared $=0.369$, Degrees of Freedom $=33389$.

Table 6. CENSUS_REGION Estimates From MLR Regression Model for Estimated Energy Saved: R-Squared $=0.293$, Adjusted R-Squared $=0.292$, Degrees of Freedom $=33,420 \ldots \ldots \ldots \ldots \ldots . .25$

Table 7. Basic Statistical Summary of FLOORAREA, RETROFITJOBHOURS and RETROFITINVOICEDCOST After Removing Missing and Zero Values. .25

Table 8. MLR Regression Model for Estimated Energy Saved: R-Squared = 0.405, Adjusted R-Squared $=0.403$, Degrees of Freedom $=19597$ 26

Table 10. Project Counts, Mean Natural Gas Realization Rates, SD Natural Gas Realization Rates for Grantees and Adjusted Prediction Method Combinations 37

Table 11. MLR Regression to Test Electricity Realization Rate as a Function of Grantees: R-Squared = 0.106, Adjusted R-Squared $=0.098$ Degrees of Freedom $=1,198$ 38

Table 12. Project Counts, Mean Electricity Realization Rates, SD Electricity Realization Rates for Grantee, and Adjusted Prediction Method Combinations...................................................... 39

Table A-1. Data Extracted for Weather-Normalization Process............................................................. 44

Table A-2. Example Normalization Scenarios for One Project .............................................................. 45

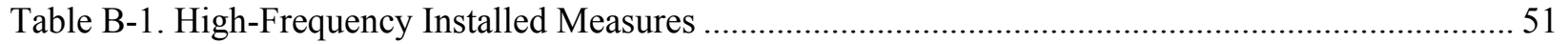

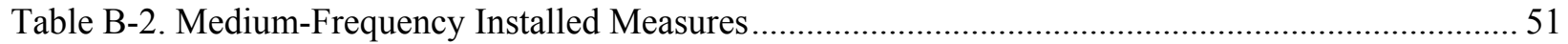

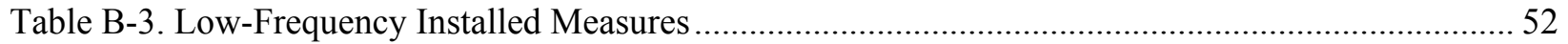

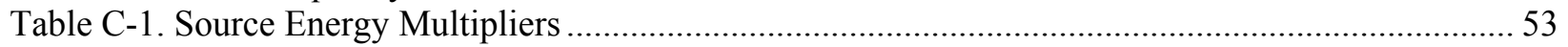

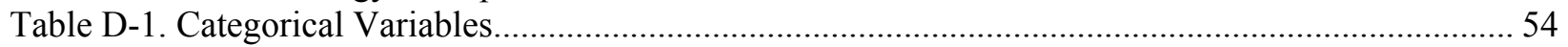

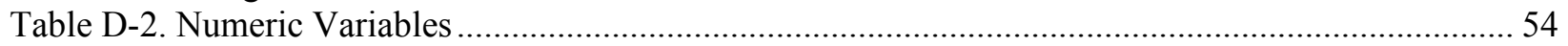

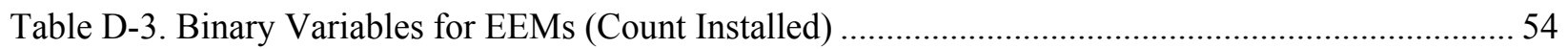

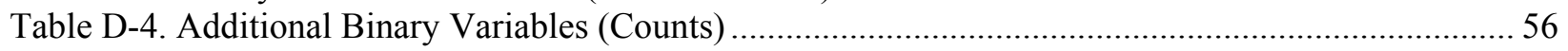

Table E-1. Ten Most Frequent Combinations of Measures .................................................................. 57 


\section{Introduction}

This report presents an analysis of data for residential single-family projects reported by 37 organizations that were awarded federal financial assistance (cooperative agreements or grants) by the U.S. Department of Energy's Better Buildings Neighborhood Program (BBNP). Background information about BBNP and the reported data, including discussions of data sources and data quality, can be found in Better Buildings Neighborhood Program-Summary of Reported Data from July 1, 2010 - September 30, 2013 (DOE 2014).

This report characterizes the energy-efficiency measures (EEMs) installed for single-family residential projects and analyzes energy savings and savings prediction accuracy for measures installed in a subset of those projects. This report is not an evaluation of the BBNP program or a final report of the recipients' activities. Additional resources related to program evaluations and final reports are described in DOE (2014):

Two additional sources of information may be useful to researchers interested in the accomplishments of BBNP award recipients. First, is an independent evaluation of BBNP conducted by Research Into Action, NMR Group, Nexant, and Evergreen Economics. A Preliminary Process and Market Evaluation report was released in December 2012 and a Preliminary Energy Savings Impact Evaluation report was released in November 2013. Final reports will be released in 2015. Second, as the recipient's final technical report is completed it will be available on the BBNP website. The final technical report was written by the recipient and contains more detailed information about the recipients' accomplishments and lessons learned. Some recipients conducted independent evaluations of their programs; the final technical report is a source for locating those evaluations.

The following specific research questions were initially identified to guide the analysis presented in this report:

1. Across all projects, how many of each measure type were installed?

○ Which combinations of measure were most common?

- Were certain measures more common in different areas of the country?

- Were certain measures more common in different vintages of homes?

2. What methods of prediction were used and how frequently?

3. What is the distribution of estimated annual energy savings for homes with particular individual improvements and combinations of improvements?

- Which measures were associated with the highest estimated savings? Lowest?

- Which measures were associated with the most variability in estimated savings? Least?

- Do estimated savings vary by geographic region, climate, and vintage of home?

$\circ$ Is there a difference in the distribution of energy savings between projects with a loan versus projects without a loan? 
4. For homes with sufficient pre- and post-retrofit utility data, how do estimated energy savings compare to utility-bill-calculated savings?

$\circ$ Which energy savings estimation methods have most accurately predicted energy savings?

- Are estimation methods more accurate for certain measures or combinations of measures? Certain vintages of homes? Certain areas of the country?

The remainder of this report is divided into the following sections (the analysis questions covered by each section are noted in the parentheses):

Section 2: Characterization of Installed Measures (Question 1)

Section 3: Analysis of Grantee-Estimated Savings (Questions 2 and 3)

Section 4: Comparing Utility-Bill-Calculated Savings to Grantee-Estimated Savings (Question 4) Section 5: Conclusions and Future Work. 


\section{Characterization of Installed Measures}

Grantees participating in the BBNP completed approximately 76,000 single-family residential projects ${ }^{5}$ between the fourth quarter of 2010 and the end of the fourth quarter of 2013 (some grantees continued to complete projects after September 30, 2013). Of these, approximately 66,000 had one or more installed measures recorded. The following are general observations about installed measures reported for the single-family home projects:

- About $87 \%$ of the projects listed one or more installed measures.

- Twenty-eight of the 37 grantees completing single-family projects had identifiable installed measures on $90 \%$ or more of their projects.

- The "Core Energy" category, used by the New York State Energy Research and Development Authority (NYSERDA) and Town of Bedford, does not clearly define specific installed measures. Seventy-seven percent of NYSERDA projects and $91 \%$ of Town of Bedford projects had "Core Energy" listed.

- There were 50,102 projects with one or more installed measures after NYSERDA and Town of Bedford were excluded.

- Forty-one installed measures categories resulted in 4,581 unique combinations.

Figure 1 shows the number of different measure types installed in single-family homes, excluding measures from NYSERDA and Town of Bedford. The two most frequent EEMs were air sealing and attic insulation. These were followed by lighting, water heater, hot water insulation, low-flow aerator, furnace, floor/foundation insulation, wall insulation, duct sealing, and then EEMs with fewer than 7,000 counts.

In lieu of project level installed measure detail, NYSERDA and Town of Bedford provided a summarized list of installed measures for approximately 16,000 of their single-family home projects. Figure 2 shows the number of different measures using this summarized list. Different categories were used; thus, they are not directly comparable to Figure 1, but there are some similarities. Insulation (which likely includes attic, wall, and floor) and air sealing were the top two categories. The "other" category was third, which most likely implies that many measures were not uniquely identified. Different types of water heaters were separated on Figure 2, whereas all water heater types are summed in one field on Figure 1. Furnace and lighting (compact fluorescent lamps for NYSERDA and Town of Bedford) were in the top 10 categories for both Figure 1 and Figure 2.

\footnotetext{
${ }^{5}$ DOE has made available project data for 75,110 single-family projects. More information about the individual measures that were installed for those projects can be found in Better Buildings Neighborhood Program Data Documentation (DOE 2015a) and the associated data files, which are available in DOE (2015b).
} 


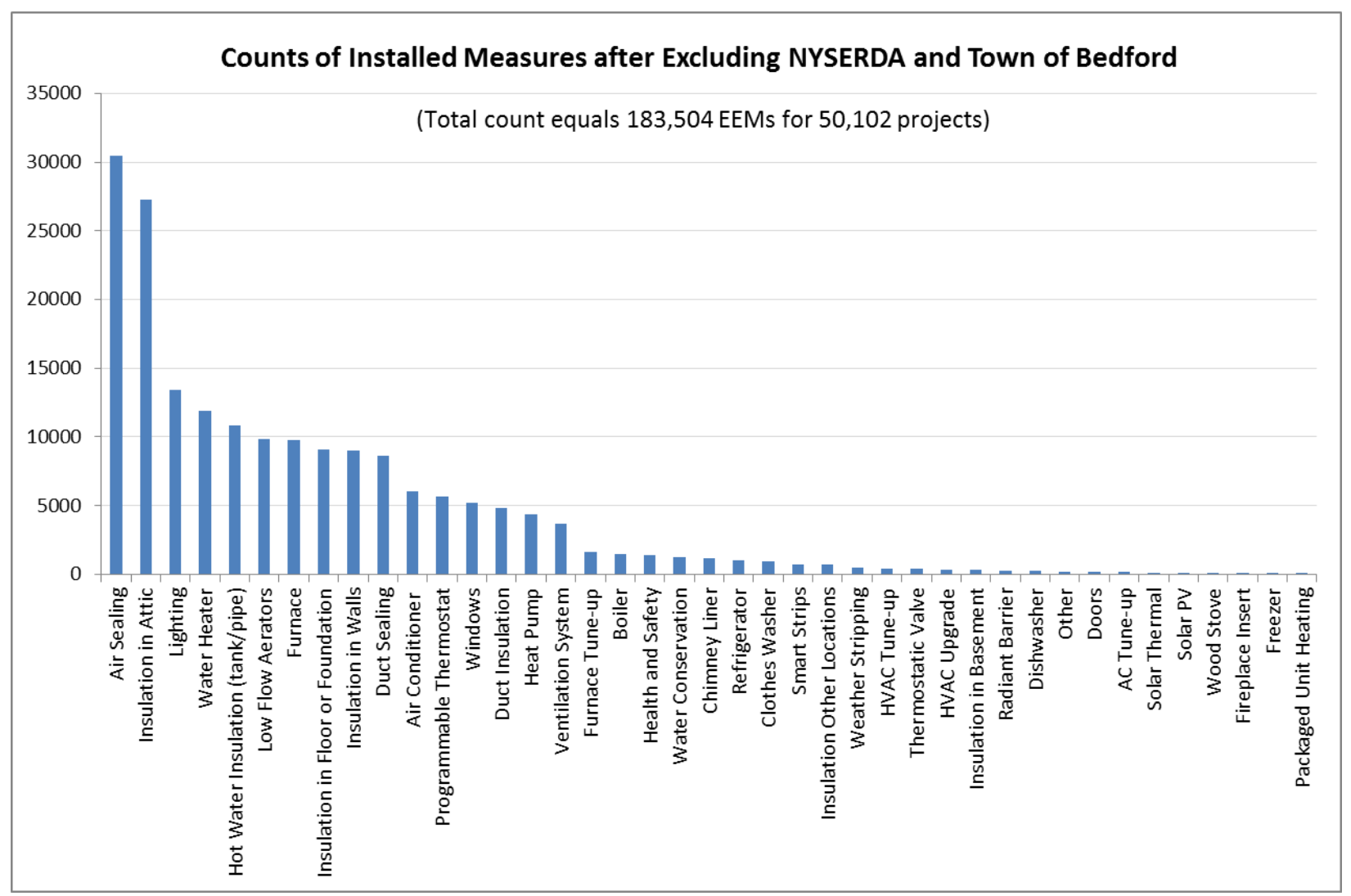

Figure 1. Number of each measure type installed for single-family homes, excluding projects from NYSERDA and Town of Bedford 


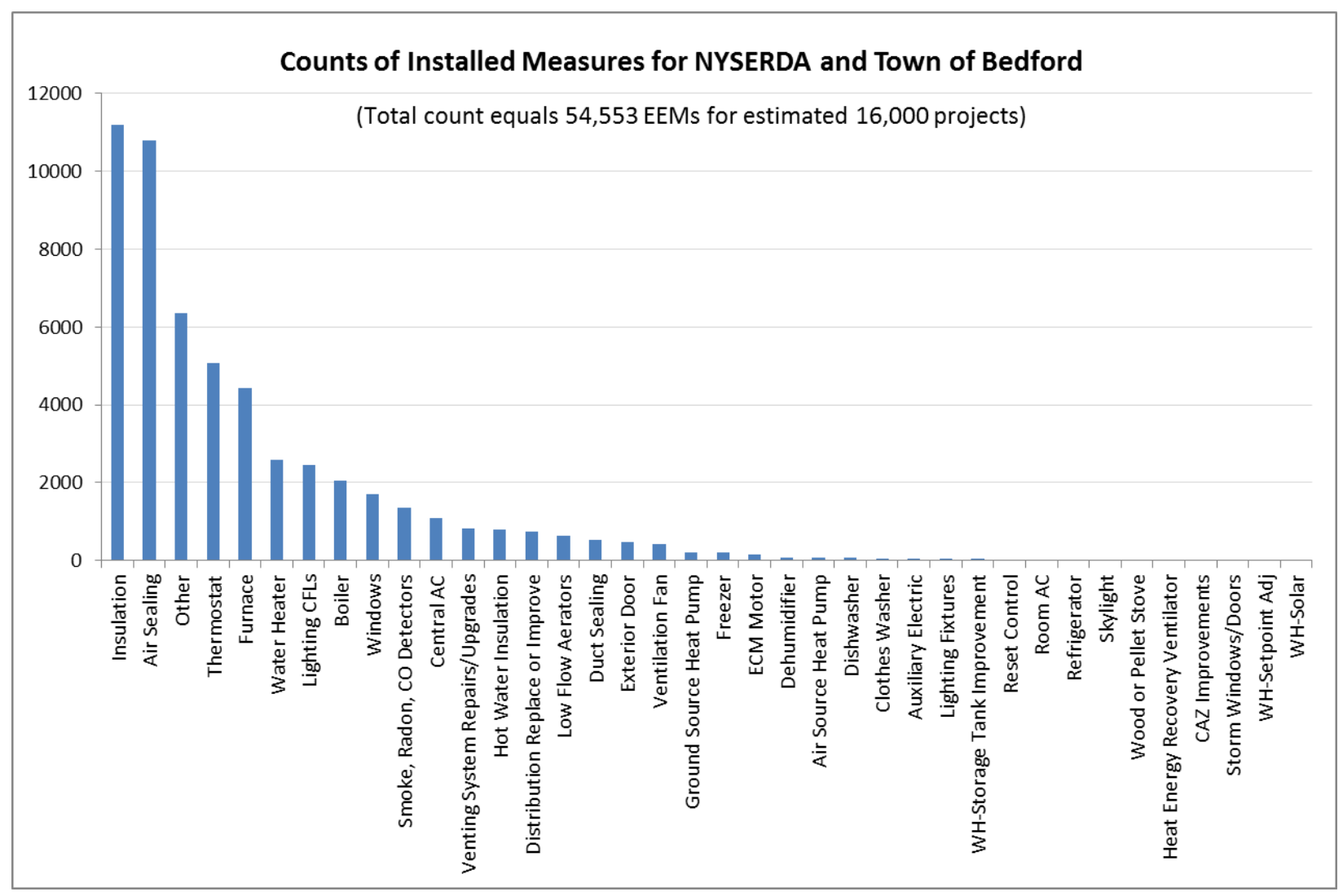

Figure 2. Number of each measure type installed for single-family homes for NYSERDA and Town of Bedford

The percentage of projects having particular measures is shown in Figure 3 for the 16 most frequent measures (excludes NYSERDA and Town of Bedford projects). The percentage of projects having particular measures for NYSERDA and Town of Bedford is shown in Figure 4 for the 16 most frequent measures. Four types of water heaters were pooled for this graph to be more consistent with the water heater category reported at the project level by other grantees. Again, there are similarities between NYSERDA projects and other grantee projects. For example, if attic insulation, wall insulation, and floor/foundation insulation projects are combined, this would be the highest percent measure on both Figure 3 and Figure 4. Air sealing would then be the second-highest percent measure. Water heaters, furnaces, and lighting upgrades are in the top seven EEMs. 


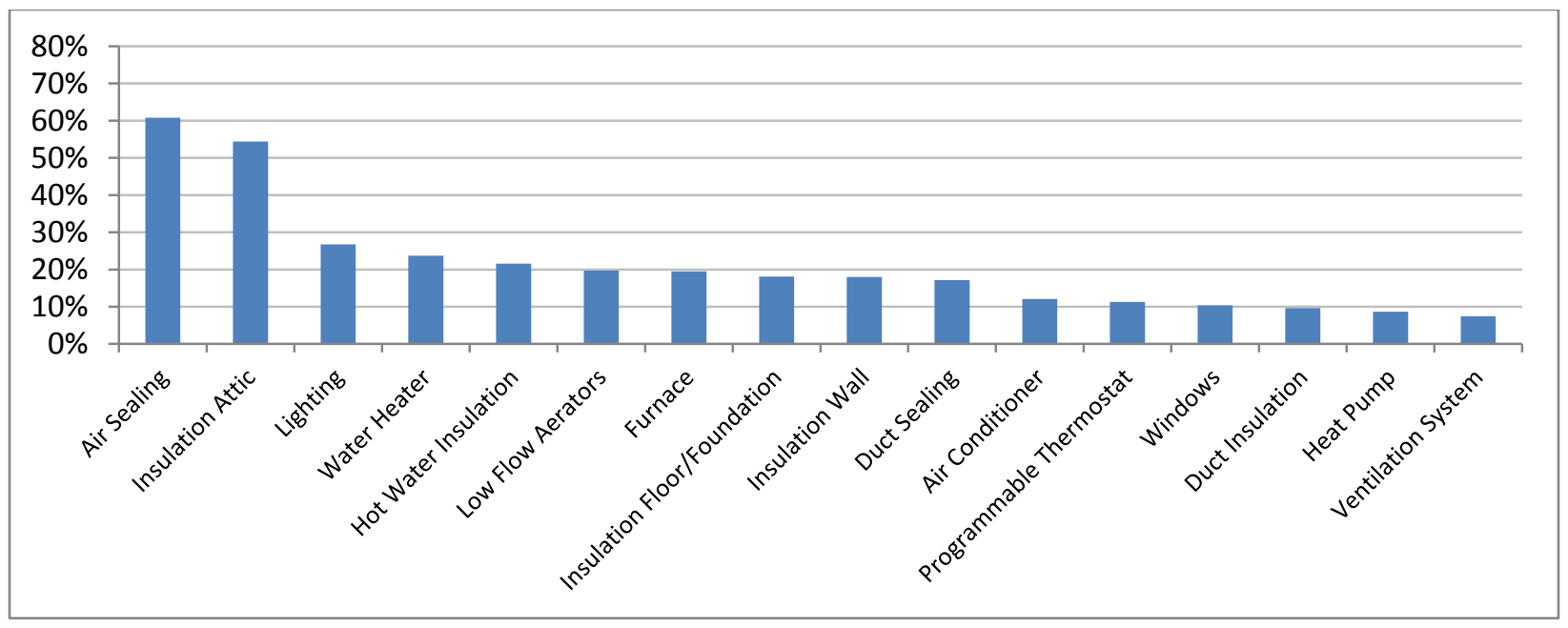

Figure 3. Percent of single-family projects that include specific measure types, excluding projects from NYSERDA and Town of Bedford

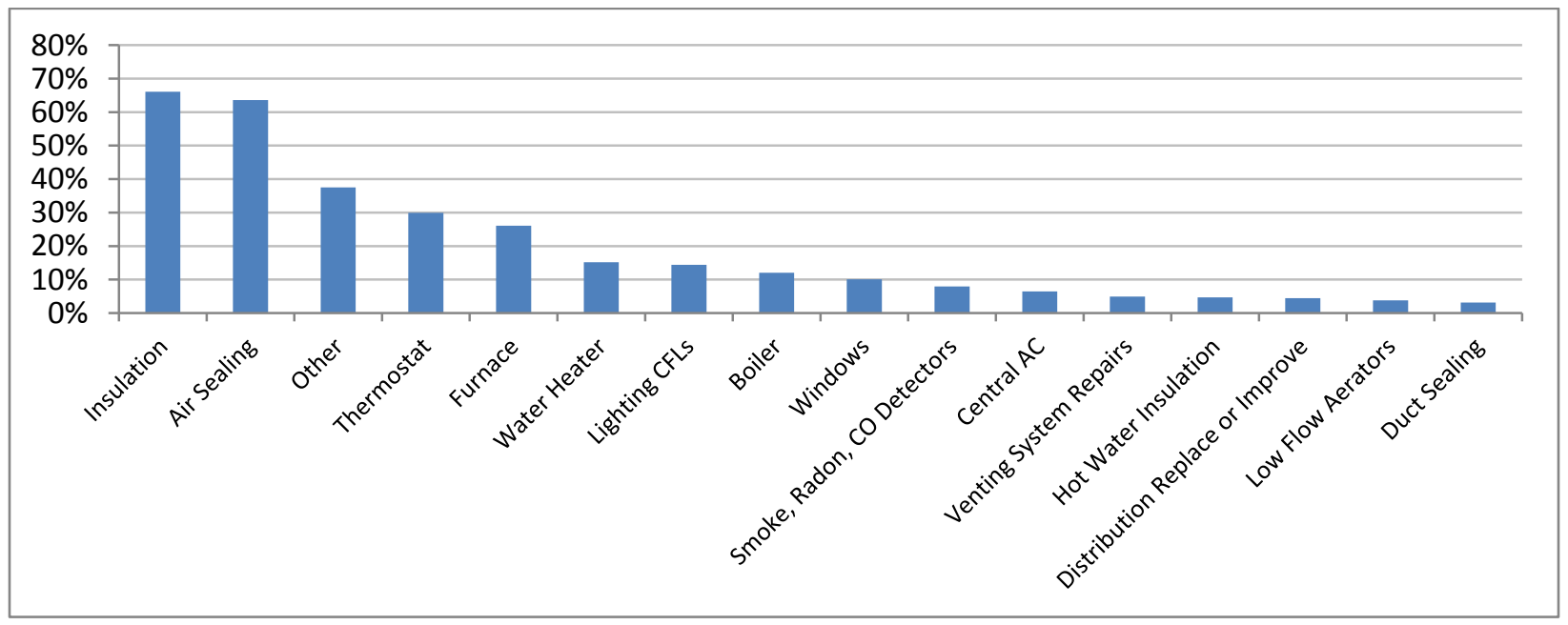

Figure 4. Percent of single-family projects that include specific measure types for NYSERDA and Town of Bedford

For Figure 5, the percentages are broken out by region of the country. NYSERDA and Town of Bedford measures were excluded from this analysis, because these measures were not reported at the individual project level. Of the remaining grantees, there were eight grantees in the Midwest completing approximately 18,000 projects; eight grantees in the Northeast completing approximately 8,000 projects; nine grantees in the South completing approximately 8,000 projects; and ten grantees in the West completing approximately 13,000 projects. Notable observations from Figure 5 include:

- Air sealing was performed in the highest percentage of projects in the Northeast and lowest in the South. 
- Measures related to domestic hot water occurred in a higher percentage of projects for the Midwest than for any other region of the country.

- Air conditioner and duct sealing measures occurred in a higher percentage of projects for the South than for any other region of the country.

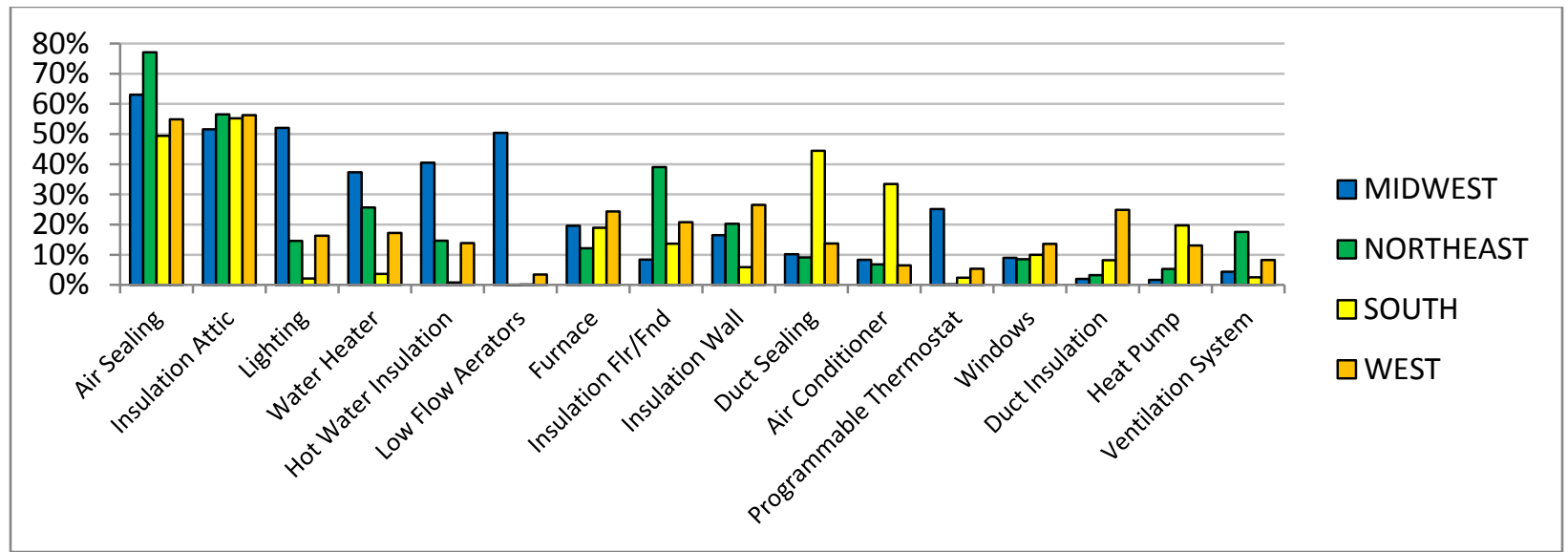

Figure 5. Percent of single-family projects that include specific measure types broken out by region of the country, excluding projects from NYSERDA and Town of Bedford

The year of construction was recorded for approximately 35,000 single-family homes. Figure 6 shows the percentage that includes specific measure types broken out by year of construction. Residential energy efficiency codes first came into effect in 1975 (U.S. Department of Energy 2010); however, actual code adoption can take anywhere from 1 to 10 years (Livingston et al. 2014). Homes were divided into categories that essentially reflect pre-code built homes (approximately 1979 and older) and homes built for each decade from $1980 \mathrm{on}$. Homes built from 2010 through 2013 were included with homes built from 2000 through 2009 just because there were very few projects on these homes. The count of projects on homes built prior to 1980 was approximately 27,000. This group was divided into homes built prior to 1960 and homes built from 1960 to 1979. Notable observations from Figure 6 include:

- Air sealing and attic insulation were generally implemented in a higher percentage of projects for older than for newer vintages of homes.

- Furnace, duct sealing, and air conditioner measures were implemented in a higher percentage of projects for homes built in the 1990s than for any other vintage; it is possible that the original heating, ventilating, and air-conditioning (HVAC) equipment in these homes was often near its end of life (e.g., approximately 20 years old) and was therefore frequently a good candidate for replacement. 


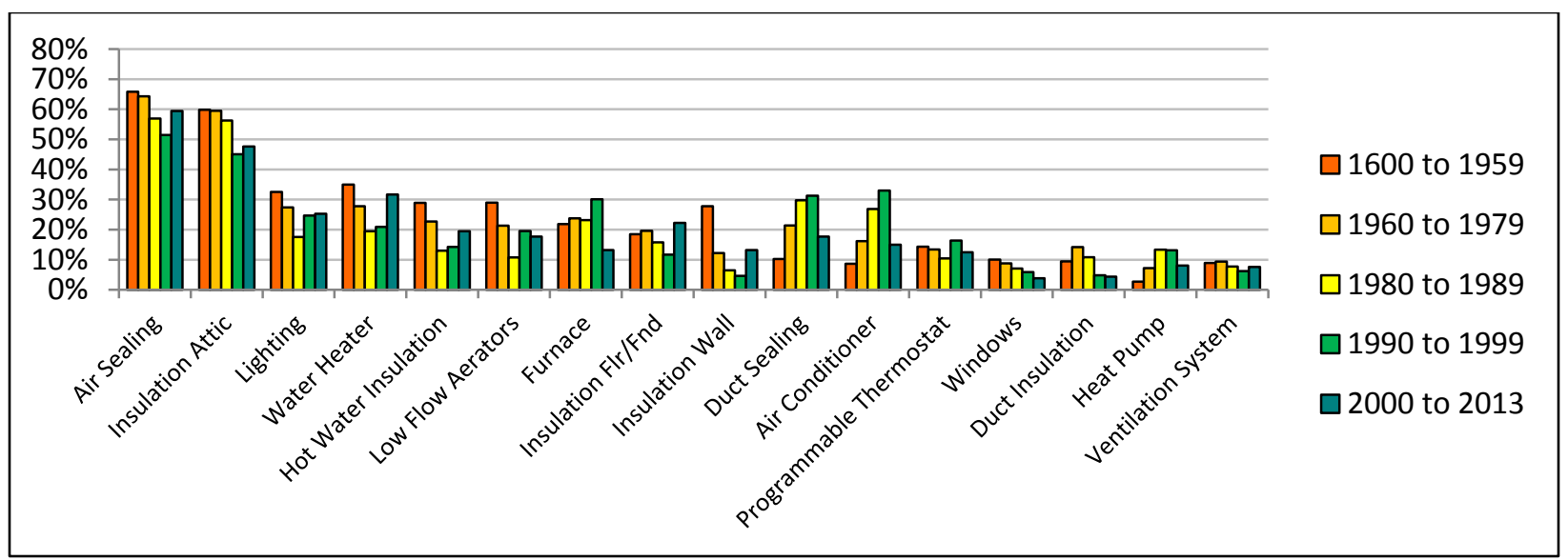

Figure 6. Percent of single-family projects that include specific measure types broken out by year of construction, excluding projects from NYSERDA and Town of Bedford

In many cases, multiple measures were installed in a single home. Analysis was performed to determine the most common measures and combinations of measures. First, measures were categorized as high-frequency, medium-frequency, or low-frequency based on their number of installs (refer to Appendix B). Medium- and low-frequency measures were grouped together and treated as individual measures. Table 1 shows the 10 most frequent combinations of measures, which represent $33 \%$ of the 50,102 single-family projects (this count excludes NYSERDA and Town of Bedford projects). A value of 1 in this table indicates that a particular measure was included in the combination.

Table 1. Ten Most Frequent Combinations of Measures

\begin{tabular}{|c|c|c|c|c|c|c|c|c|c|c|c|c|c|c|c|}
\hline 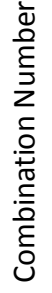 & 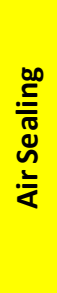 & 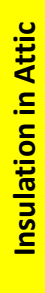 & 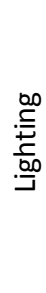 & 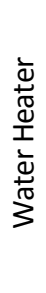 & 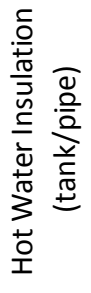 & $\begin{array}{l}n \\
0 \\
+0 \\
\frac{0}{0} \\
0 \\
0 \\
3 \\
0 \\
4 \\
3 \\
0\end{array}$ & 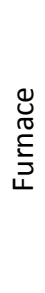 & 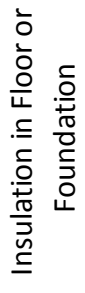 & 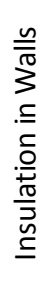 & 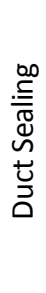 & 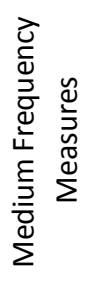 & 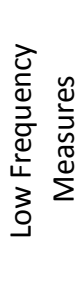 & 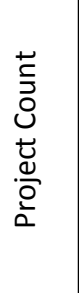 & 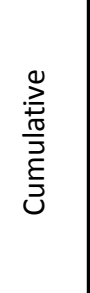 & 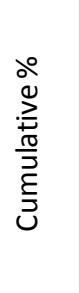 \\
\hline 1 & 0 & 0 & 0 & 0 & 0 & 0 & 0 & 0 & 0 & 0 & 1 & 0 & 3689 & 3689 & $7 \%$ \\
\hline 2 & 1 & 1 & 0 & 0 & 0 & 0 & 0 & 0 & 0 & 0 & 0 & 0 & 3598 & 7287 & $15 \%$ \\
\hline 3 & 1 & 1 & 0 & 0 & 0 & 0 & 0 & 1 & 0 & 0 & 0 & 0 & 1964 & 9251 & $18 \%$ \\
\hline 4 & 1 & 1 & 0 & 0 & 0 & 0 & 1 & 0 & 0 & 1 & 1 & 0 & 1208 & 10459 & $21 \%$ \\
\hline 5 & 0 & 0 & 0 & 1 & 0 & 0 & 0 & 0 & 0 & 0 & 0 & 0 & 1109 & 11568 & $23 \%$ \\
\hline 6 & 0 & 1 & 0 & 0 & 0 & 0 & 0 & 0 & 0 & 0 & 0 & 0 & 1007 & 12575 & $25 \%$ \\
\hline 7 & 1 & 1 & 0 & 0 & 0 & 0 & 0 & 0 & 1 & 0 & 0 & 0 & 978 & 13553 & $27 \%$ \\
\hline 8 & 0 & 0 & 1 & 0 & 1 & 1 & 0 & 0 & 0 & 0 & 0 & 0 & 954 & 14507 & $29 \%$ \\
\hline 9 & 0 & 0 & 1 & 1 & 1 & 1 & 1 & 0 & 0 & 0 & 1 & 0 & 935 & 15442 & $31 \%$ \\
\hline 10 & 1 & 0 & 0 & 0 & 0 & 0 & 0 & 0 & 0 & 0 & 0 & 0 & 931 & 16373 & $33 \%$ \\
\hline
\end{tabular}

The fact that "Medium-Frequency Measures" occur most frequently showcases the diversity of measures installed across the BBNP. Air sealing and attic insulation alone was the second most frequent combination of measures, representing approximately $8 \%$ of the projects. Air sealing 
and insulation in attic both occurred in 5 of the 10 most frequent combinations of measures. In many cases, either water heater replacement or insulation in attic was the only measure installed in the home, according to the grantee reporting. Distribution plots of energy saved for the combinations in Table 1 are shown in Appendix E. 


\section{Analysis of Grantee-Estimated Savings}

Grantees reported estimations of savings for approximately 47,500 of the single-family projects. Section 3.1 describes the types of methods that were used to estimate savings and how frequently they were used. Section 3.2 includes tabular and graphical summaries of the estimated savings values. Finally, the approach and results of a multiple linear regression (MLR) analysis of estimated savings values are described in Sections 3.3-3.5.

\subsection{Savings Estimation Methods}

Two fields in Better Buildings Neighborhood Information System (BBNIS) database indicated methods of energy saving prediction:

- AUDITSOFTWARENAME

- PREDICTIONMETHODTYPEDESC.

A pick list was used in the spreadsheet template that most grantees used to submit data; however, some grantees pasted in data, meaning they entered names that were not in the pick list. A few grantees supplied data using XML files and then these fields were "free-form" entry. This resulted in many software names and prediction methods that were not in the original pick list. Grantee responses were categorized as one of the following:

1. Simulation — simulation software listed or indicated

2. Missing or None - indication that software or prediction method was not reported such as blank field, zero, "NA," or the word "missing"

3. Unknown - possible simulation software but not a well-known simulation software tool

4. Deemed-deemed savings listed

5. Other-a method listed but likely not a simulation software tool.

Although the AUDITSOFTWARENAME field was supposed to list simulation software only, entries such as "deemed savings" were occasionally entered in this field. The agreement between the two fields is poor, as indicated in Figure 7. In particular, the prediction method had a very high percentage of entries of missing or none. Further examination of the data indicated that in some cases a grantee might have entered the software tool used in the AUDITSOFTWARENAME but not in the PREDICTIONMETHODTYPEDESC.

To adjust for this, the audit software category was inserted into the prediction method when the prediction method was "Missing or None." Figure 8 shows the change in prediction method categories after making this adjustment. The agreement is improved, but the Prediction Method Category still indicates a higher percentage of projects using "Deemed" than reported for the Audit Software Category. 

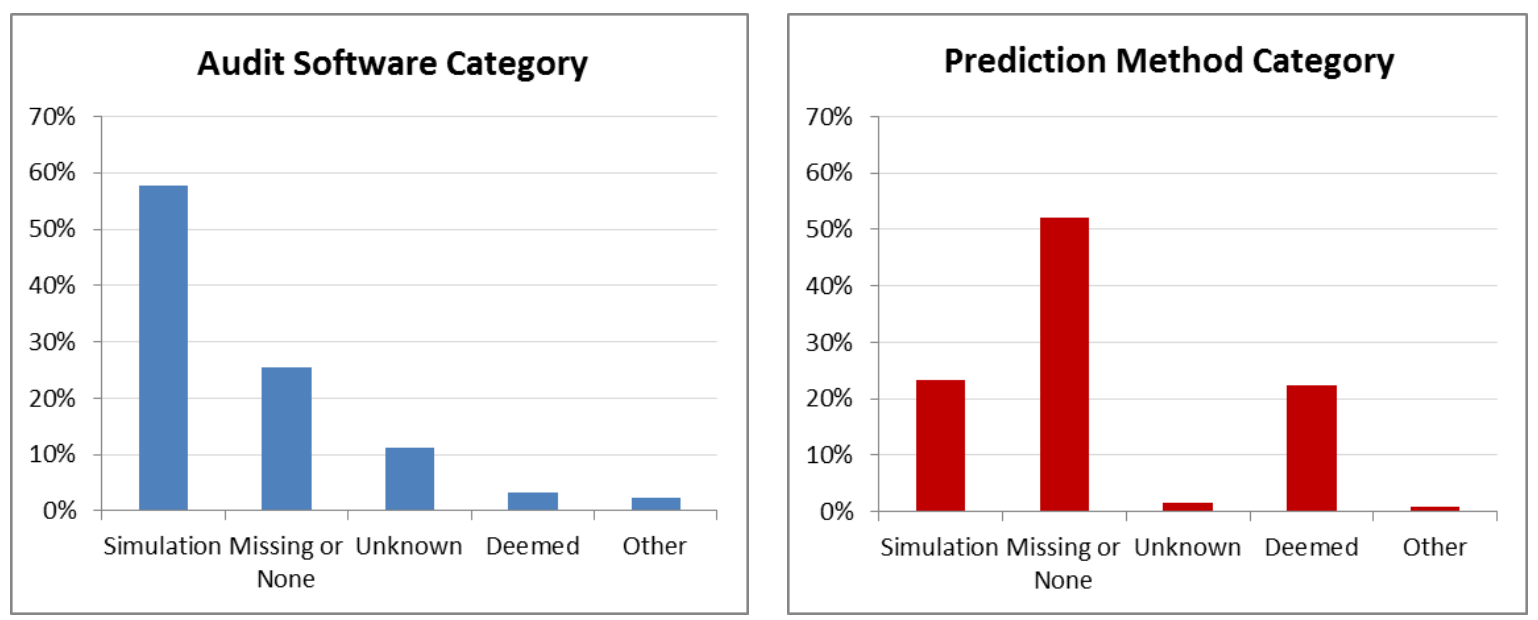

Figure 7. Percentage of single-family projects using particular estimation methods

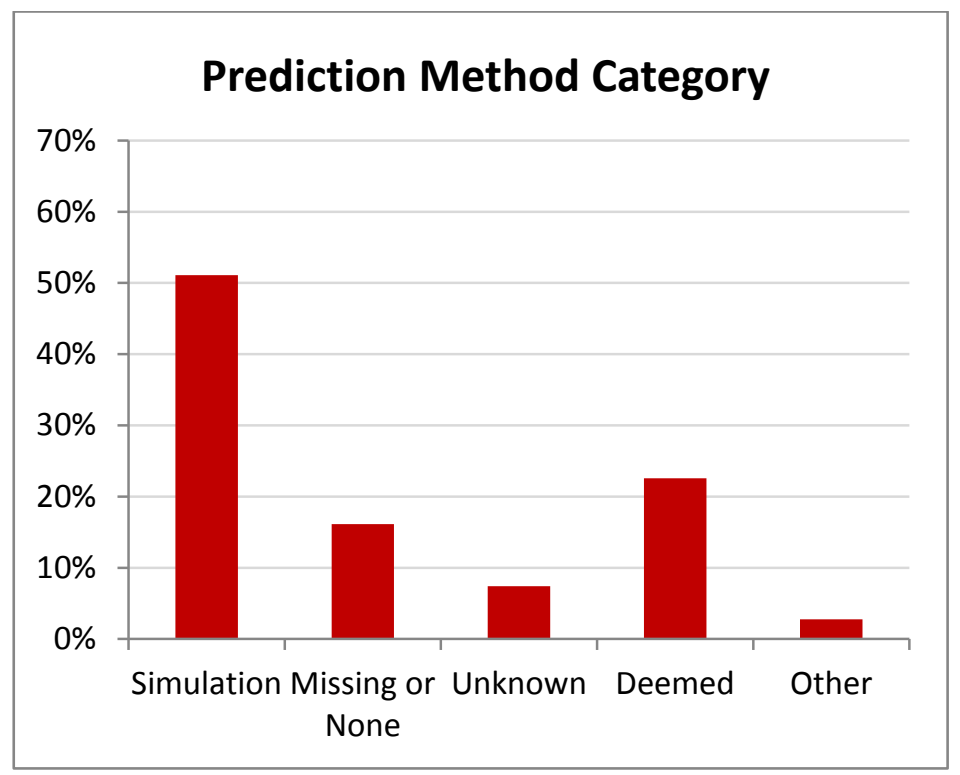

Figure 8. Percentage of single-family projects using particular prediction methods after adjustments

\subsection{Statistical Summary of Estimated Savings}

For many projects, estimated savings were reported for more than one fuel type. The total estimated source energy savings was calculated by first converting the savings for each fuel type to source energy and then summing these estimated savings. Site-to-source multipliers used for this project are listed in Appendix C. The projects were filtered to include only projects with one or more EEMs and then projects with missing values for estimated total source energy savings were excluded. Extremely low and extremely high estimated savings were suspected to be outliers; therefore, additional filtering was done to include projects between the 0.5 and 99.5 percentiles of estimated source energy savings. 
A simple analysis was done as a first check to see if particular measures might correlate with estimated savings. Quartiles were determined based on estimated savings and then the data were summarized by these quartiles, including statistics on EEM counts and the proportions of the most common installed measures, as seen in Table 2 (Quartile 1 includes projects with the lowest estimated savings and Quartile 4 includes projects with the highest estimated savings).

Table 2. Statistics on EEM Counts and Proportion of Projects That Include Specific Measures Broken Out by Quartiles of Estimated Source Energy Savings (MMBtu/year)

\begin{tabular}{|l|c|c|c|c|}
\hline \multicolumn{1}{|c|}{ Quartiles } & $\mathbf{1}$ & $\mathbf{2}$ & $\mathbf{3}$ & $\mathbf{4}$ \\
\hline Project Count & 12337 & 11815 & 11635 & 11721 \\
\hline 2.5th Percentile EEM Count & 1 & 1 & 1 & 1 \\
\hline Median EEM Count & 3 & 3 & 3 & 4 \\
\hline 97.5th Percentile EEM Count & 7 & 8 & 8 & 9 \\
\hline Mean EEM Count & 3.3 & 3.7 & 3.8 & 4.1 \\
\hline Standard Deviation (SD) EEM Count & 2.0 & 2.0 & 2.1 & 2.1 \\
\hline Proportion Air Sealing & 0.38 & 0.60 & 0.71 & 0.76 \\
\hline Proportion Insulation Attic & 0.29 & 0.51 & 0.69 & 0.71 \\
\hline Proportion Lighting & 0.43 & 0.32 & 0.18 & 0.16 \\
\hline Proportion Water Heater & 0.35 & 0.24 & 0.18 & 0.19 \\
\hline Proportion Hot Water Insulation & 0.36 & 0.28 & 0.14 & 0.11 \\
\hline Proportion Low-Flow Aerators & 0.38 & 0.23 & 0.11 & 0.08 \\
\hline Proportion Furnace & 0.16 & 0.17 & 0.23 & 0.23 \\
\hline Proportion Insulation Floor Foundation & 0.08 & 0.15 & 0.19 & 0.29 \\
\hline Proportion Insulation Wall & 0.07 & 0.14 & 0.21 & 0.31 \\
\hline Proportion Duct Sealing & 0.07 & 0.17 & 0.22 & 0.24 \\
\hline Proportion Medium-Frequency Measures & 0.42 & 0.45 & 0.53 & 0.53 \\
\hline Proportion Low-Frequency Measures & 0.19 & 0.27 & 0.20 & 0.23 \\
\hline Mean Energy Saved & $\mathbf{1 0 . 8}$ & $\mathbf{2 6 . 4}$ & $\mathbf{4 3 . 1}$ & $\mathbf{9 4 . 3}$ \\
\hline SD Energy Saved & 5.2 & 4.0 & 6.3 & 41.5 \\
\hline Relative SD & 0.48 & 0.15 & 0.15 & 0.44 \\
\hline
\end{tabular}

As seen in Table 2, the Median EEM Count increases from 3 (Quartile 1) to 4 (Quartile 4). This indicates some potential correlation between the average number of EEMs and the estimated energy saved, but it is likely only one of many factors that contribute to the large differences in average estimated savings across the Quartiles. This simple analysis shows a correlation of greater estimated energy savings with higher proportions of air sealing combined with attic insulation. Other EEMs (furnace installations, floor and foundation insulation, etc.) had proportions less than 0.5 but still increased with increasing energy savings. The proportions for lighting, water heater, hot water insulation, and low-flow aerators were all greater for the lowest energy savings quartile. A variance test indicated that the SD of estimated energy saved is significantly greater for Quartile 4 than the SD for the other quartiles. This is possibly due to a greater number of combinations within this Quartile and the fact that Quartile 4 contains the 
upper "tail" of estimated energy savings values. The results in Table 2 show that estimated energy savings is likely a function of the different EEMs used on a project.

Because there were so many combinations of EEMs, trying to determine which individual measures had the highest or lowest estimated energy savings variability was virtually impossible. Table 3 lists the ten most frequent combinations (also listed in Table 1). The $2.5^{\text {th }}$ percentile, median, $97.5^{\text {th }}$ percentile of estimated energy savings are shown in Table 3 for each combination along with the $95^{\text {th }}$ percentile range $\left(97.5^{\text {th }}\right.$ percentile minus $2.5^{\text {th }}$ percentile $)$. The $95^{\text {th }}$ percentile range is a measure of variability. From this table, Combination 1 has the largest $95^{\text {th }}$ percentile range (highlighted in yellow) and includes only medium-frequency EEMs. Combinations 2, 3, 7, and 10 show large variability (highlighted in light orange) and include both air sealing and attic insulation, except Combination 10, which includes air sealing but not attic insulation.

Combinations 4 and 6 show medium variability (highlighted in light green); Combination 4 includes air sealing and attic insulation; Combination 6 includes only attic insulation.

Combinations 5, 8, and 9 do not include air sealing or attic insulation and show the lowest variability (not highlighted). Distribution plots of these ten most frequent combinations listed in Table 1 are shown in Appendix E. In general the distributions are nonnormal; however, the differences in variability between combinations can be seen.

Table 3. Variability of Estimated Source Energy Savings (MMBtu/year) by Ten Most Frequent Combinations

\begin{tabular}{|c|c|c|c|c|c|r|r|r|r|}
\hline $\begin{array}{c}\text { Combi- } \\
\text { nation }\end{array}$ & $\begin{array}{c}\text { Air } \\
\text { Sealing }\end{array}$ & $\begin{array}{c}\text { Insula- } \\
\text { tion } \\
\text { Attic }\end{array}$ & Lighting & $\begin{array}{c}\text { Water } \\
\text { Heater }\end{array}$ & $\begin{array}{c}\text { Med.- } \\
\text { Freq. } \\
\text { Mea- } \\
\text { sures }\end{array}$ & $\begin{array}{c}\text { 2.5th } \\
\text { Pctl. } \\
\text { Energy } \\
\text { Saved }\end{array}$ & $\begin{array}{c}\text { Median } \\
\text { Energy } \\
\text { Saved }\end{array}$ & $\begin{array}{c}\text { 97.5th } \\
\text { Pctl. } \\
\text { Energy } \\
\text { Saved }\end{array}$ & $\begin{array}{c}\text { 95th } \\
\text { Pctl. } \\
\text { Range }\end{array}$ \\
\hline 1 & 0 & 0 & 0 & 0 & 1 & 3 & 33 & 149 & 146 \\
\hline 2 & 1 & 1 & 0 & 0 & 0 & 8 & 38 & 130 & 122 \\
\hline 3 & 1 & 1 & 0 & 0 & 0 & 11 & 43 & 140 & 129 \\
\hline 4 & 1 & 1 & 0 & 0 & 1 & 13 & 41 & 109 & 96 \\
\hline 5 & 0 & 0 & 0 & 1 & 0 & 1 & 9 & 38 & 37 \\
\hline 6 & 0 & 1 & 0 & 0 & 0 & 3 & 21 & 100 & 97 \\
\hline 7 & 1 & 1 & 0 & 0 & 0 & 12 & 51 & 149 & 137 \\
\hline 8 & 0 & 0 & 1 & 0 & 0 & 2 & 11 & 32 & 30 \\
\hline 9 & 0 & 0 & 1 & 1 & 1 & 2 & 11 & 43 & 41 \\
\hline 10 & 1 & 0 & 0 & 0 & 0 & 1 & 21 & 134 & 133 \\
\hline
\end{tabular}

\subsection{Multiple Linear Regression Approach}

MLR was used to develop empirical models to test the significance and the amount of energy savings that could be attributed to the various project measures. This section covers the approach taken, the resulting models, and the conclusions that can be drawn from these models.

The general model equation for MLR follows:

$$
y=\beta_{0}+\beta_{1} x_{1}+\beta_{2} x_{2}+\ldots+\beta_{n} x_{n}+\varepsilon
$$


where,

$\mathrm{y}$ is the dependent variable

$\beta_{0}$ is the intercept

$\beta_{1}$ through $\beta_{n}$ are the coefficients

$x_{1}$ through $x_{n}$ are the independent variables (inputs)

$\varepsilon$ is the remaining error.

In MLR, a least-squares-fit algorithm is applied to a data set that contains multiple records; each record contains one $y$-value and its associated $x$-values. Most statistical software programs calculate the coefficients and probability values that allow one to determine which independent variables are significant. Although one starts out initially with a model containing practically all possible independent variables, common practice is to eliminate insignificant variables until a "reduced" model containing only significant variables is achieved.

The output from most MLR programs is a table that contains the following statistics for each variable used in the model:

- Coefficient

- Standard error

- $t$ value

- Probability value.

The coefficient is determined from the least-squares fit, the standard error is essentially the SD calculated for each coefficient, the $t$ value is the coefficient divided by the standard error and the probability value is determined from the Student's $t$ distribution (Interpreting Regression Output 2007). The probability value $(\operatorname{Pr}(>|t|))$ is used to determine whether a variable is significant. In general, a probability value of 0.05 or less is considered significant. The $\mathrm{R}$ language was used for statistical analysis of this study's data (R Core Team 2014). The output from the R program uses the term Estimate for coefficients (Rodríguez 2013). The absolute t value gives a reasonable indication of the importance of a variable. In addition to the table, the regression output includes the estimates for R-squared and adjusted R-squared. R-squared is also referred to as the coefficient of determination and indicates how well data points fit a line or curve regardless of whether the terms in the model are significant. Adjusted R-squared takes into consideration whether the model improves significantly as terms are added (Montgomery 1997).

\subsection{Multiple Linear Regression Independent Variables}

The independent variables collected in the BBNP database were screened for completeness and variable validity. The variables considered for MLR analysis are listed in Appendix D. The variables fall into three types: (1) categorical, (2) numeric, and (3) binary. Often categorical variables are converted to binaries by creating a binary variable for each category. There were only three categorical variables of interest. Because it was desirable to see the estimated regression coefficient regardless of whether the particular category was significant, these 
variables were left as is (not converted to binary variables). For categorical variables, the $\mathrm{R}$ language automatically assigned one category as a control and the other categories were then compared against the assigned control. For these reasons, if a categorical variable was found significant in the model, coefficients and $\mathrm{P}$ values for all the categories were reported, regardless of whether individual $P$ values were 0.05 or less.

The three categorical variables are the GRANTEE (randomly assigned letter codes for each grantee), CENSUS_REGION and PRED_METHOD_CAT_2 (adjusted as described in Section 3.1). Because specific grantees are unique to each census region, a separate model was generated using CENSUS_REGION (excluding GRANTEE) and then using GRANTEE (excluding CENSUS_REGION). The reason for including GRANTEE or CENSUS_REGION in the model is that other factors such as climate and fuel type can impact the estimate of energy savings. Rather than attempt to join climate variables to the data or determine proportions of fuel types for each location, GRANTEE or CENSUS_REGION can be used to account for some of these additional factors. With the exception of RETROFIT_YR, the numeric variables had substantial missing observations. Numeric variables with many missing observations cannot be used in the MLR analysis as is. In some cases a numeric variable can be treated as a binary variable where the binary only indicates whether the information has been reported.

RENEWABLEINVOICEDCOST_LISTED is set to 1 when TOTALRENEWABLEINVOICEDCOST is reported. The reason for using this variable is that 256 projects were found that had renewable invoiced cost reported but no other indication of renewable measures; thus, RENEWABLEINVOICEDCOST_LISTED becomes an additional indicator that a renewable measure was installed. Most other numeric variables with many missing observations were excluded from the MLR analysis of this data. On the other hand, when the number of missing observations is smaller, a subset can be analyzed. FLOORAREA, RETROFITJOBHOURS, and RETROFITINVOICEDCOST were tested on a subset of data after filtering from $0.5^{\text {th }}$ percentile to $99.5^{\text {th }}$ percentile of these variables.

The EEMs were coded as binary variables where 1 means the particular measure was installed on a project and 0 means it was not. Appendix D includes a table of 41 EEM categories with the counts of projects where the measures were installed. Packaged unit heating only occurred on two projects and thus was not included in the regression analysis.

The binary variables LOANAMOUNT_LISTED and LOAN_OBTAINED were essentially the same. LOAN_OBTAINED includes an additional 25 projects where a loan approval date-but no loan amount - was reported. The loan amount was reported on 8,053 projects.

LOANAMOUNT_LISTED generally gave slightly higher adjusted R-squared values and became the default for testing the impact of having a loan for the project.

Four binary variables were created to examine the possible correlation between estimated energy savings and service provider certifications:

1. AUDIT_BPI_CERT_auditor was BPI certified

2. AUDIT_OTHER_CERT_-auditor was certified but not BPI certified

3. CONTRACT_BPI_CERT—contractor was BPI certified

4. CONTRACT_OTHER_CERT_contractor was certified but not BPI certified. 
Appendix D includes a complete listing of binary variables considered for the MLR analysis.

\subsection{Regression Analysis of Estimated Savings}

The total estimated source energy savings (MMBtu/year) was the dependent variable modeled as a function of the various independent variables described in Section 3.4. To evaluate the resulting model, $70 \%$ of the available data was randomly selected as the training data set. These were the data used to create a model. The model was then applied to the remaining $30 \%$ of the data to determine how well the model can predict. R-squared and adjusted R-squared were used for comparison. If a binary variable did not have at least 10 counts in the training data set, it was excluded from further consideration.

An initial model had an adjusted R-squared of 0.371 with many variables being significant. Figure 9 shows the estimates of energy saved versus the regression model predictions and the residuals versus the regression model predictions. If the model were perfect, all observations would fall on the black line indicating perfect agreement between the regression model and observations. The residuals plot (lower graph in Figure 9) is a diagnostic tool used to see if the residuals are random across the prediction range or if some pattern emerges. As seen in Figure 9, the variability (as indicated by the residuals) increases with increasing predicted values. When this occurs, the probability of incorrectly determining the significance of variables increases.

The residuals were analyzed in more detail to determine a variance stabilizing transformation (Box et. al. 1978). This analysis indicated that the log of energy saved should help stabilize the variance. The problem with transforming the dependent variable was that interpreting the effect of the independent variables on the untransformed dependent variable became more difficult. The approach taken was to determine potentially significant variables using the model with log of energy saved, and then create a model of energy saved as a function of just the variables found significant using the $\log$ transformation. For model reduction using log of energy saved, the stepAIC function was used with the Bayesian Information Criterion option (Henze et al. 2014). The probability values from the model of energy saved were used as a final determination of the significance of a variable without further removal of variables.

Figure 10 shows the model results using log of estimated energy saved. Although the residuals from the model using the log of estimated energy saved still are not entirely uniform over the prediction range, the adjusted R-squared is 0.435 (a substantial improvement over 0.371 for the initial model). The model was then applied to the test data. This gave an adjusted R-squared value of 0.433 , indicating that the model can predict with approximately the same level of accuracy as observed from the training data set. Figure 11 shows plots of energy saved from the test data set versus regression predicted values. 


\section{Model of ESTIMATED ENERGY SAVED}

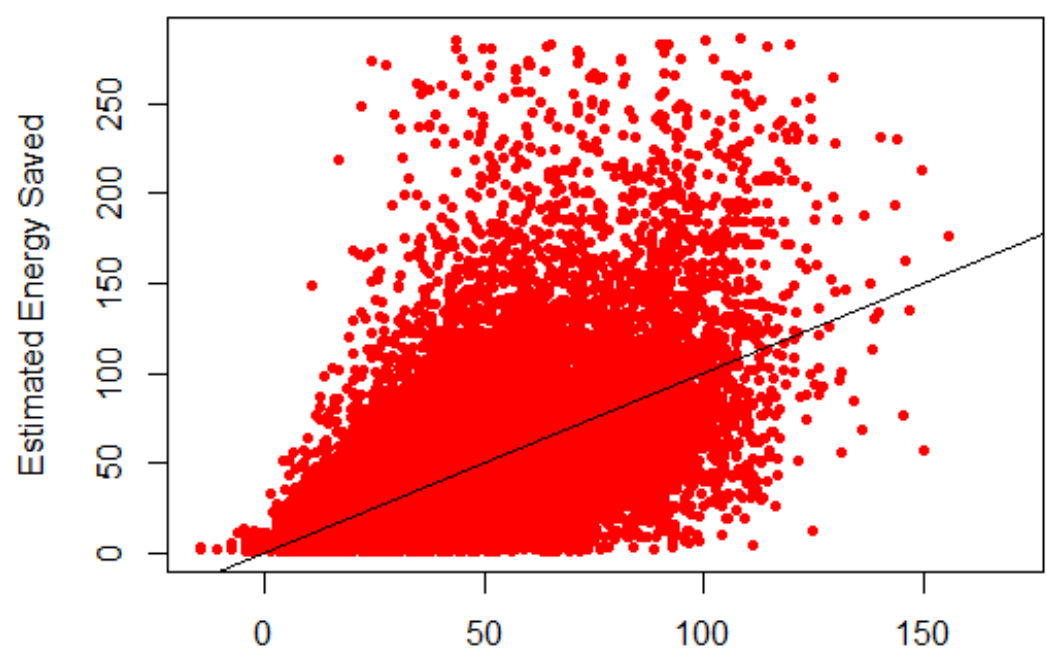

Predicted Values

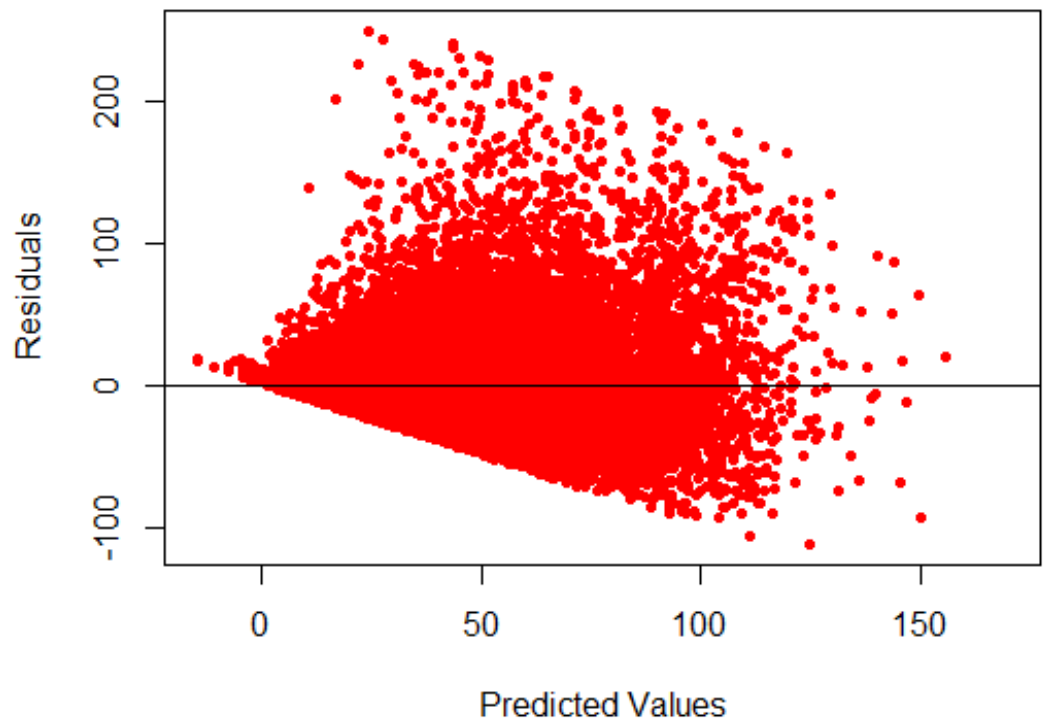

Figure 9. Estimated energy saved versus MLR model predictions for initial MLR model and residuals versus MLR model predictions. Energy saved has units of source MMBtu/year. 


\section{Model of log(ESTIMATED ENERGY SAVED)}
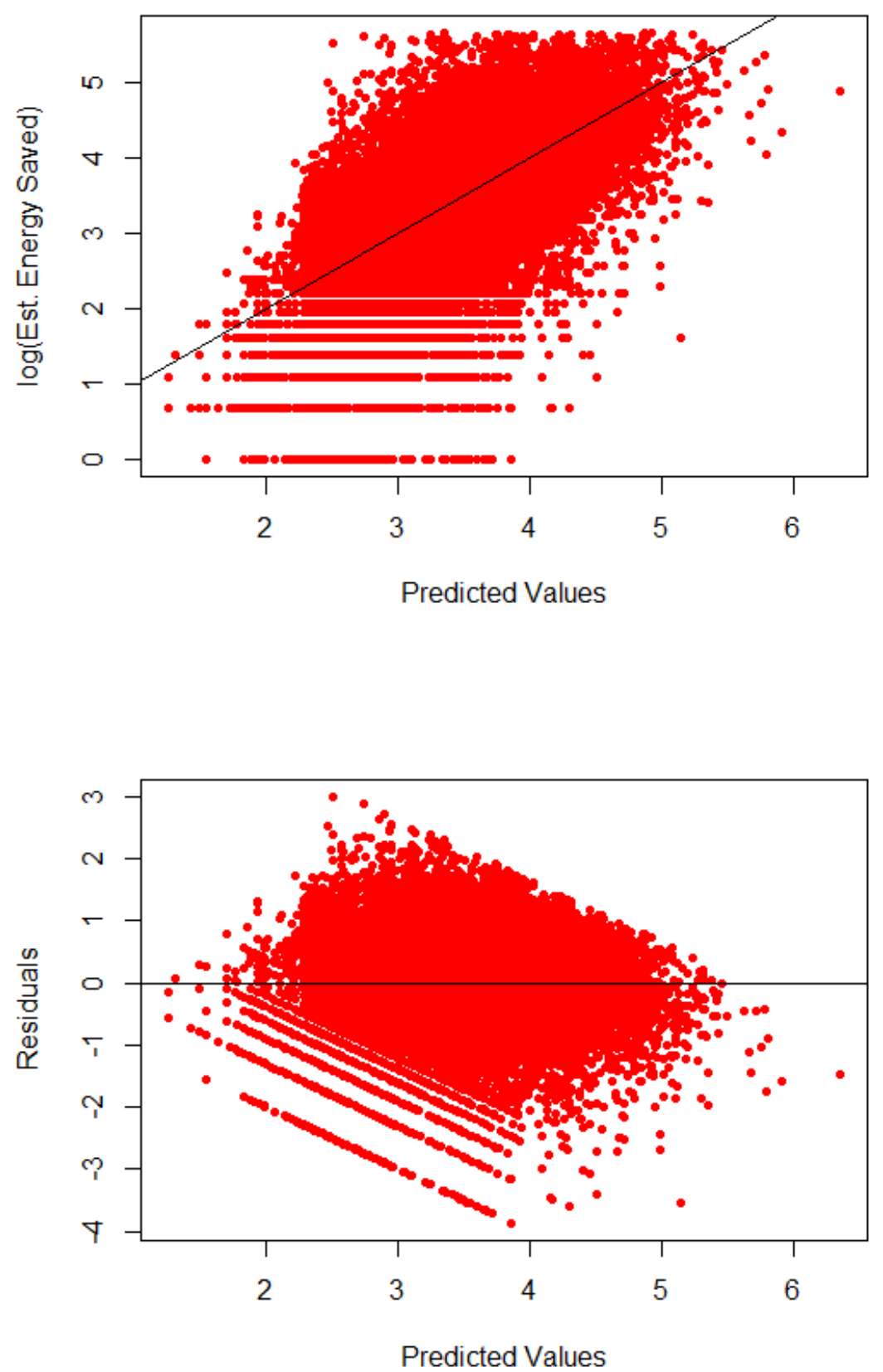

Figure 10. Log of estimated energy saved versus MLR model predictions and residuals versus regression model predictions. Energy saved has units of source MMBtu/year. 


\section{Model of $\log (E S T I M A T E D$ ENERGY SAVED)}
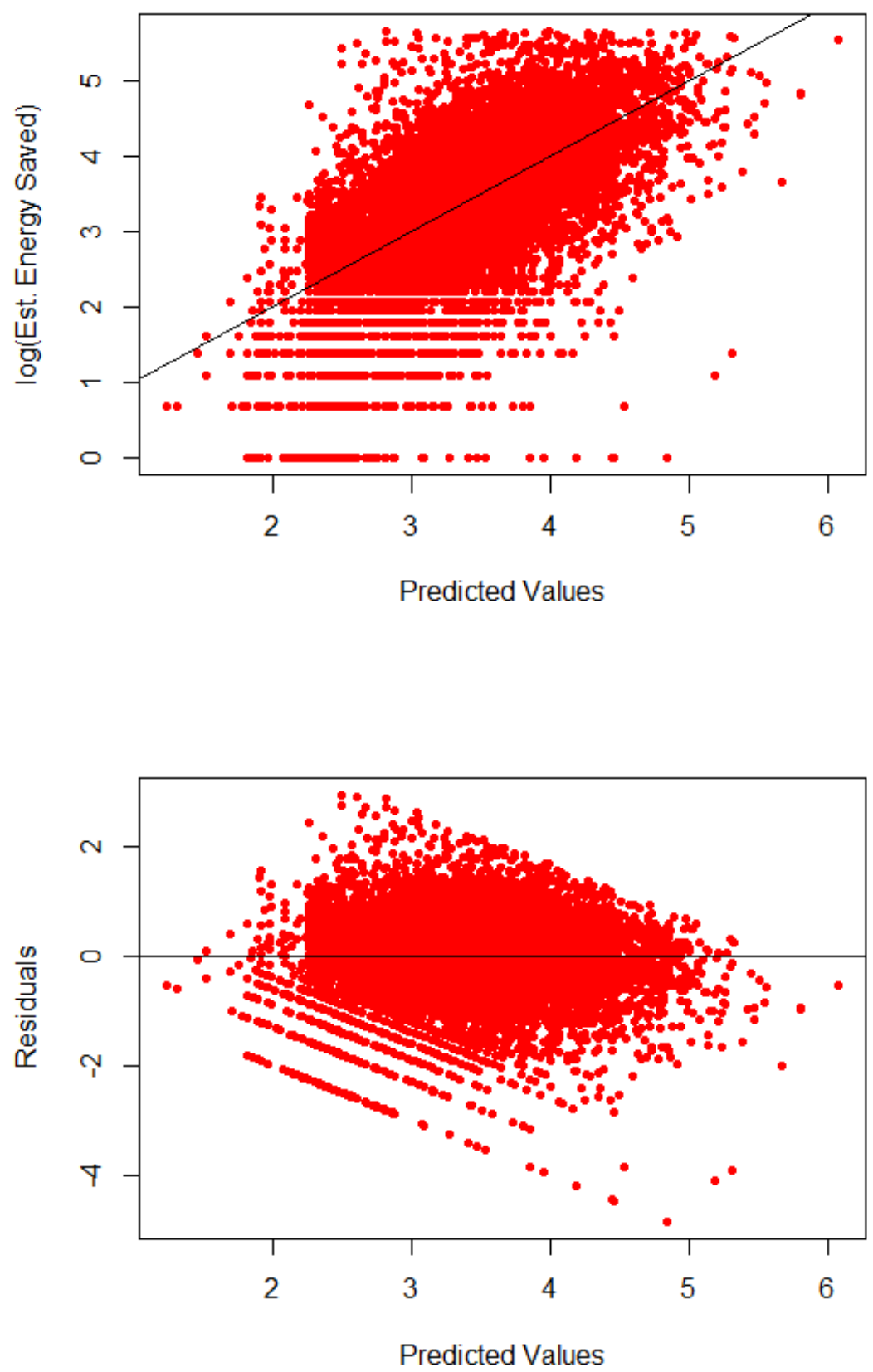

Figure 11. Log of estimated energy saved versus MLR model predictions and residuals versus MLR model predictions using the test data set. Energy saved has units of source MMBtu/year.

Table 4 lists all the significant ${ }^{6}$ variables using log of estimated source energy saved as the dependent variable. The adjusted R-squared value of 0.435 indicates that about $44 \%$ of the

\footnotetext{
${ }^{6}$ If a categorical variable (e.g., Grantee, Prediction Method) was found to be significant, all categories for the variable are reported in the table regardless of whether the $\mathrm{P}$ value for an individual category is 0.05 or less.
} 
variability in the log of estimated source energy saved is explained by the model (and about $56 \%$ is not explained). Table 5 lists the same variables as Table 4 (variables found significant in the log of estimated source energy saved) when the dependent variable is estimated energy saved in source MMBtu/year. The adjusted R-squared value of 0.369 indicates that about $37 \%$ of the variability in the estimated source energy saved is explained by the model. At least 22 of the EEMs are significant in the model and 18 have positive estimates (when estimated energy saved is used as the dependent variable). These estimates are approximations of the savings that can be attributed to each installed measure because of the binary coding. Some of the measures with the highest estimates include solar PV (B_INST_SOLAR_PV), heat pumps (B_INST_HEAT_PUMP) and solar thermal (B_INST_SOLAR_THERMAL). Some of the measures with the lowest estimates include low flow aerators (B_INST_LOWFLOW) and thermostatic expansion valves (B_INST_THERMO_VLV). Although possible, the savings is unlikely to actually be negative. Applying MLR to this type of data presents a number of difficulties. There is variability in the estimated energy saved for all EEMs. If the estimated savings is relatively low, as is likely for low flow aerators and thermostatic expansion valves, there is likely a low signal to noise ratio. When low flow aerators and thermostatic expansion valves were installed, they were most often installed along with other EEMs. Both the variability in an individual EEM and the additional variability in estimated energy saved from combinations of EEMs make it difficult to extract the exact estimated savings from each EEM. Furthermore, substantial uncertainty in the dependent variable contributes to uncertainty in the estimates. This becomes even more complicated because many combinations occur in a very unbalanced way (as opposed to a carefully designed experiment where combinations are controlled). As shown in Table 1, air sealing most often was done with attic insulation, so the energy saved on these projects is from both measures. If the energy saved from both is generally less than if each measure had been observed individually, regression estimates for each measure will likely be underestimated. The main point is that the estimates from MLR are only approximations.

Many of the variables and the signs of their estimates have plausible explanations. For example, LOANAMOUNT_LISTED has a positive estimate of 8.3 MMBtu; obtaining a loan will likely allow the occupant to invest in more EEMs. Installing attic insulation should result in positive estimated energy savings; the MLR model confirms this. Installing a more efficient air conditioner or furnace should also result in positive estimated energy savings; the MLR model confirms this as well. As previously mentioned, climate and the types of fuels used can vary from one location to another. The difference between GRANTEEs appears to capture these differences. Estimates for grantees range from -22.7 to 52.4.

RETROFIT_YR (the year the project was completed) was found to be significant with a negative estimate. The negative estimate implies that projects occurring in later years of the BBNP were generally associated with lower estimated energy savings than projects occurring in the earlier years of the program. It is not understood exactly why this occurred. Possibly projects with high potential for energy savings were generally completed first or perhaps estimates were moderated over time. Another possibility is that the grantees most active in the later years of the program targeted lower energy savings levels. 
Table 4. MLR Regression Model for Log (Estimated Energy Saved): R-Squared $\mathbf{0} \mathbf{0 . 4 3 7}$, Adjusted R-Squared $=0.435$, Degrees of Freedom $=33389$

\begin{tabular}{|c|c|c|c|c|}
\hline Variable & Estimate & $\begin{array}{l}\text { Std. } \\
\text { Error }\end{array}$ & $\mathrm{t}$ value & $\operatorname{Pr}(>|t|)$ \\
\hline (Intercept) & 132.7486 & 11.3581 & 11.6900 & $<2 \mathrm{e}-16$ \\
\hline B_INST_AC & 0.2509 & 0.0162 & 15.5100 & $<2 \mathrm{e}-16$ \\
\hline B_INST_AC_TUNE & -0.2564 & 0.0627 & -4.0900 & 0.0000 \\
\hline B_INST_AIR_SEALING & 0.2301 & 0.0113 & 20.4400 & $<2 \mathrm{e}-16$ \\
\hline B_INST_BOILER & 0.4152 & 0.0243 & 17.0700 & $<2 \mathrm{e}-16$ \\
\hline B_INST_DISHWASHER & -0.2379 & 0.0604 & -3.9400 & 0.0001 \\
\hline B_INST_DUCT_INSUL & 0.1463 & 0.0150 & 9.7400 & $<2 \mathrm{e}-16$ \\
\hline B_INST_DUCT_SEALING & 0.1134 & 0.0137 & 8.2700 & $<2 \mathrm{e}-16$ \\
\hline B_INST_DHW_INSUL & 0.1651 & 0.0176 & 9.3900 & $<2 \mathrm{e}-16$ \\
\hline B_INST_FIREPLACE_INSERT & -0.6221 & 0.1736 & -3.5800 & 0.0003 \\
\hline B_INST_FURNACE & 0.3016 & 0.0118 & 25.5800 & $<2 \mathrm{e}-16$ \\
\hline B_INST_HEAT_PUMP & 0.7151 & 0.0166 & 43.1600 & $<2 \mathrm{e}-16$ \\
\hline B_INST_INSUL_ATTIC & 0.3787 & 0.0098 & 38.7000 & $<2 \mathrm{e}-16$ \\
\hline B_INST_INSUL_FLR_FND & 0.1111 & 0.0127 & 8.7200 & $<2 \mathrm{e}-16$ \\
\hline B_INST_INSUL_WALL & 0.3764 & 0.0113 & 33.4300 & $<2 \mathrm{e}-16$ \\
\hline B_INST_LOWFLOW & -0.3057 & 0.0198 & -15.4300 & $<2 \mathrm{e}-16$ \\
\hline B_INST_SOLAR_PV & 1.3489 & 0.0971 & 13.8900 & $<2 \mathrm{e}-16$ \\
\hline B_INST_SOLAR_THERMAL & 0.4374 & 0.0928 & 4.7100 & 0.0000 \\
\hline B_INST_WATER_CONSERV & 0.3840 & 0.0326 & 11.7600 & $<2 \mathrm{e}-16$ \\
\hline B_INST_WTHR_STRPNG & 0.2041 & 0.0436 & 4.6900 & 0.0000 \\
\hline B_INST_THERMO_VLV & -0.5756 & 0.0456 & -12.6100 & $<2 \mathrm{e}-16$ \\
\hline B_INST_CHIMNEY_LINER & 0.4076 & 0.0473 & 8.6200 & $<2 \mathrm{e}-16$ \\
\hline B_INST_SMART_STRIPS & 0.1946 & 0.0574 & 3.3900 & 0.0007 \\
\hline GRANTEE AA & 0.1686 & 0.0404 & 4.1700 & 0.0000 \\
\hline GRANTEE B & 0.6097 & 0.0638 & 9.5600 & $<2 \mathrm{e}-16$ \\
\hline GRANTEE BB & 0.0295 & 0.0405 & 0.7300 & 0.4669 \\
\hline GRANTEE C & 0.4857 & 0.0507 & 9.5700 & $<2 \mathrm{e}-16$ \\
\hline GRANTEE CC & 0.7418 & 0.0391 & 18.9800 & $<2 \mathrm{e}-16$ \\
\hline GRANTEE D & 0.1490 & 0.0560 & 2.6600 & 0.0078 \\
\hline GRANTEE DD & 0.4940 & 0.0318 & 15.5500 & $<2 \mathrm{e}-16$ \\
\hline GRANTEE E & 0.0584 & 0.1488 & 0.3900 & 0.6947 \\
\hline GRANTEE EE & 0.3513 & 0.0418 & 8.4100 & $<2 \mathrm{e}-16$ \\
\hline GRANTEE F & -0.0726 & 0.0468 & -1.5500 & 0.1211 \\
\hline GRANTEE FF & -0.3088 & 0.0376 & -8.2000 & 0.0000 \\
\hline GRANTEE G & 0.8695 & 0.0437 & 19.8800 & $<2 \mathrm{e}-16$ \\
\hline GRANTEE GG & 0.3978 & 0.0524 & 7.5900 & 0.0000 \\
\hline GRANTEE H & 0.0167 & 0.0385 & 0.4300 & 0.6648 \\
\hline GRANTEE HH & -0.0673 & 0.0407 & -1.6500 & 0.0981 \\
\hline
\end{tabular}




\begin{tabular}{|c|c|c|c|c|}
\hline Variable & Estimate & $\begin{array}{l}\text { Std. } \\
\text { Error }\end{array}$ & $t$ value & $\operatorname{Pr}(>|t|)$ \\
\hline GRANTEE I & 0.1299 & 0.0494 & 2.6300 & 0.0086 \\
\hline GRANTEE II & 0.8885 & 0.0551 & 16.1100 & $<2 \mathrm{e}-16$ \\
\hline GRANTEE J & 0.2490 & 0.0399 & 6.2300 & 0.0000 \\
\hline GRANTEE K & 0.5273 & 0.0865 & 6.1000 & 0.0000 \\
\hline GRANTEE L & 0.3460 & 0.0330 & 10.4700 & $<2 \mathrm{e}-16$ \\
\hline GRANTEE M & 0.6172 & 0.1540 & 4.0100 & 0.0001 \\
\hline GRANTEE N & 0.3655 & 0.0554 & 6.6000 & 0.0000 \\
\hline GRANTEE O & 0.3627 & 0.0503 & 7.2100 & 0.0000 \\
\hline GRANTEE P & 1.0422 & 0.0384 & 27.1100 & $<2 \mathrm{e}-16$ \\
\hline GRANTEE Q & 0.9971 & 0.0409 & 24.3600 & $<2 \mathrm{e}-16$ \\
\hline GRANTEE R & 0.0171 & 0.0619 & 0.2800 & 0.7826 \\
\hline GRANTEE S & 0.2110 & 0.0333 & 6.3300 & 0.0000 \\
\hline GRANTEE T & 0.3571 & 0.0561 & 6.3600 & 0.0000 \\
\hline GRANTEE U & -0.0123 & 0.0366 & -0.3400 & 0.7361 \\
\hline GRANTEE V & 0.2831 & 0.0447 & 6.3400 & 0.0000 \\
\hline GRANTEE W & 1.1233 & 0.0440 & 25.5400 & $<2 \mathrm{e}-16$ \\
\hline GRANTEE X & -0.3302 & 0.0691 & -4.7800 & 0.0000 \\
\hline GRANTEE Y & 0.0187 & 0.0796 & 0.2400 & 0.8141 \\
\hline GRANTEE Z & 0.3911 & 0.0433 & 9.0200 & $<2 \mathrm{e}-16$ \\
\hline RETROFIT_YR & -0.0650 & 0.0057 & -11.5100 & $<2 \mathrm{e}-16$ \\
\hline YEARBUILT_PRE_1950 & 0.0720 & 0.0100 & 7.2000 & 0.0000 \\
\hline YEARBUILT_1970_1979 & 0.0529 & 0.0146 & 3.6400 & 0.0003 \\
\hline $\begin{array}{l}\text { PRED_METHOD_CAT_2 Missing or } \\
\text { None }\end{array}$ & -0.1255 & 0.0314 & -4.0000 & 0.0001 \\
\hline PRED_METHOD_CAT_2 Other & -0.0519 & 0.0304 & -1.7000 & 0.0883 \\
\hline PRED_METHOD_CAT_2 Simulation & -0.0809 & 0.0159 & -5.1000 & 0.0000 \\
\hline PRED_METHOD_CAT_2 Unknown & -0.1958 & 0.0296 & -6.6200 & 0.0000 \\
\hline LOANAMOUNT_LISTED & 0.2089 & 0.0150 & 13.9400 & $<2 \mathrm{e}-16$ \\
\hline AUDIT_BPI_CERT & 0.1298 & 0.0157 & 8.2500 & $<2 \mathrm{e}-16$ \\
\hline AUDIT_OTHER_CERT & 0.1722 & 0.0216 & 7.9900 & 0.0000 \\
\hline INST_ELECT_SAVINGS_LISTED & 0.4496 & 0.0145 & 30.9300 & $<2 \mathrm{e}-16$ \\
\hline INST_NG_SAVINGS_LISTED & 0.1353 & 0.0135 & 10.0500 & $<2 \mathrm{e}-16$ \\
\hline RENEWABLEINVOICEDCOST_LISTED & 1.0426 & 0.0525 & 19.8600 & $<2 \mathrm{e}-16$ \\
\hline CUSTOMERCONTRIBUTION_LISTED & 0.1041 & 0.0228 & 4.5700 & 0.0000 \\
\hline SUBSIDY_LISTED & -0.1176 & 0.0228 & -5.1700 & 0.0000 \\
\hline OTHERFUNDS_LISTED & -0.2961 & 0.0223 & -13.2900 & $<2 \mathrm{e}-16$ \\
\hline RETROFITCUSTCONTRIB_LISTED & 0.0915 & 0.0153 & 5.9600 & 0.0000 \\
\hline REASON_COMFORT & -0.4614 & 0.0677 & -6.8200 & 0.0000 \\
\hline REASON_SAVINGS & 0.6483 & 0.0495 & 13.1000 & $<2 \mathrm{e}-16$ \\
\hline
\end{tabular}


Table 5. MLR Regression Model for Estimated Energy Saved: R-Squared $=\mathbf{0 . 3 7 0}$, Adjusted R-Squared $=0.369$, Degrees of Freedom $=33389$

\begin{tabular}{|c|c|c|c|c|}
\hline Variable & Estimate & $\begin{array}{c}\text { Std. } \\
\text { Error }\end{array}$ & t value & $\operatorname{Pr}(>|t|)$ \\
\hline$(\text { Intercept })^{7}$ & 5157.28 & 491.02 & 10.50 & $<2 \mathrm{e}-16$ \\
\hline B_INST_AC & 11.04 & 0.70 & 15.80 & $<2 \mathrm{e}-16$ \\
\hline B_INST_AC_TUNE & -1.78 & 2.71 & -0.65 & 0.5128 \\
\hline B_INST_AIR_SEALING & 7.40 & 0.49 & 15.20 & $<2 \mathrm{e}-16$ \\
\hline B_INST_BOILER & 15.85 & 1.05 & 15.07 & $<2 \mathrm{e}-16$ \\
\hline B_INST_DISHWASHER & 0.05 & 2.61 & 0.02 & 0.9843 \\
\hline B_INST_DUCT_INSUL & 4.95 & 0.65 & 7.63 & 0.0000 \\
\hline B_INST_DUCT_SEALING & 4.90 & 0.59 & 8.27 & $<2 \mathrm{e}-16$ \\
\hline B_INST_DHW_INSUL & 3.76 & 0.76 & 4.95 & 0.0000 \\
\hline B_INST_FIREPLACE_INSERT & -1.77 & 7.51 & -0.24 & 0.8133 \\
\hline B_INST_FURNACE & 10.33 & 0.51 & 20.26 & $<2 \mathrm{e}-16$ \\
\hline B_INST_HEAT_PUMP & 30.85 & 0.72 & 43.08 & $<2 \mathrm{e}-16$ \\
\hline B_INST_INSUL_ATTIC & 10.57 & 0.42 & 24.98 & $<2 \mathrm{e}-16$ \\
\hline B_INST_INSUL_FLR_FND & 4.95 & 0.55 & 9.00 & $<2 \mathrm{e}-16$ \\
\hline B_INST_INSUL_WALL & 14.46 & 0.49 & 29.71 & $<2 \mathrm{e}-16$ \\
\hline B_INST_LOWFLOW & -6.68 & 0.86 & -7.79 & 0.0000 \\
\hline B_INST_SOLAR_PV & 79.81 & 4.20 & 19.01 & $<2 \mathrm{e}-16$ \\
\hline B_INST_SOLAR_THERMAL & 26.68 & 4.01 & 6.65 & 0.0000 \\
\hline B_INST_WATER_CONSERV & 8.19 & 1.41 & 5.80 & 0.0000 \\
\hline B_INST_WTHR_STRPNG & 6.03 & 1.88 & 3.20 & 0.0014 \\
\hline B_INST_THERMO_VLV & -8.60 & 1.97 & -4.36 & 0.0000 \\
\hline B_INST_CHIMNEY_LINER & 12.34 & 2.04 & 6.04 & 0.0000 \\
\hline B_INST_SMART_STRIPS & 6.08 & 2.48 & 2.45 & 0.0142 \\
\hline GRANTEE AA & 4.50 & 1.75 & 2.58 & 0.0100 \\
\hline GRANTEE B & 7.89 & 2.76 & 2.86 & 0.0042 \\
\hline GRANTEE BB & -8.94 & 1.75 & -5.10 & 0.0000 \\
\hline GRANTEE C & 6.26 & 2.19 & 2.85 & 0.0043 \\
\hline GRANTEE CC & 25.04 & 1.69 & 14.82 & $<2 \mathrm{e}-16$ \\
\hline GRANTEE D & -1.53 & 2.42 & -0.63 & 0.5290 \\
\hline GRANTEE DD & 5.14 & 1.37 & 3.74 & 0.0002 \\
\hline GRANTEE E & -5.69 & 6.43 & -0.88 & 0.3765 \\
\hline GRANTEE EE & 1.81 & 1.81 & 1.00 & 0.3155 \\
\hline GRANTEE F & -10.34 & 2.02 & -5.11 & 0.0000 \\
\hline GRANTEE FF & -22.73 & 1.63 & -13.97 & $<2 \mathrm{e}-16$ \\
\hline GRANTEE G & 31.21 & 1.89 & 16.50 & $<2 \mathrm{e}-16$ \\
\hline GRANTEE GG & 12.17 & 2.26 & 5.37 & 0.0000 \\
\hline
\end{tabular}

\footnotetext{
${ }^{7}$ The large value for the intercept is the result of including RETROFIT_YR in the model (2010 through 2013).
} 


\begin{tabular}{|c|c|c|c|c|}
\hline Variable & Estimate & $\begin{array}{c}\text { Std. } \\
\text { Error }\end{array}$ & t value & $\operatorname{Pr}(>|t|)$ \\
\hline GRANTEE H & -10.50 & 1.66 & -6.31 & 0.0000 \\
\hline GRANTEE HH & -4.09 & 1.76 & -2.32 & 0.0202 \\
\hline GRANTEE I & -0.05 & 2.14 & -0.02 & 0.9806 \\
\hline GRANTEE II & 34.12 & 2.38 & 14.31 & $<2 \mathrm{e}-16$ \\
\hline GRANTEE J & -1.87 & 1.73 & -1.08 & 0.2788 \\
\hline GRANTEE K & -1.45 & 3.74 & -0.39 & 0.6990 \\
\hline GRANTEE L & 3.28 & 1.43 & 2.30 & 0.0216 \\
\hline GRANTEE M & 27.45 & 6.66 & 4.12 & 0.0000 \\
\hline GRANTEE N & -0.70 & 2.39 & -0.29 & 0.7705 \\
\hline GRANTEE O & -1.03 & 2.17 & -0.47 & 0.6360 \\
\hline GRANTEE P & 36.63 & 1.66 & 22.05 & $<2 \mathrm{e}-16$ \\
\hline GRANTEE Q & 52.40 & 1.77 & 29.61 & $<2 \mathrm{e}-16$ \\
\hline GRANTEE R & -5.30 & 2.67 & -1.98 & 0.0474 \\
\hline GRANTEE S & 2.57 & 1.44 & 1.78 & 0.0747 \\
\hline GRANTEE T & 4.32 & 2.43 & 1.78 & 0.0747 \\
\hline GRANTEE U & 2.54 & 1.58 & 1.61 & 0.1077 \\
\hline GRANTEE V & -2.65 & 1.93 & -1.37 & 0.1704 \\
\hline GRANTEE W & 46.16 & 1.90 & 24.28 & $<2 \mathrm{e}-16$ \\
\hline GRANTEE X & -19.51 & 2.99 & -6.53 & 0.0000 \\
\hline GRANTEE Y & -16.88 & 3.44 & -4.90 & 0.0000 \\
\hline GRANTEE Z & 5.47 & 1.87 & 2.92 & 0.0035 \\
\hline RETROFIT_YR & -2.56 & 0.24 & -10.49 & $<2 \mathrm{e}-16$ \\
\hline YEARBUILT_PRE_1950 & 6.08 & 0.43 & 14.06 & $<2 \mathrm{e}-16$ \\
\hline YEARBUILT_1970_1979 & 1.25 & 0.63 & 1.98 & 0.0474 \\
\hline PRED_METHOD_CAT_2 Missing or None & -2.51 & 1.36 & -1.85 & 0.0642 \\
\hline PRED_METHOD_CAT_2 Other & -0.76 & 1.32 & -0.58 & 0.5623 \\
\hline PRED_METHOD_CAT_2 Simulation & -0.24 & 0.69 & -0.34 & 0.7317 \\
\hline PRED_METHOD_CAT_2 Unknown & -8.82 & 1.28 & -6.90 & 0.0000 \\
\hline LOANAMOUNT_LISTED & 8.30 & 0.65 & 12.81 & $<2 \mathrm{e}-16$ \\
\hline AUDIT_BPI_CERT & 4.79 & 0.68 & 7.04 & 0.0000 \\
\hline AUDIT_OTHER_CERT & 7.85 & 0.93 & 8.43 & $<2 \mathrm{e}-16$ \\
\hline INST_ELECT_SAVINGS_LISTED & 11.17 & 0.63 & 17.78 & $<2 \mathrm{e}-16$ \\
\hline INST_NG_SAVINGS_LISTED & 0.24 & 0.58 & 0.41 & 0.6833 \\
\hline RENEWABLEINVOICEDCOST_LISTED & 53.96 & 2.27 & 23.78 & $<2 \mathrm{e}-16$ \\
\hline CUSTOMERCONTRIBUTION_LISTED & 4.14 & 0.98 & 4.20 & 0.0000 \\
\hline SUBSIDY_LISTED & -4.22 & 0.98 & -4.29 & 0.0000 \\
\hline OTHERFUNDS_LISTED & -13.64 & 0.96 & -14.17 & $<2 \mathrm{e}-16$ \\
\hline RETROFITCUSTCONTRIB_LISTED & 7.60 & 0.66 & 11.46 & $<2 \mathrm{e}-16$ \\
\hline REASON_COMFORT & -14.22 & 2.93 & -4.86 & 0.0000 \\
\hline REASON_SAVINGS & 23.01 & 2.14 & 10.76 & $<2 \mathrm{e}-16$ \\
\hline
\end{tabular}


When CENSUS_REGION was substituted for GRANTEE the adjusted R-squared decreased to 0.292 , but most of the variable estimates remained approximately the same. The estimates for just the CENSUS_REGION categories are listed in Table 6. These estimates are referenced to the MIDWEST. Hence the NORTHEAST shows 2.73 MMBtu greater than the MIDWEST, the SOUTH shows 10.23 MMBtu less than the MIDWEST and the WEST shows 2.33 MMBtu less.

Table 6. CENSUS_REGION Estimates From MLR Regression Model for Estimated Energy Saved: R-Squared $=0.293$, Adjusted R-Squared $=0.292$, Degrees of Freedom $=33,420$

\begin{tabular}{|l|r|r|r|r|}
\hline \multicolumn{1}{|c|}{ Variable } & Estimate & \multicolumn{1}{c|}{$\begin{array}{c}\text { Std. } \\
\text { Error }\end{array}$} & \multicolumn{1}{c|}{ t value } & $\operatorname{Pr}(>|\mathbf{t}|)$ \\
\hline CENSUS_REGION NORTHEAST & 2.73 & 0.83 & 3.31 & 0.0009 \\
\hline CENSUS_REGION SOUTH & -10.23 & 0.75 & -13.73 & $<2 \mathrm{e}-16$ \\
\hline CENSUS_REGION WEST & -2.33 & 0.72 & -3.25 & 0.0011 \\
\hline
\end{tabular}

The adjusted R-squared increased when GRANTEE was used in the regression rather than CENSUS_REGION. This indicates that the GRANTEE variable better accounted for locationdependent differences (e.g., climate and fuel type) and accounted for fundamental differences between the grantee programs. For example, one grantee might have targeted a deeper level of air sealing energy savings than other grantees. While the binary variable for the air sealing retrofit measure approximated the average air sealing savings, the grantee variables helped capture variations in savings between grantees.

The next step was to include FLOORAREA, RETROFITJOBHOURS, and RETROFITINVOICEDCOST. First, the training data set was filtered to include only values greater than zero for these variables. Second, the $0.5^{\text {th }}$ percentile and the $99.5^{\text {th }}$ percentile values were determined and finally the training data set was filtered by each of these numeric variables to include values within these percentile ranges. Table 7 lists some basic statistics for these variables after removing missing and zero values. This reduced the available observations from more than 30,000 to less than 20,000 , which is still a substantial amount of data.

Table 7. Basic Statistical Summary of FLOORAREA, RETROFITJOBHOURS and RETROFITINVOICEDCOST After Removing Missing and Zero Values

\begin{tabular}{|l|c|c|c|c|c|}
\hline \multicolumn{1}{|c|}{ Variable } & $\begin{array}{c}\text { 0.5th } \\
\text { Pctl. }\end{array}$ & $\begin{array}{c}\text { 25th } \\
\text { Pctl. }\end{array}$ & Median & $\begin{array}{c}\text { 75th } \\
\text { Pctl. }\end{array}$ & $\begin{array}{c}\text { 99.5th } \\
\text { Pctl. }\end{array}$ \\
\hline FLOORAREA & 672 & 1412 & 1920 & 2594 & 6300 \\
\hline RETROFITJOBHOURS & 2 & 8 & 24 & 47 & 294 \\
\hline RETROFITINVOICEDCOST & 138 & 2047 & 4910 & 9500 & 31259 \\
\hline
\end{tabular}

The same method was used to determine significant variables by first creating a model using log of estimated energy saved followed by a model using estimated energy saved to obtain estimates in source MMBtu. Table 8 is the model using estimated energy saved as the dependent variable. Even on this reduced data set, 13 of 18 measures have positive estimates and most have estimates that are comparable to estimates found using the larger data set. The primary purpose of this test was to see if any of the three numeric variables are significant. As it turns out, all three were found significant with positive estimates. 
Table 8. MLR Regression Model for Estimated Energy Saved: R-Squared $=0.405$, Adjusted R-Squared $=0.403$, Degrees of Freedom $=19597$

\begin{tabular}{|c|c|c|c|c|}
\hline Variable & Estimate & Std. Error & $t$ value & $\operatorname{Pr}(>|t|)$ \\
\hline (Intercept) & 3820.00 & 727.00 & 5.26 & 0.0000 \\
\hline B_INST_AC & 4.21 & 0.84 & 5.01 & 0.0000 \\
\hline B_INST_AIR_SEALING & 5.07 & 0.62 & 8.16 & 0.0000 \\
\hline B_INST_BOILER & 6.27 & 1.53 & 4.10 & 0.0000 \\
\hline B_INST_CLTH_WASH & 5.08 & 2.18 & 2.33 & 0.0198 \\
\hline B_INST_DUCT_INSUL & 3.48 & 0.83 & 4.20 & 0.0000 \\
\hline B_INST_DUCT_SEALING & 3.74 & 0.75 & 4.98 & 0.0000 \\
\hline B_INST_DHW_INSUL & 7.55 & 1.43 & 5.29 & 0.0000 \\
\hline B_INST_FURNACE & 8.50 & 0.59 & 14.53 & $<2 \mathrm{e}-16$ \\
\hline B_INST_FURNACE_TUNE & -33.80 & 21.20 & -1.59 & 0.1117 \\
\hline B_INST_HEAT_PUMP & 22.50 & 1.03 & 21.80 & $<2 \mathrm{e}-16$ \\
\hline B_INST_INSUL_ATTIC & 7.39 & 0.54 & 13.75 & $<2 \mathrm{e}-16$ \\
\hline B_INST_INSUL_FLR_FND & 1.89 & 0.67 & 2.83 & 0.0047 \\
\hline B_INST_INSUL_WALL & 8.93 & 0.58 & 15.36 & $<2 \mathrm{e}-16$ \\
\hline B_INST_LOWFLOW & -9.35 & 1.42 & -6.57 & 0.0000 \\
\hline B_INST_WATER_HEATER & -0.85 & 0.63 & -1.35 & 0.1762 \\
\hline B_INST_WINDOWS & -3.59 & 0.80 & -4.50 & 0.0000 \\
\hline B_INST_INSUL_BSMT & -8.45 & 4.17 & -2.03 & 0.0425 \\
\hline B_INST_CHIMNEY_LINER & 7.94 & 2.03 & 3.92 & 0.0001 \\
\hline GRANTEE AA & -14.10 & 3.94 & -3.57 & 0.0004 \\
\hline GRANTEE BB & -33.30 & 3.82 & -8.72 & $<2 \mathrm{e}-16$ \\
\hline GRANTEE CC & 14.10 & 3.91 & 3.62 & 0.0003 \\
\hline GRANTEE D & -32.00 & 4.83 & -6.63 & 0.0000 \\
\hline GRANTEE DD & -1.65 & 4.00 & -0.41 & 0.6806 \\
\hline GRANTEE E & -17.70 & 8.23 & -2.15 & 0.0318 \\
\hline GRANTEE EE & -26.80 & 3.93 & -6.81 & 0.0000 \\
\hline GRANTEE F & -28.20 & 3.93 & -7.18 & 0.0000 \\
\hline GRANTEE FF & -28.10 & 3.73 & -7.52 & 0.0000 \\
\hline GRANTEE G & 6.47 & 4.31 & 1.50 & 0.1334 \\
\hline GRANTEE H & -21.60 & 17.80 & -1.21 & 0.2253 \\
\hline GRANTEE HH & -24.70 & 3.87 & -6.40 & 0.0000 \\
\hline GRANTEE I & -10.80 & 3.98 & -2.72 & 0.0066 \\
\hline GRANTEE II & 23.10 & 4.09 & 5.65 & 0.0000 \\
\hline GRANTEE J & -21.30 & 3.96 & -5.39 & 0.0000 \\
\hline GRANTEE K & -36.50 & 11.10 & -3.29 & 0.0010 \\
\hline GRANTEE L & -8.85 & 3.74 & -2.37 & 0.0178 \\
\hline GRANTEE M & -14.60 & 9.21 & -1.58 & 0.1131 \\
\hline GRANTEE N & -8.60 & 4.38 & -1.96 & 0.0498 \\
\hline
\end{tabular}




\begin{tabular}{|c|c|c|c|c|}
\hline Variable & Estimate & Std. Error & t value & $\operatorname{Pr}(>|t|)$ \\
\hline GRANTEE P & 1.21 & 4.50 & 0.27 & 0.7883 \\
\hline GRANTEE Q & 30.10 & 4.25 & 7.07 & 0.0000 \\
\hline GRANTEE R & -20.50 & 4.27 & -4.81 & 0.0000 \\
\hline GRANTEE S & -17.70 & 3.72 & -4.76 & 0.0000 \\
\hline GRANTEE T & -17.10 & 4.37 & -3.91 & 0.0001 \\
\hline GRANTEE U & -10.80 & 3.90 & -2.77 & 0.0057 \\
\hline GRANTEE V & -12.70 & 3.99 & -3.18 & 0.0015 \\
\hline GRANTEE X & -30.10 & 4.48 & -6.71 & 0.0000 \\
\hline GRANTEE Y & -33.70 & 4.71 & -7.16 & 0.0000 \\
\hline GRANTEE Z & 26.10 & 21.90 & 1.19 & 0.2330 \\
\hline RETROFIT_YR & -1.89 & 0.36 & -5.24 & 0.0000 \\
\hline YEARBUILT_UNKNOWN & 7.66 & 1.65 & 4.64 & 0.0000 \\
\hline YEARBUILT_PRE_1950 & 8.85 & 0.74 & 11.97 & $<2 \mathrm{e}-16$ \\
\hline YEARBUILT_1950_1959 & 5.63 & 0.80 & 7.01 & 0.0000 \\
\hline YEARBUILT_1960_1969 & 5.62 & 0.87 & 6.49 & 0.0000 \\
\hline YEARBUILT_1970_1979 & 5.40 & 0.86 & 6.32 & 0.0000 \\
\hline YEARBUILT_1980_1989 & 2.72 & 0.90 & 3.01 & 0.0026 \\
\hline PRED_METHOD_CAT_2 Missing or None & 2.06 & 1.47 & 1.40 & 0.1604 \\
\hline PRED_METHOD_CAT_2 Other & -0.02 & 1.47 & -0.01 & 0.9902 \\
\hline PRED_METHOD_CAT_2 Simulation & 1.03 & 0.84 & 1.22 & 0.2237 \\
\hline PRED_METHOD_CAT_2 Unknown & -8.71 & 1.54 & -5.67 & 0.0000 \\
\hline LOANAMOUNT_LISTED & 4.89 & 0.76 & 6.47 & 0.0000 \\
\hline AUDIT_BPI_CERT & 7.00 & 0.82 & 8.54 & $<2 \mathrm{e}-16$ \\
\hline AUDIT_OTHER_CERT & 6.76 & 0.98 & 6.88 & 0.0000 \\
\hline INST_ELECT_SAVINGS_LISTED & 11.40 & 0.82 & 13.97 & $<2 \mathrm{e}-16$ \\
\hline INST_NG_SAVINGS_LISTED & -9.05 & 0.84 & -10.81 & $<2 \mathrm{e}-16$ \\
\hline INST_OTHER_SAVINGS_LISTED & -6.12 & 1.23 & -5.00 & 0.0000 \\
\hline RENEWABLEINVOICEDCOST_LISTED & 31.80 & 3.56 & 8.94 & $<2 \mathrm{e}-16$ \\
\hline CUSTOMERCONTRIBUTION_LISTED & 3.30 & 1.10 & 3.00 & 0.0027 \\
\hline SUBSIDY_LISTED & -3.83 & 1.05 & -3.66 & 0.0003 \\
\hline OTHERFUNDS_LISTED & -15.10 & 1.02 & -14.76 & $<2 \mathrm{e}-16$ \\
\hline TAXCREDIT_LISTED & -5.03 & 1.75 & -2.88 & 0.0040 \\
\hline REASON_COMFORT & -16.40 & 3.66 & -4.49 & 0.0000 \\
\hline REASON_SAVINGS & 27.20 & 2.36 & 11.54 & $<2 \mathrm{e}-16$ \\
\hline RETROFITJOBHOURS & 0.0553 & 0.0071 & 7.79 & 0.0000 \\
\hline RETROFITINVOICEDCOST & 0.0013 & 0.0001 & 24.13 & $<2 \mathrm{e}-16$ \\
\hline FLOORAREA & 0.0056 & 0.0002 & 22.84 & $<2 \mathrm{e}-16$ \\
\hline
\end{tabular}


One factor that was found significant in all the MLR models is LOANAMOUNT_LISTED. The loan amount listed coefficient for the model in Table 5 was approximately $8 \mathrm{MMBtu}$ (source energy) and approximately 5 MMBtu (source energy) for the model in Table 8 . The model in Table 8 includes the continuous variable RETROFITINVOICEDCOST, which also has a positive coefficient, indicating greater estimated energy savings as the project cost increases. This is likely because more measures can be installed with increased availability of funds. A few statistics can be examined to confirm this with the data used for creating the model in Table 8 . The mean retrofit invoiced cost for projects not listing loans was approximately $\$ 5,000$ and the mean estimated source energy savings was $39 \mathrm{MMBtu}$. The mean retrofit invoiced cost for projects listing loans was approximately $\$ 11,000$ and the mean estimated source energy savings was $50 \mathrm{MMBtu}$. The mean loan amount was approximately $\$ 10,000$, which covers most of the project cost.

\subsection{Regional and Vintage Comparisons to the Residential Energy Consumption Survey}

The MLR analysis attributed some differences in the estimated source energy savings (MMBtu/ year) to census regions (refer to Table 6). When FLOORAREA, RETROFITJOBHOURS, and RETROFITINVOICEDCOST were included in the MLR model, several year-built time period variables were also found to be significant (refer to Table 8). To determine whether these differences in estimated savings correlated to energy consumption by region and vintage of homes, comparisons were made to baseline energy use calculated using the 2009 Residential Energy Consumption Survey (RECS) (U.S. Energy Information Administration 2012).

Only single-family detached homes from RECS were included. Homes from the state of New York (REPORTABLE_DOMAIN = 3) were excluded because they were excluded from the MLR analysis in Section 3.5. The MLR analysis demonstrated that many factors contribute to estimated energy savings. As shown in Figures 5 and 6, there are significant regional and vintage differences for installed measures. One cannot simply calculate the mean estimated energy saved by region or vintage, because all the other factors contribute to the mean estimated energy saved. To make a comparison, the overall mean estimated energy savings was determined from the filtered data (approximately $43 \mathrm{MMBtu} /$ year). This mean value was then adjusted by the MLR coefficients for census region differences (Table 6) and then by vintage home differences (YEARBUILT variables from Table 8) because these represent the observed difference from the mean.

Figure 12 shows a comparison by census region. There is negligible difference between the Midwest and Northeast for RECS baseline energy used. This is also true of estimated energy saved. There does appear to be a slight decrease in both baseline energy used and estimated energy saved for the South compared to the Midwest. The West shows a substantial decline in baseline energy used, but the estimated energy saved is comparable to the Midwest and slightly higher than the South. Thus, the estimated energy saved does not appear to correlate just with baseline energy used by region. A word of caution is needed here, particularly for the comparison of Better Buildings project data to RECS data in the West. RECS is based on a statistically representative sampling of homes in different regions of the country. Based on RECS, $44 \%$ of the single-family homes in the West Census Region are in California and approximately $8 \%$ of the single-family homes in the West Census Region are in Colorado. The 
Better Building projects were not a statistically representative sampling of homes. For Better Buildings, approximately $27 \%$ of the West Census Region single-family home projects were in California and approximately $24 \%$ of the West Census Region single-family home projects were in Colorado. Differences such as these may obscure correlations between Better Buildings and RECS data.

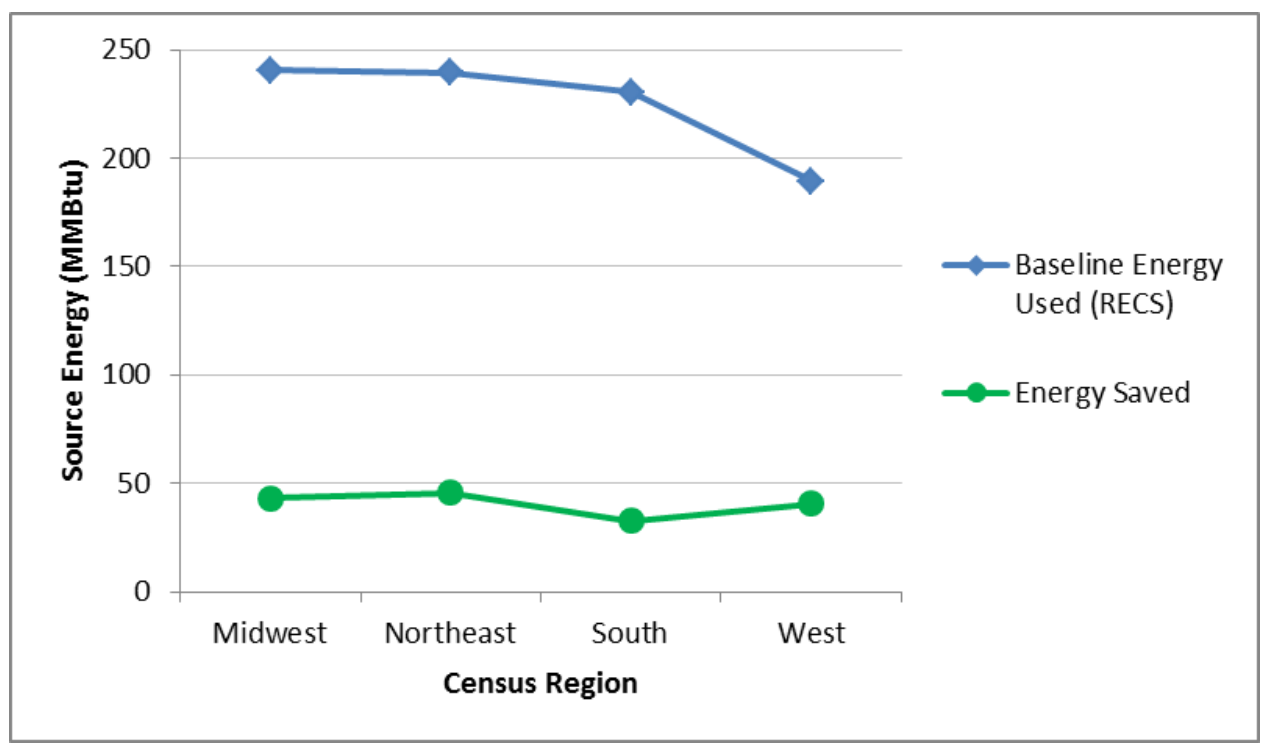

Figure 12. Comparison of baseline energy used (from RECS) to estimated energy saved attributable to census regions

Figure 13 shows a comparison by vintage of homes (year built). There is a significant increase in baseline energy used going from older homes to newer homes, whereas the estimated energy saved shows a slight decreasing trend. The primary reason for the observed increase in baseline energy used is that newer homes are larger than older homes (U.S. Energy Information Administration 2012). In fact, when the baseline energy used is divided by the enclosed square feet, homes built from 1960 to 1979 average $98 \mathrm{kBtu} / \mathrm{ft}^{2}$, whereas homes built from 2000 to current average $81 \mathrm{kBtu} / \mathrm{ft}^{2}$. 


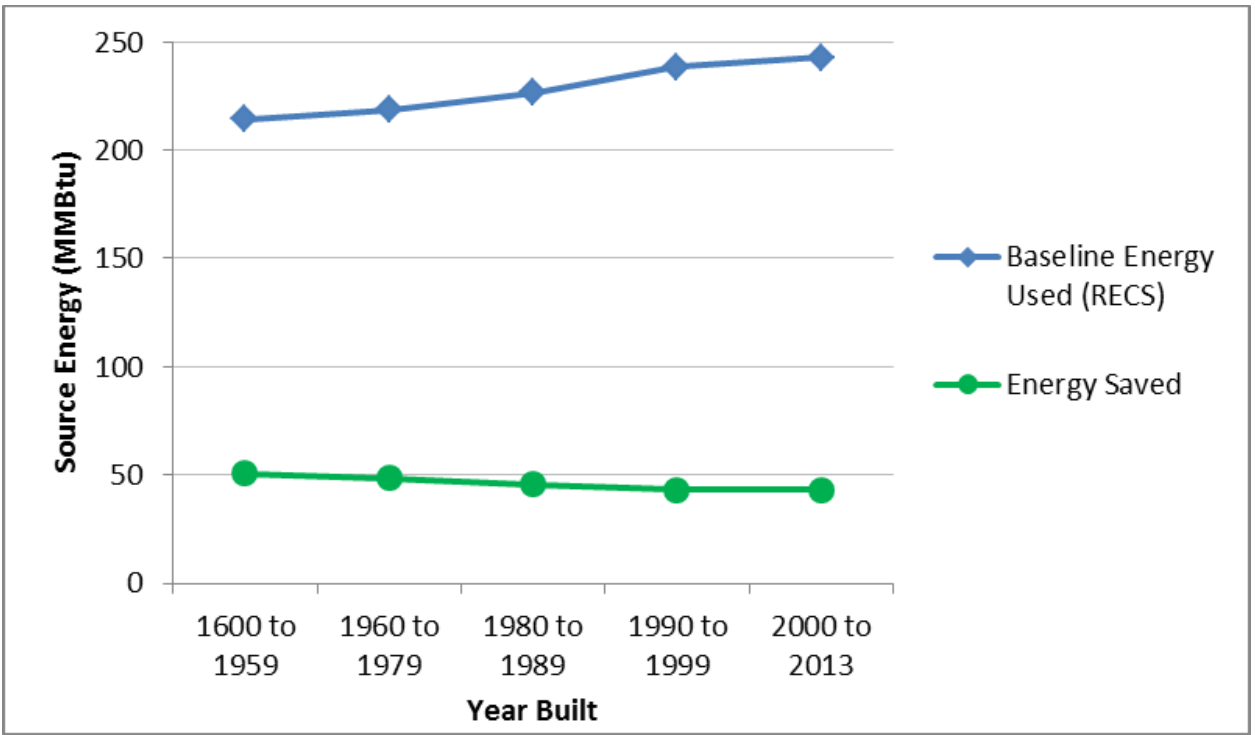

Figure 13. Comparison of baseline energy used (from RECS) to estimated energy saved attributable to vintage of homes 


\section{Comparing Utility-Bill-Calculated Savings to Grantee-Estimated Savings}

Utility-bill energy consumption data provided by the grantees were weather normalized to Typical Meteorological Year 3 (TMY3) weather data for a subset of the residential single-family projects with sufficient data. Appendix A provides details about the utility data processing, development of regression models, and calculation of TMY3-normalized energy uses. Normalized site energy uses were converted to source energy uses using the same site-source multipliers that were applied in Section 3.2 (refer to Appendix C). Utility-bill-calculated TMY3 normalized energy uses are referred to as normalized energy uses or normalized energy savings (PRE - POST) throughout the remainder of this report.

Pre-retrofit normalized energy uses were compared to the estimated pre-retrofit energy uses. These estimated uses were based on grantee-reported estimated energy savings and estimated savings expressed as a proportion of baseline energy use. Because the normalized natural gas source energy uses never exceeded $500 \mathrm{MMBtu}$, the database estimates greater than 500 were filtered out (23 records of 5,372). Whereas the utility data were normalized to TMY3, the type of weather data used to predict savings by the grantees (if any) is unknown. Different grantees likely did use different weather data, which adds to the uncertainty in comparisons between normalized and estimated energy uses and savings.

A plot of the filtered data is shown in Figure $14(\mathrm{~N}=5,349)$ comparing pre-retrofit natural gas energy use. The adjusted R-squared value after filtering was 0.447 . For reference, a line of perfect agreement is shown (slope $=1$ and intercept $=0$ ). For natural gas, 14 of a possible 35 grantees had projects with pre-retrofit normalized energy use matched to estimated pre-retrofit energy use. Overall this represents $9 \%$ of single-family projects, but samples ranged from fewer than $1 \%$ to as high as $63 \%$ of the single-family projects for individual grantees. Only five grantees have sample sizes of $10 \%$ or more of their single-family projects.

An adjusted R-squared value of 0.481 was observed for the pre-retrofit normalized electricity energy uses versus the estimated pre-retrofit energy uses based on grantee-reported data. No additional filtering was done for these data. Figure 15 shows the normalized versus estimated trend for electricity $(\mathrm{N}=6,732)$. Again for reference, a line of perfect agreement is shown (slope $=1$ and intercept $=0$ ). For electricity, 22 of a possible 35 grantees had projects with pre-retrofit normalized energy use matched to estimated pre-retrofit energy use. This represents $11 \%$ of single-family projects, but samples ranged from fewer than $1 \%$ to as many as $58 \%$ of the singlefamily projects for individual grantees. Ten grantees had sample sizes of $10 \%$ or more of their single-family projects. 


\section{Pre-retrofit Natural Gas}

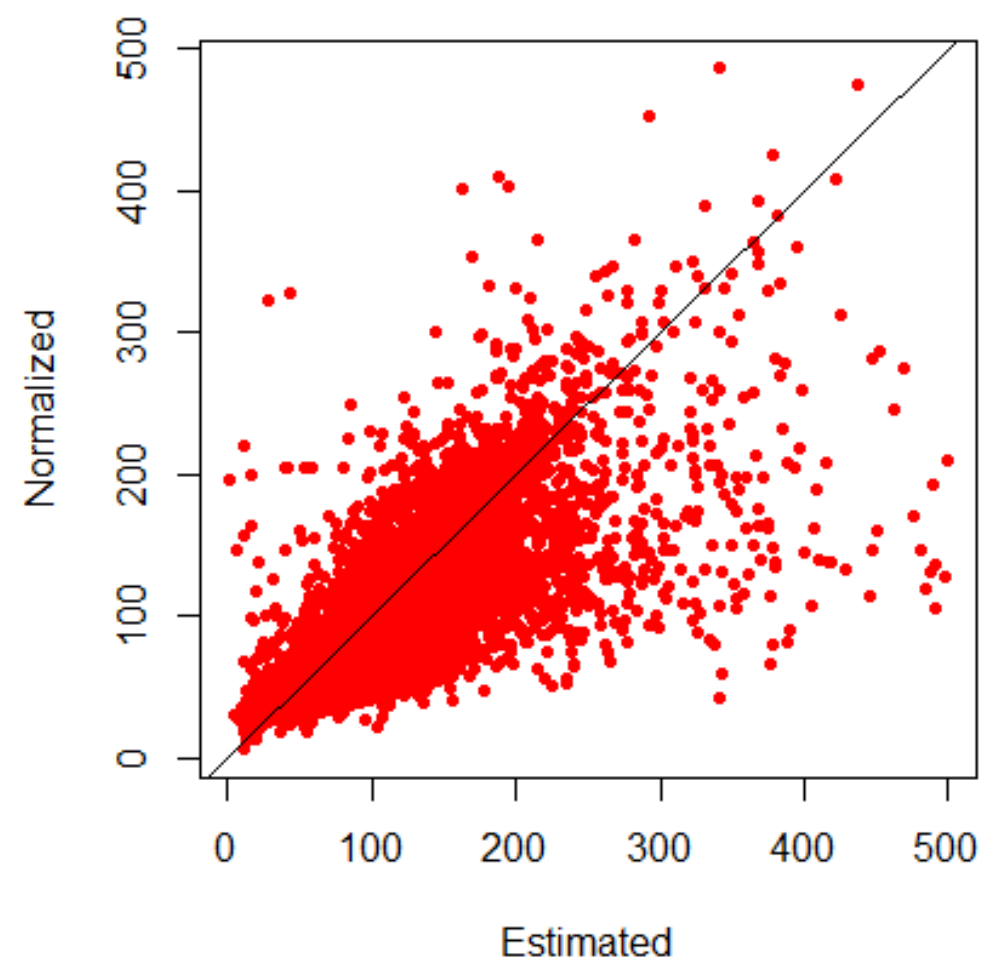

Figure 14. Normalized pre-retrofit natural gas energy uses (“Normalized”) versus estimated preretrofit natural gas use ("Estimated"). All estimates are in source MMBtu. $N=5,349$. 


\section{Pre-retrofit Electricity}

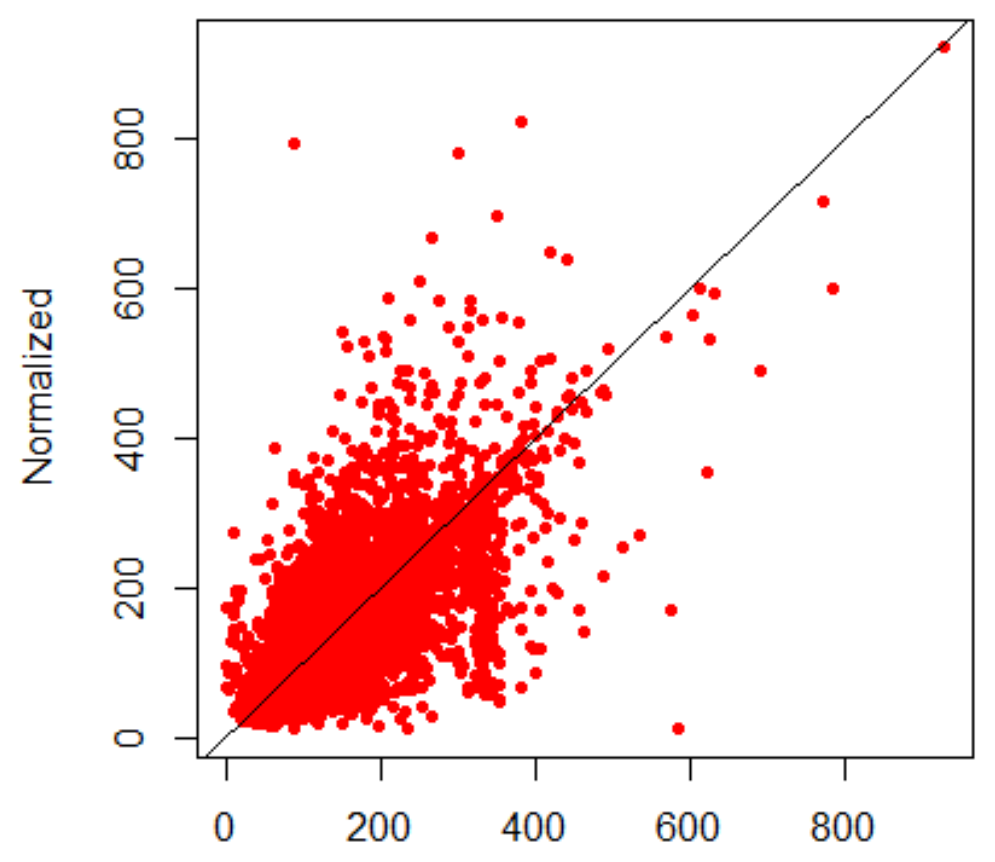

Estimated

Figure 15. Normalized pre-retrofit electricity energy use ("Normalized") versus estimated electricity use ("Estimated"). All estimates are in source MMBtu. $\mathbf{N}=6,732$.

The results are noisier when comparing the normalized natural gas savings to the granteeestimated natural gas savings. Also, because calculating normalized natural gas energy savings requires both PRE and POST normalized energy uses, far fewer homes can be considered for the comparison (1,418 homes before removing outliers). An observation was considered an outlier if the grantee-estimated natural gas savings exceeded 150, if the grantee-estimated natural gas savings was less than -50 , or if the normalized natural gas savings was less than -50 . Figure 16 shows this comparison after outlier removal $(\mathrm{N}=1,408)$. The adjusted $\mathrm{R}$-squared for this correlation was 0.244 . Regardless of the noise, the correlation is found to be significant based on the regression of normalized natural gas savings versus the grantee-estimated natural gas savings. Most observations fall below and to the right of the line for perfect agreement. This indicates that estimates generally exceeded normalized natural gas savings based on utility consumption data. Only nine grantees had data for this comparison and the overall sample size was only $2 \%$ of single-family projects. Two grantees had sample sizes of $10 \%$ or more of their total single-family projects. Because the overall sample size was small and did not adequately represent all the grantees, any conclusions apply only to the available data. 


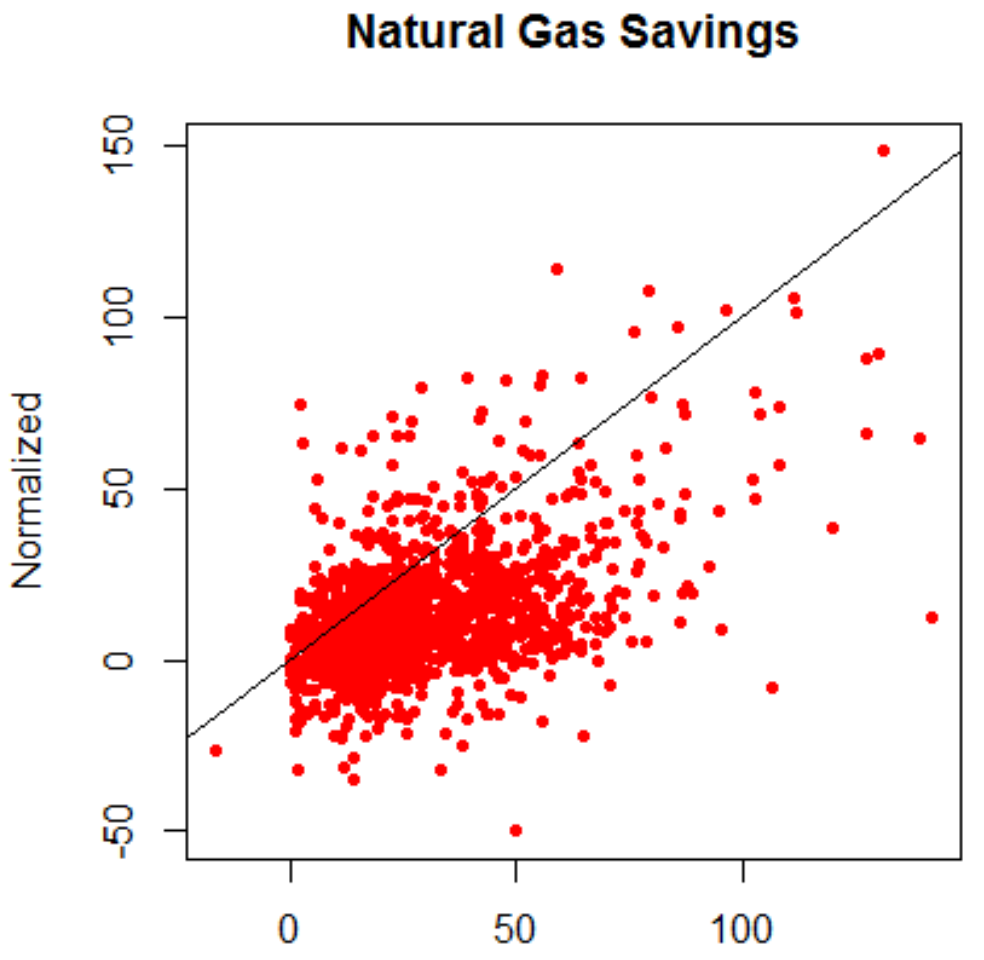

Estimated

Figure 16. Normalized natural gas savings ("normalized") versus grantee estimated natural gas savings ("estimated"). All estimates are in source MMBtu. $\mathrm{N}=1,408$.

Figure 17 shows the comparison of normalized electricity savings versus the grantee-estimated electricity savings again after some outlier removal $(\mathrm{N}=1,614)$. There were 1,656 observations prior to removing outliers. An observation was considered an outlier if the grantee-estimated electricity savings exceeded 150 , if the grantee-estimated electricity savings was less than 0 , or if the normalized electricity savings was less than -80 . The adjusted R-squared for this correlation was only 0.122 , but the correlation did test as significant. Again, most observations fall below and to the right of the line of perfect agreement. For both natural gas and electricity, the results indicate some overprediction of savings. Seventeen grantees had data for this comparison and the overall sample size was only $3 \%$ of single-family projects. Three grantees had sample sizes of $10 \%$ or more of their single-family projects. Again, because the overall sample size was small and did not adequately represent all the grantees, any conclusions apply only to the available data. 


\section{Electricity Savings}

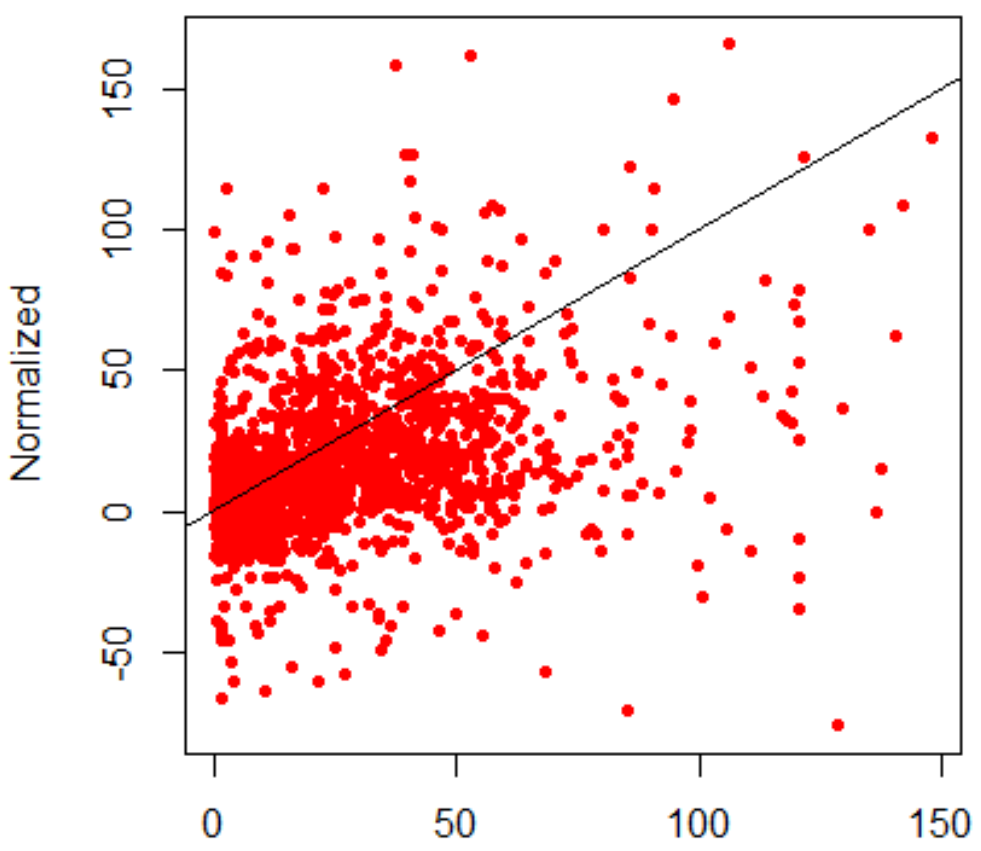

Estimated

Figure 17. Normalized electricity savings ("normalized") versus grantee estimated electricity savings ("estimated"). All estimates are in source MMBtu. $N=1,614$.

The next step was to see how the natural gas realization rate (normalized/estimated) varied by GRANTEE and the adjusted prediction method (covered in Section 3.1). A realization rate equal to 1.0 indicated that the normalized energy savings from utility data were the same as estimated energy savings. Realization rates greater than 1.0 indicated underprediction of savings (the normalized energy savings exceeded the estimate). Realization rates less than 1.0 indicated overprediction (the normalized energy savings was less than the estimate).

To calculate the natural gas realization rate, both the normalized natural gas savings and the estimated natural gas savings were needed for the project. Low estimated natural gas savings can result in extremely distorted realization rates. A few filtering approaches were investigated. The researchers eventually chose to filter out projects lower than the $25^{\text {th }}$ percentile of estimated savings, which still kept $75 \%$ of the realization rate data but substantially reduced the realization rate variability. The percentile filtering approach was chosen and the $25^{\text {th }}$ percentile selected based on investigations of tradeoffs between reducing variability in realization rates and maintaining a substantial sample size. Projects with estimated savings less than the $25^{\text {th }}$ percentile (13.68 MMBtu for natural gas) were filtered out of the analysis. Before filtering, the $0.5^{\text {th }}$ percentile of natural gas realization rates was -10.49 , the mean was 0.48 , and the $99.5^{\text {th }}$ percentile was 8.04 . After filtering, the $0.5^{\text {th }}$ percentile of natural gas realization rates was -1.24 , the mean was 0.44 , and the $99.5^{\text {th }}$ percentile was 2.60 . After removing projects with the low estimated savings, a final filtering was applied to keep only observations between the recalculated $0.5^{\text {th }}$ percentile $(-1.24)$ and $99.5^{\text {th }}$ percentile $(2.60)$ for further analysis. 
Table 9 shows the MLR results when just GRANTEE as a category is included in the model. The resulting model has a very low adjusted R-squared of 0.111 , indicating that only $11 \%$ of the natural gas realization rate variability can be explained by differences in grantees, but a few of the grantees (bold and yellow highlight in table) were found to be significantly different from the reference grantee (Grantee A). Based on the estimates, Grantee DD and Grantee S had average natural gas realization rates substantially greater than Grantee A, whereas Grantee FF was only somewhat greater on average. When MLR was applied considering both GRANTEE and the adjusted prediction method as categories, adjusted prediction methods were not found to be significant. The same grantees were found to be significant with comparable estimates and the adjusted R-squared remained essentially the same, indicating no model improvement by including the adjusted prediction methods.

The natural gas realization rate data have a number of issues. After filtering, the data contained only eight grantees. This represented only $2 \%$ of single-family projects and only two of these grantees had sample sizes larger than $10 \%$ of their projects. Project counts, mean natural gas realization rates and the SD of natural gas realization rates are listed for the GRANTEE and adjusted prediction method combinations in Table 10. The table is sorted first by the adjusted prediction method then by the GRANTEE category. The grantees using "deemed" and having more than 40 projects are highlighted in gray. The grantees using "simulation" and having more than 20 projects are highlighted in yellow. Based on the project counts, the data are very unbalanced. For example, Grantee A had the most projects in the data set, but all the prediction methods were "deemed." All but three of Grantee F's 277 projects used "simulation" for the prediction method. Only Grantee L had a somewhat reasonable split between projects using "deemed" and projects using "simulation," but the total project count is far lower than Grantee A or Grantee F. These highly correlated combinations make it impossible to determine statistically if the differences in realization rates were truly due to the grantee or the prediction method used. EEMs were also investigated and similar issues were observed. In the filtered data, Grantee FF had the highest proportion of duct sealing projects, whereas as Grantee DD had the highest proportion of floor/foundation insulation projects. If a reasonably balanced mix of prediction methods and EEMs had occurred across all grantees and if the realization rate data were more representative of all single-family projects, the MLR analysis would have a better chance of determining whether prediction methods and EEMs significantly affected natural gas realization rates.

Table 9. MLR Regression to Test NG Realization Rate as Function of Grantees: R-Squared $=0.116$, Adjusted R-Squared $=0.111$ Degrees of Freedom $=1,035$

\begin{tabular}{|l|r|r|r|r|}
\hline \multicolumn{1}{|c|}{ Variable } & \multicolumn{1}{c|}{ Estimate } & \multicolumn{1}{c|}{ Std. Error } & \multicolumn{1}{c|}{$\boldsymbol{t}$ value } & \multicolumn{1}{c|}{$\operatorname{Pr}(>|\mathbf{t}|)$} \\
\hline (Intercept) & 0.280 & 0.022 & 12.790 & $<2 \mathrm{e}-16$ \\
\hline GRANTEE DD & $\mathbf{0 . 4 4 2}$ & $\mathbf{0 . 0 5 4}$ & $\mathbf{8 . 2 4 0}$ & $\mathbf{0 . 0 0 0}$ \\
\hline GRANTEE F & $\mathbf{0 . 2 9 3}$ & $\mathbf{0 . 0 3 6}$ & $\mathbf{8 . 0 3 0}$ & $\mathbf{0 . 0 0 0}$ \\
\hline GRANTEE FF & $\mathbf{0 . 1 6 1}$ & $\mathbf{0 . 0 5 9}$ & $\mathbf{2 . 7 3 0}$ & $\mathbf{0 . 0 0 6}$ \\
\hline GRANTEE HH & -0.037 & 0.155 & -0.240 & 0.810 \\
\hline GRANTEE L & $\mathbf{0 . 2 7 6}$ & $\mathbf{0 . 0 6 1}$ & $\mathbf{4 . 5 4 0}$ & $\mathbf{0 . 0 0 0}$ \\
\hline GRANTEE S & $\mathbf{0 . 7 9 4}$ & $\mathbf{0 . 1 3 6}$ & $\mathbf{5 . 8 3 0}$ & $\mathbf{0 . 0 0 0}$ \\
\hline
\end{tabular}


Table 10. Project Counts, Mean Natural Gas Realization Rates, SD Natural Gas Realization Rates for Grantees and Adjusted Prediction Method Combinations

\begin{tabular}{|c|l|r|r|r|}
\hline GRANTEE & \multicolumn{1}{|c|}{$\begin{array}{c}\text { Adjusted } \\
\text { Prediction } \\
\text { Method }\end{array}$} & $\begin{array}{c}\text { Mean Natural } \\
\text { Project } \\
\text { Count }\end{array}$ & $\begin{array}{c}\text { SD Natural } \\
\text { Realization } \\
\text { Rates }\end{array}$ & $\begin{array}{c}\text { Sas } \\
\text { Realization } \\
\text { Rates }\end{array}$ \\
\hline A & Deemed & $\mathbf{4 9 2}$ & $\mathbf{0 . 2 8}$ & $\mathbf{0 . 4 5}$ \\
\hline F & Deemed & 3 & 0.39 & 0.27 \\
\hline FF & Deemed & $\mathbf{7 9}$ & $\mathbf{0 . 4 4}$ & $\mathbf{0 . 4 8}$ \\
\hline L & Deemed & $\mathbf{4 6}$ & $\mathbf{0 . 5 8}$ & $\mathbf{0 . 4 6}$ \\
\hline S & Deemed & 7 & 1.07 & 0.31 \\
\hline DD & Missing or None & 1 & 0.40 & NA \\
\hline HH & Missing or None & 9 & 0.17 & 0.82 \\
\hline DD & Other & 10 & 0.65 & 0.40 \\
\hline HH & Other & 1 & 0.85 & NA \\
\hline S & Other & 6 & 1.07 & 0.78 \\
\hline DD & Simulation & $\mathbf{8 7}$ & $\mathbf{0 . 7 3}$ & $\mathbf{0 . 6 3}$ \\
\hline F & Simulation & $\mathbf{2 7 4}$ & $\mathbf{0 . 5 7}$ & $\mathbf{0 . 4 8}$ \\
\hline H & Simulation & 2 & 0.01 & 0.02 \\
\hline L & Simulation & $\mathbf{2 7}$ & $\mathbf{0 . 5 2}$ & $\mathbf{0 . 4 7}$ \\
\hline
\end{tabular}

The same analysis that was applied to the natural gas realization rates was applied to electricity realization rates. As with natural gas, low estimated electricity savings can result in extremely distorted realization rates, so estimated savings less than the $25^{\text {th }}$ percentile (6.39 MMBtu for electricity) were filtered out. The electricity realization rates had greater variability than natural gas realization rates. Before filtering, the $0.5^{\text {th }}$ percentile of electricity realization rates was -40.28 , the mean was 2.64 , and the $99.5^{\text {th }}$ percentile was 41.41 . After filtering, the $0.5^{\text {th }}$ percentile of natural gas realization rates was -4.71 , the mean was 0.64 , and the $99.5^{\text {th }}$ percentile was 6.96. After projects with low estimated savings were removed, a final filtering was applied to keep only observations between the $0.5^{\text {th }}$ percentile $(-4.71)$ and $99.5^{\text {th }}$ percentile $(6.96)$ for further analysis.

Table 11 shows the MLR results when just GRANTEE as a category is included in the model. The resulting model has a very low adjusted R-squared of 0.098 , indicating that only $10 \%$ of the electricity realization rate variability can be explained by differences in grantees. The significant grantees are highlighted in yellow. Grantee J and Grantee L (highlighted and in bold) were found to be significant at confidence levels greater than 99\% (1 - Pr), whereas Grantee F and Grantee FF were found to be significant at confidence levels greater than 95\% (but not 99\%). When MLR was applied considering both GRANTEE and the adjusted prediction method as categories, the prediction method of "other" was found to be significant but only just slightly greater than $95 \%$ confidence level. The same grantees were found to be significant with comparable estimates and the adjusted R-squared increased slightly indicating a slight model improvement by including the adjusted prediction methods. 
Table 11. MLR Regression to Test Electricity Realization Rate as a Function of Grantees: R-Squared $=0.106$, Adjusted R-Squared $=0.098$ Degrees of Freedom $=1,198$

\begin{tabular}{|l|r|r|r|r|}
\hline \multicolumn{1}{|c|}{ Variable } & \multicolumn{1}{c|}{ Estimate } & Std. Error & \multicolumn{1}{c|}{$\boldsymbol{t}$ value } & \multicolumn{1}{c|}{$\operatorname{Pr}(>|\mathbf{t}|)$} \\
\hline (Intercept) & 0.333 & 0.082 & 4.070 & 0.000 \\
\hline GRANTEE B & 0.346 & 0.320 & 1.080 & 0.280 \\
\hline GRANTEE DD & 0.122 & 0.122 & 1.000 & 0.318 \\
\hline GRANTEE F & 0.554 & 0.239 & 2.320 & 0.020 \\
\hline GRANTEE FF & 0.192 & 0.097 & 1.980 & 0.048 \\
\hline GRANTEE G & -0.176 & 0.197 & -0.890 & 0.372 \\
\hline GRANTEE H & 0.539 & 0.335 & 1.610 & 0.107 \\
\hline GRANTEE I & -0.288 & 0.296 & -0.970 & 0.332 \\
\hline GRANTEE J & $\mathbf{0 . 8 2 3}$ & $\mathbf{0 . 0 9 9}$ & $\mathbf{8 . 3 3 0}$ & $<\mathbf{2 e - 1 6}$ \\
\hline GRANTEE L & $\mathbf{0 . 6 1 3}$ & $\mathbf{0 . 1 9 4}$ & $\mathbf{3 . 1 5 0}$ & $\mathbf{0 . 0 0 2}$ \\
\hline GRANTEE O & 0.333 & 0.277 & 1.200 & 0.230 \\
\hline GRANTEE S & -0.356 & 0.188 & -1.900 & 0.058 \\
\hline
\end{tabular}

Issues comparable to those with the natural gas realization rates were also apparent with the electricity realization rates. After filtering, the data for electricity realization rate analysis contained 17 grantees. This represented only $2 \%$ of single-family projects and only two of these grantees had sample sizes larger than $10 \%$ of their projects. Project counts, mean electricity realization rates, and the SD of electricity realization rates are listed for the GRANTEE and adjusted prediction method combinations in Table 12. The table is sorted first by the adjusted prediction method then by the GRANTEE category. Grantees using "deemed" and having more than 100 projects are highlighted in gray and grantees using "simulation" and having more than 100 projects are highlighted in yellow. The data are very unbalanced. For example, Grantee FF had 402 projects in these data but all with a prediction method of "deemed." All but 19 of Grantee DD's 129 projects used "simulation" for the prediction method. Only 33 projects used the prediction method of "other" and these were split between Grantee O and Grantee S. As with natural gas realization rate data, these highly correlated combinations make it impossible to determine statistically if the differences in realization rates were truly due to the grantee or the prediction method used. EEMs were also investigated and similar issues were observed. In the filtered data, Grantee FF had the highest proportion of installed air conditioning systems, whereas as Grantee DD had the highest proportion of floor/foundation insulation projects. 
Table 12. Project Counts, Mean Electricity Realization Rates, SD Electricity Realization Rates for Grantee, and Adjusted Prediction Method Combinations

\begin{tabular}{|c|l|r|r|r|}
\hline GRANTEE & \multicolumn{1}{|c|}{$\begin{array}{c}\text { Adjusted } \\
\text { Prediction } \\
\text { Method }\end{array}$} & $\begin{array}{c}\text { Project } \\
\text { Count }\end{array}$ & \multicolumn{1}{c|}{$\begin{array}{c}\text { Mean Natural } \\
\text { Ras } \\
\text { Rates }\end{array}$} & $\begin{array}{c}\text { SD Natural } \\
\text { Gas } \\
\text { Realization } \\
\text { Rates }\end{array}$ \\
\hline A & Deemed & $\mathbf{1 5 7}$ & $\mathbf{0 . 3 3}$ & $\mathbf{1 . 2 2}$ \\
\hline DD & Deemed & 19 & 0.69 & 0.70 \\
\hline F & Deemed & 2 & 0.89 & 1.32 \\
\hline FF & Deemed & $\mathbf{4 0 2}$ & $\mathbf{0 . 5 2}$ & $\mathbf{0 . 6 2}$ \\
\hline G & Deemed & 32 & 0.16 & 0.89 \\
\hline J & Deemed & $\mathbf{3 4 8}$ & $\mathbf{1 . 1 6}$ & $\mathbf{1 . 1 9}$ \\
\hline L & Deemed & 13 & 1.04 & 2.06 \\
\hline S & Deemed & 14 & -0.35 & 1.76 \\
\hline O & Other & 10 & 1.06 & 1.82 \\
\hline S & Other & 23 & 0.18 & 0.88 \\
\hline B & Simulation & 11 & 0.68 & 0.47 \\
\hline DD & Simulation & $\mathbf{1 1 0}$ & $\mathbf{0 . 4 1}$ & $\mathbf{0 . 9 4}$ \\
\hline F & Simulation & 19 & 0.89 & 0.72 \\
\hline G & Simulation & 1 & -0.06 & $\mathrm{NA}$ \\
\hline H & Simulation & 10 & 0.87 & 0.75 \\
\hline I & Simulation & 13 & 0.05 & 1.25 \\
\hline L & Simulation & 21 & 0.89 & 1.95 \\
\hline O & Simulation & 5 & -0.12 & 0.36 \\
\hline
\end{tabular}

In summary, both natural gas and electricity realization rates have high variability and determining which factors contributed to the variability was difficult. There were significant differences between grantees, but these might have been due to differences in prediction methods used by grantees, the particular EEMs installed by grantees, house vintage, region of the country, or a variety of other reasons. A larger, more balanced, and more representative data set would be needed to differentiate between additional potential driving factors for realization rates. Collecting additional detailed information about the characteristics of the homes (e.g., system types) and changes in occupancy during the periods that utility bills are collected would also help improve future regression modeling and realization rate analyses. 


\section{Conclusions and Future Work}

The analysis in this report yielded the following conclusions:

- Air sealing and attic insulation were the most common installed measures; both were present in five of the top ten most frequent combinations of measures.

- The percentage of projects having certain installed measures varied by:

○ Region of the country (e.g., houses in the South had the highest percentage of air conditioner replacement measures)

- Vintage of the home (e.g., houses built in the 1990s had the highest percentage of air conditioner replacement measures)

- Simulations were used more often than "deemed savings" methods in estimating overall energy savings on projects. However, the MLR analysis of total energy savings estimated by grantees indicated no significant differences in estimated savings between the deemed method and simulations.

- The five measures ${ }^{8}$ with the highest estimated energy savings, based on the MLR analysis, are solar PV, heat pumps, solar thermal, boilers and wall insulation.

- The five measures with the lowest estimated energy savings, based on the MLR analysis, are low-flow aerators, thermostatic expansion valves, air conditioner tune-ups, dishwashers, and fireplace inserts.

- For the top ten EEM combinations (excluding medium frequency measures), those with air sealing and attic insulation appear to have the greatest variation in estimated energy savings across all projects. Combinations with lighting and water heater installation have the least variation in estimated energy savings.

- There were significant differences in estimated energy savings per project by geographic region. The South had the lowest estimated average savings compared to three other standard census regions. There was not a significant correlation between estimated savings per project and regional energy consumption determined from RECS 2009 data, meaning that regions with higher average household energy consumption - according to RECS - did not necessarily have higher estimated savings values.

- MLR models of estimated energy savings using grantees as categories gave better fits than models using census region. The grantee categories captured location-dependent differences (e.g., climate, typical fuel types) as well as programmatic differences between grantees not captured by other regression variables.

- Based on the MLR analysis, the vintage ${ }^{9}$ of homes showed significant differences in estimated energy savings. Homes built before 1950 had the highest estimated savings compared to homes built in other years.

\footnotetext{
${ }^{8}$ For this analysis, measures included traditional EEMs (e.g., insulation, equipment upgrades) as well as measures involving renewable energy (e.g., solar PV). Grantees estimated the reduction in net energy use that would result from solar installations and this was treated as the associated energy savings.

${ }^{9}$ The vintage of the home could be a proxy for many things, including the construction practices and energy codes at the time the house was built.
} 
- Based on the MLR analysis, projects with loans had approximately 5 to 8 MMBtu greater estimated annual source energy savings than projects without loans. The mean retrofit invoiced cost on projects with loans was more than double the mean retrofit invoiced cost on projects without loans.

- Estimated energy savings were generally greater than the savings derived from utility data for the small subset of projects that had sufficient utility data:

$\circ$ For natural gas, $68 \%$ of projects in the subset (data from 9 grantees, representing only $2 \%$ of single-family projects) had estimates greater than 1.5 times the normalized utility savings.

$\circ$ For electricity, $53 \%$ of projects in the subset (data from 17 grantees, representing only $3 \%$ of single-family projects) had estimates greater than 1.5 times the normalized utility savings.

- Although savings were generally over-estimated for homes in the small subset, the average savings derived from utility data were positive. According to these utility data, the average annual source electricity savings was 17.1 MMBtu and the average annual source natural gas savings was 13.2 MMBtu.

Some ideas for future work follow:

- Conduct focused studies within subsets of data (e.g., data for a particular grantee) that present unique opportunities for insights.

- Investigate the potential benefit of calibrating savings prediction models to pre-retrofit billing data to improve the accuracy of savings predictions. 


\section{References}

Box, G.; Hunter, W.; Hunter, J. (1978). Statistics for Experimenters. New York: John Wiley \& Sons; pp. 232-235.

ANSI/BPI-2400-S-2012. (2012). Standard Practice for Standardized Qualification of WholeHouse Energy Savings Predictions by Calibration to Energy Use History. Building Performance Institute, Inc. Accessed April 6, 2015: http://www.bpi.org/Web\%20Download/BPI\%20Standards/BPI-2400-S2012 Standard_Practice for_Standardized_Qualification_of_WholeHouse \%20Energy\%20Savings_9-28-12_sg.pdf.

Henze, G.; Pless, S.; Petersen, A.; Long, N.; Scambos, A. (2014). Control Limits for Building Energy End Use Based on Engineering Judgment, Frequency Analysis, and Quantile Regression. Golden, CO: National Renewable Energy Laboratory, NREL/TP-5500-60020.

"Interpreting Regression Output." (2007). Princeton University. Accessed January 13, 2014 : http://dss.princeton.edu/online_help/analysis/interpreting_regression.htm.

Kissock, K.; Heberl, J.; Claridge, D. (2012). Development of a Toolkit for Calculating Linear, Change-Point Linear and Multiple-Linear Inverse Building Energy Analysis Models. Atlanta, GA: ASHRAE, Technical Report 1050-RP. Accessed April 6, 2015:

http://repository.tamu.edu/bitstream/handle/1969.1/2847/ESL-TR-02-11-02.pdf?sequence=1

Livingston, O.V.; Cole, P.C.; Elliott, D.B.; Bartlett, R. (2014). Building Energy Codes Program: National Benefits Assessment, 1992-2040." Rev 1. Richland, WA: Pacific Northwest National Laboratory, PNNL-22610.

Montgomery, D.C. (1997). Design and Analysis of Experiments. $4^{\text {th }}$ edition. New York: John Wiley \& Sons; pp. 556-557.

R Core Team. (2014). "R: A Language and Environment for Statistical Computing." Vienna, Austria: R Foundation for Statistical Computing. Accessed April 6, 2015: http://www.Rproject.org/.

Rodríguez, G. (2013). “Introducing R.” Princeton University, Accessed January 13, 2014: http://data.princeton.edu/R/linearModels.html.

U.S. Department of Energy. (2010). "Building Energy Codes 101: An Introduction, May 2010." Accessed April 22, 2015: http://www.energycodes.gov/sites/default/files/becu/BECU_Codes_101 Slide_Notes.pdf.

U.S. Department of Energy. (2014). Better Buildings Neighborhood Program-Summary of Reported Data from July 1, 2010 - September 30, 2013. Accessed November 20, 2014: http://energy.gov/sites/prod/files/2014/09/f18/bbnp_summary_reported_data 9-15-2014.pdf. 
U.S. Department of Energy. (2015a). Better Buildings Neighborhood Program Data Documentation. Accessed April 30, 2014: http://energy.gov/eere/better-buildings-neighborhoodprogram/downloads/better-buildings-neighborhood-program-data

U.S. Department of Energy. (2015b). Better Buildings Neighborhood ProgramAccomplishments. Accessed April 30, 2015:http://energy.gov/eere/better-buildingsneighborhood-program/accomplishments

U.S. Energy Information Administration. (2012). "Residential Energy Consumption Survey (RECS)." Accessed July 16, 2012: http://www.eia.gov/consumption/residential/. 


\section{Appendix A: Utility Data Normalization Approach}

This appendix describes the procedures used to calculate pre-retrofit and post-retrofit annual normalized energy uses based on the utility energy consumption data reported by the grantees.

\section{Extracting and Merging BBNIS Project Data and Utility Data}

The first step was to extract and merge data records from two sources: (1) project data from the BBNIS and (2) utility data from the processed utility data csv file. Table A1 shows the data that were extracted from each source and used in the overall process. Each record in the BBNIS project data corresponds to a unique retrofit project. Each record in the utility data csv file corresponds to a unique meter reading ${ }^{10}$ for a particular fuel type for a particular project (typically these were monthly readings). Thus, a single record in the BBNIS project data was typically linked to many records in the utility data csv file.

Table A-1. Data Extracted for Weather-Normalization Process

\begin{tabular}{|c|c|c|}
\hline $\begin{array}{l}\text { BBNIS Project Data } \\
\text { Variable Name }\end{array}$ & Variable Description & Exclude record when... \\
\hline AWARDEENUMBER & Awardee Number & NULL \\
\hline RETROFITREFNUM & Retrofit Reference Number & NULL \\
\hline RETROFITCOMPLETIONDATE & Retrofit Completion Date & Year or month is NULL \\
\hline BUILDINGUNITTYPE & $\begin{array}{l}\text { Building Unit Type } \\
1 \text { or } 5: \text { Residential (single-family) } \\
\text { 6: Residential (multifamily unit) } \\
\text { 7: Residential (multifamily building) } \\
\text { 2: Commercial }\end{array}$ & NULL or NOT equal to 1 or 5 \\
\hline ZIP5DIGIT & ZIP code (five digit) & $\begin{array}{l}\text { NULL or not a valid } 5 \text { digit zip code } \\
\text { in area of awardee (investigated } \\
\text { visually by plotting zip codes on a } \\
\text { map). }\end{array}$ \\
\hline Utility Data csv File & Variable Description & Exclude record when... \\
\hline Variable Name & & \\
\hline AWARDEENUMBER & Awardee Number & NULL \\
\hline RETROFITREFNUM & Retrofit Reference Number & NULL \\
\hline READYEAR & Read Year & NULL \\
\hline READMONTH & Read Month & NULL \\
\hline READDAY & Read Day & $\begin{array}{l}\text { Assumed to be day } 15 \text { of the month } \\
\text { if NULL, only if the read day is } \\
\text { missing for all records in a set, } \\
\text { otherwise the scenario is excluded. }\end{array}$ \\
\hline FUELTYPE & $\begin{array}{l}\text { Fuel Type (ELECTRICITY, FUEL OIL, } \\
\text { KEROSENE, LPG, NATURAL GAS, or } \\
\text { WOOD) }\end{array}$ & $\begin{array}{l}\text { NULL, FUEL OIL, KEROSENE, } \\
\text { LPG, or WOOD. }\end{array}$ \\
\hline FUELQUANTITY & Fuel Quantity & NULL \\
\hline FUELUNIT & $\begin{array}{l}\text { Fuel Units (CCF, CORDS, GALLONS, } \\
\text { KWH, or THERMS) }\end{array}$ & $\begin{array}{l}\text { Natural gas must be in CCF or } \\
\text { THERMS. When natural gas values } \\
\text { are in CCF, they are converted to } \\
\text { therms before processing. } \\
\text { Electricity must be in kWh. All other } \\
\text { units or NULL units cause the } \\
\text { scenario to be excluded. }\end{array}$ \\
\hline
\end{tabular}

\footnotetext{
${ }^{10}$ Grantees were not required to distinguish between actual and estimated meter readings, so all meter readings were treated as actual readings.
} 
The records were joined by matching both AWARDEENUMBER and RETROFITREFNUM ${ }^{11}$ and a table was created with records that represented all unique combinations of AWARDEENUMBER, RETROFITREFNUM, FUELTYPE, FUEL UNITS, PRE/POST retrofit. PRE/POST values were determined by querying the utility data and determining if any meter readings had been done before the retrofit completion date (PRE) and/or after the retrofit completion date (POST). For example, a single project with pre- and post-retrofit utility data for natural gas and electricity would have produced four records, such as the example data in Table A2.

Table A-2. Example Normalization Scenarios for One Project

\begin{tabular}{|l|l|l|l|l|}
\hline AWARDEENUMBER & RETROFITREFNUM & FUELTYPE & FUEL UNITS & PRE/POST \\
\hline 1234 & 25 & ELECTRICITY & KWH & PRE \\
\hline 1234 & 25 & ELECTRICITY & KWH & POST \\
\hline $\mathbf{1 2 3 4}$ & $\mathbf{2 5}$ & NATURAL GAS & THERMS & PRE \\
\hline 1234 & 25 & NATURAL GAS & THERMS & POST \\
\hline
\end{tabular}

Each record in the table that was created required its own normalization analysis (fuel types had to be analyzed separately and pre/post retrofit data had to be analyzed separately because retrofits to the building could have changed the baseload and temperature-dependent behavior of the building).

\section{Preparing Utility Data for Normalization}

The next step was to prepare the utility data for normalization. For each normalization scenario (e.g., the bold row in Table 2 is one scenario), the appropriate utility data were queried, resulting in a list such as:

\begin{tabular}{|c|c|c|c|c|c|c|}
\hline AWARDEENUM & RETROFITREFNUM & READDATE & FUELTYPE & FUELUNIT & FUELQUANTITY & DAYS IN PERIOD \\
\hline 1234 & 25 & $1 / 5 / 2011$ & NATURAL GAS & THERMS & 238 & N/A \\
1234 & 25 & $2 / 6 / 2011$ & NATURAL GAS & THERMS & 227 & 32 \\
1234 & 25 & $3 / 7 / 2011$ & NATURAL GAS & THERMS & 215 & 29 \\
1234 & 25 & $4 / 5 / 2011$ & NATURAL GAS & THERMS & 167 & 29 \\
1234 & 25 & $5 / 4 / 2011$ & NATURAL GAS & THERMS & 101 & 29 \\
1234 & 25 & $6 / 5 / 2011$ & NATURAL GAS & THERMS & 78 & 32 \\
1234 & 25 & $7 / 5 / 2011$ & NATURAL GAS & THERMS & 44 & 30 \\
1234 & 25 & $8 / 5 / 2011$ & NATURAL GAS & THERMS & 58 & 31 \\
1234 & 25 & $9 / 4 / 2011$ & NATURAL GAS & THERMS & 52 & 30 \\
1234 & 25 & $10 / 3 / 2011$ & NATURAL GAS & THERMS & 59 & 29 \\
1234 & 25 & $11 / 1 / 2011$ & NATURAL GAS & THERMS & 78 & 29 \\
1234 & 25 & $12 / 3 / 2011$ & NATURAL GAS & THERMS & 185 & 32 \\
1234 & 25 & $1 / 7 / 2012$ & NATURAL GAS & THERMS & 250 & 35 \\
\hline
\end{tabular}

The number of days in each billing period (DAYS IN PERIOD) was calculated based on the differences in read dates. The DAYS IN PERIOD could not be calculated for the first meter

\footnotetext{
${ }^{11}$ RETROFITREFNUM alone cannot be used as a key because in some cases multiple grantees used the same numbering scheme for RETROFITREFNUM (e.g., "1, 2, 3, 4, 5, ..., etc."). Also, spaces in RETROFITREFNUM are ignored when matching and matching is case sensitive.
} 
reading; therefore, it was always excluded from the analysis. Also, the billing period that contained the retrofit completion date was always excluded from the analysis. The total time span of the utility data was then calculated by summing the DAYS IN PERIOD of those records where FUEL QUANTITY was not NULL. The normalization was not attempted unless the total time span was at least 330 days $^{12}$ and had at least 10 billing periods.

If a project had more than one utility bill record with the same fuel type and date, the mean of the nonzero fuel quantities on that date was calculated and used as the fuel quantity for that date. If the mean value was more than $1 \%$ different from any of the other nonzero values, the scenario was excluded from the analysis. This procedure allowed for combining duplicate rows in the utility billing data, specifically where one was in CCF and the other therms (because the CCF value was converted to therms before this step).

If any of the fuel quantities were less than zero (indicating power generation or some sort of error in reporting), the scenario was excluded from the analysis. Also, if there was no fuel use at all the scenario was excluded.

The average daily temperature for each billing period was required for the normalization. These data were obtained by querying the National Ocean and Atmospheric Administration National Climatic Data Center's Integrated Surface Database. The closest on-land weather station was located based on the latitude and longitude associated with the five-digit ZIP code for the project and then the daily average temperature for the billing period was calculated based on historical hourly temperature data for that period. National Climatic Data Center hourly temperature data may be missing for some time periods during the billing period. When this occured, missing data were filled forward based on adjacent data and then the average daily temperature was calculated. The average daily temperature was filled a maximum of 3 days in the case of missing data. If more weather data were missing, the next closest weather station was used.

\section{Creating the Regression Models}

The ASHRAE Inverse Modeling Toolkit (IMT) software was used to create the regression models (Kissock et al. 2002). The following data were provided to the IMT software for each normalization scenario:

- Average daily energy use for each billing period

- Average daily temperature for each billing period

- Date of the last day in each billing period.

When the normalization scenario was for natural gas utility data, the IMT software was used to create a three-parameter heating model (see Figure A1 for an example). When the normalization scenario was for electricity utility data, the IMT software was used to create three separate regression models:

\footnotetext{
${ }^{12}$ A similar 330-day minimum threshold is used in Building Performance Institute Standard 2400 (BPI 2012).
} 
1. Three-parameter heating model,

$$
Y_{h}=\left\{\begin{array}{r}
Y c p+L S(X-X c p), X<X c p \\
Y c p, \text { otherwise }
\end{array}\right.
$$

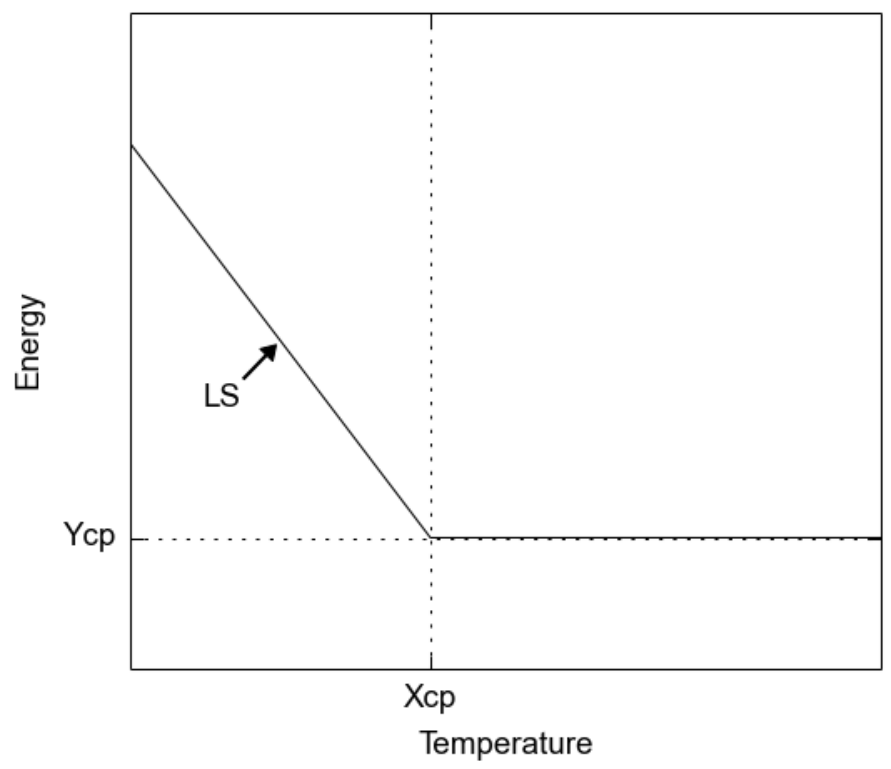

Figure A-1. Three-parameter heating model

2. Three-parameter cooling model,

$$
Y_{h}=\left\{\begin{array}{r}
Y c p+R S(X-X c p), X>X c p \\
Y c p, \text { otherwise }
\end{array}\right.
$$

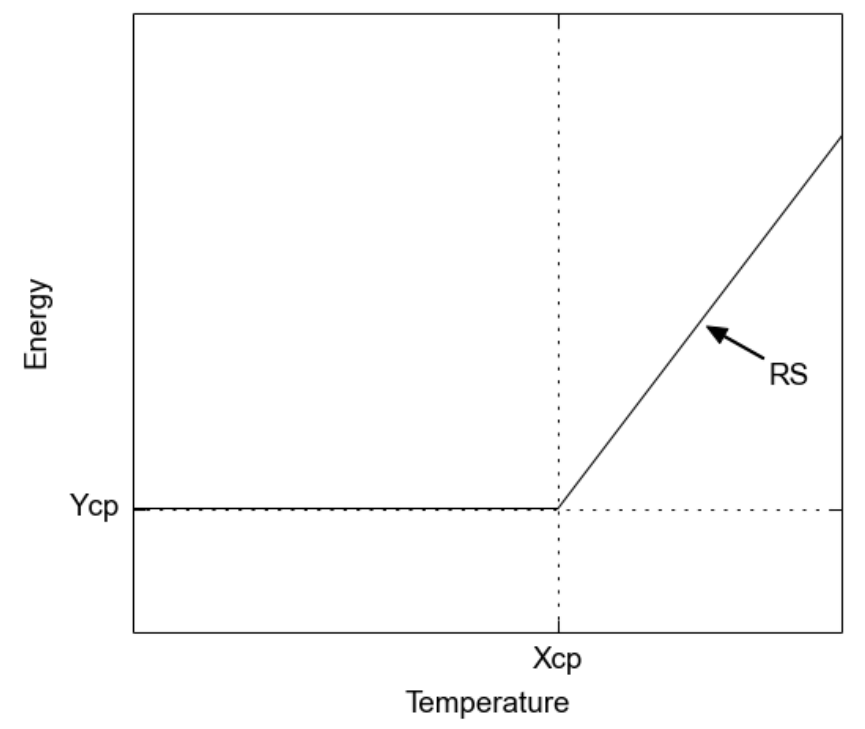

Figure A-2. Three-parameter cooling model 
3. Five-parameter model

$$
f(x)=\left\{\begin{array}{r}
Y c p+L S(X-X c p 1), X<X c p 1 \\
Y c p+R S(X-X c p 2), X>X c p 2 \\
Y c p, \text { otherwise }
\end{array}\right.
$$

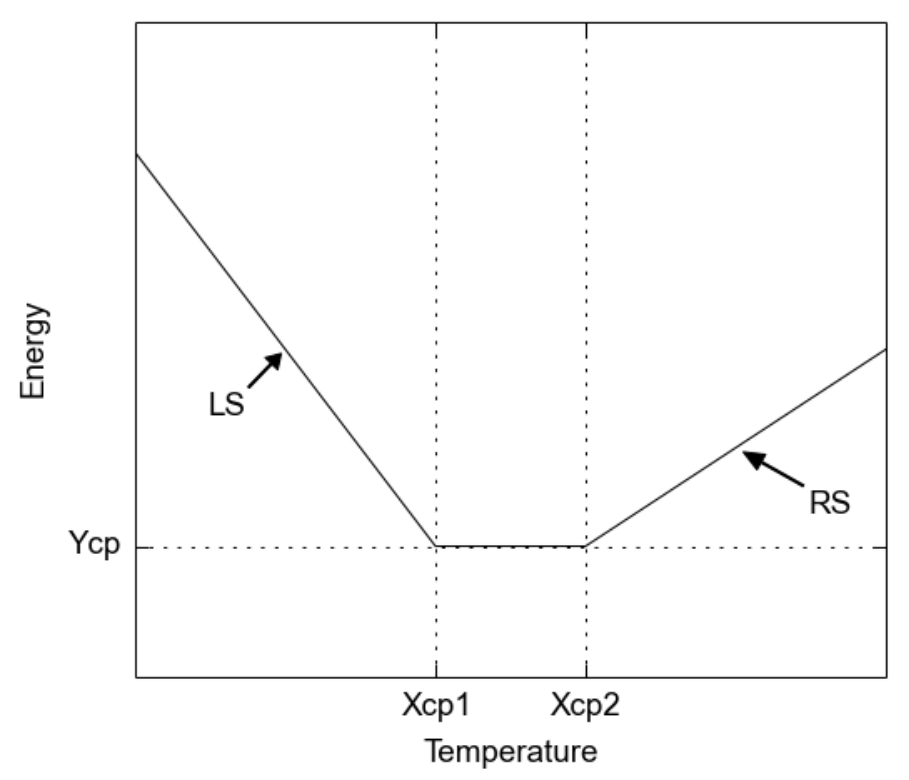

Figure A-3. Five-parameter model

For each model mentioned above, residuals were calculated by subtracting the modeled energy use from the actual energy use. The mean and SD were calculated for the residuals. Billing periods with residuals more than three SDs from the mean were considered for removal; up to two of them were removed. If more than two were identified, the two that deviated the most from the mean were removed. Finally, a new regression model was calculated using the remaining data and that model was considered moving forward.

Some regression models were excluded based on fit parameter values and statistical metrics that characterized the goodness-of-fit, including the R squared value and the coefficient of variation of the root mean squared error (CV-RMSE). The goal of the filtering was to eliminate models where there was lower confidence that the regression equations accurately predicted the energy consumption of the home. For example, the utility data did not contain information about occupancy changes. If major occupancy changes occurred within the time period of the billing data, it should have been less likely that the models fitted to those data would yield a high $\mathrm{R}$ squared and low CV-RMSE values.

Natural gas scenarios were excluded if no three-parameter heating regression model had:

$$
\text { - } \text { CV-RMSE }<20 \%{ }^{13}
$$

\footnotetext{
${ }^{13} \mathrm{~A}$ similar CV-RMSE threshold is used in BPI Standard 2400 (BPI, 2012).
} 
- $\mathrm{R}^{2} \geq 0.7$

- Change-point temperature of $40^{\circ}-80^{\circ} \mathrm{F}$

- $\quad$ Left slope (heating slope) $\geq-1$ and $\leq 0$

- At least 100 days of utility data with average billing period temperatures below the change-point temperature.

For the electricity scenario, each of the three separate regression models (three-parameter heating, three-parameter cooling, and five-parameter) was created if the following applicable criteria were satisfied:

- Three-parameter heating:

○ $\mathrm{CV}$-RMSE $<20 \%$

○ $\mathrm{R}^{2} \geq 0.7$

$\circ$ C-change-point temperature of $40^{\circ}-80^{\circ} \mathrm{F}$

$\circ \quad$ Left slope (heating slope) $\geq-10$ and $\leq 0$

- At least 100 days of utility data with average billing period temperatures below the change-point temperature.

- Three-parameter cooling:

- CV-RMSE $<20 \%$

- $\mathrm{R}^{2} \geq 0.7$

○ Change-point temperature of $50^{\circ}-100^{\circ} \mathrm{F}$

$\circ$ Right slope (cooling slope) $\geq 0$ and $\leq 10$

- At least 100 days of utility data with average billing period temperatures above the change-point temperature.

- Five-parameter:

- CV-RMSE $<20 \%$

○ $\mathrm{R}^{2} \geq 0.7$

- Heating change-point temperature of $40^{\circ}-80^{\circ} \mathrm{F}$

$\circ$ Cooling change-point temperature of $50^{\circ}-100^{\circ} \mathrm{F}$

$\circ \quad$ Left slope (heating slope) $\geq-10$ and $\leq 0$

$\circ$ Right slope (cooling slope) $\geq 0$ and $\leq 10$

- At least 100 days of utility data with average billing period temperatures below the change-point temperature (Xcp1)

- At least 100 days of utility data with average billing period temperatures above the change-point temperature (Xcp2). 
Additionally for the electricity scenario, the IMT software was used to create a "mean" model (assumed no temperature-dependent energy consumption) if the CV-RMSE was $<20 \%$ and the mean energy use was nonnegative. From the four possible models created for each electricity scenario, the model with the lowest CV-RMSE value was selected.

\section{Calculating the TMY3 Normalized Energy Use}

The final step was to calculate the TMY3 normalized annual energy use for each normalization scenario where the IMT software successfully created a model (mean, three-parameter, or fiveparameter). First, the closest TMY3 weather station was selected based on the latitude and longitude associated with the five-digit ZIP code for the project. Then, the TMY3 year was split into periods of time having approximately the same median length as the billing periods used to develop the regression model (e.g., 30-day periods). The daily-average temperature was calculated for each period of the TMY3 year based on the hourly temperature data in the TMY3 file. Finally, the regression model for that scenario was used to estimate the energy consumption for each period in the TMY3 file and those estimated energy consumptions were summed to calculate the annual normalized energy consumption. 


\section{Appendix B: Energy-Efficiency Measure Tables}

This appendix includes a number of tables on the EEMs installed for residential single-family projects. NYSERDA and Town of Bedford were excluded from the counts in the tables.

Table B-1. High-Frequency Installed Measures

\begin{tabular}{|l|r|}
\hline \multicolumn{1}{|c|}{ Measure } & \multicolumn{1}{c|}{ Count } \\
\hline Air Sealing & 30465 \\
\hline Insulation in Attic & 27248 \\
\hline Lighting & 13397 \\
\hline Water Heater & 11890 \\
\hline Hot Water Insulation (tank/pipe) & 10804 \\
\hline Low-flow aerators & 9876 \\
\hline Furnace & 9762 \\
\hline Insulation in Floor or Foundation & 9066 \\
\hline Insulation in Walls & 9019 \\
\hline Duct Sealing & 8592 \\
\hline
\end{tabular}

Table B-2. Medium-Frequency Installed Measures

\begin{tabular}{|l|r|}
\hline \multicolumn{1}{|c|}{ Measure } & Count \\
\hline Air Conditioner & 6048 \\
\hline Programmable Thermostat & 5660 \\
\hline Windows & 5193 \\
\hline Duct Insulation & 4810 \\
\hline Heat Pump & 4344 \\
\hline Ventilation System & 3717 \\
\hline
\end{tabular}


Table B-3. Low-Frequency Installed Measures

\begin{tabular}{|l|r|}
\hline \multicolumn{1}{|c|}{ Measure } & \multicolumn{1}{c|}{ Count } \\
\hline Furnace Tune-up & 1611 \\
\hline Boiler & 1449 \\
\hline Health and Safety & 1430 \\
\hline Water Conservation & 1253 \\
\hline Chimney Liner & 1154 \\
\hline Refrigerator & 1056 \\
\hline Clothes Washer & 965 \\
\hline Smart Strips & 738 \\
\hline Insulation Other Locations & 723 \\
\hline Weather Stripping & 483 \\
\hline HVAC Tune-up & 411 \\
\hline Thermostatic Valve & 388 \\
\hline HVAC Upgrade & 341 \\
\hline Insulation in Basement & 306 \\
\hline Radiant Barrier & 236 \\
\hline Dishwasher & 228 \\
\hline Other & 208 \\
\hline Doors & 192 \\
\hline AC Tune-up & 187 \\
\hline Solar Thermal & 103 \\
\hline Solar PV & 72 \\
\hline Wood Stove & 33 \\
\hline Fireplace Insert & 23 \\
\hline Freezer & 21 \\
\hline Packaged Unit Heating & 2 \\
\hline
\end{tabular}




\section{Appendix C: Source Energy Multipliers}

This appendix includes a table of source energy multipliers used for the most common fuel types that grantees included in estimated energy saved.

Table C-1. Source Energy Multipliers

\begin{tabular}{|l|c|}
\hline \multicolumn{1}{|c|}{ Fuel Type } & $\begin{array}{c}\text { Site-to-Source } \\
\text { Multiplier }\end{array}$ \\
\hline Electricity & 3.365 \\
\hline Natural Gas & 1.092 \\
\hline Fuel Oil & 1.158 \\
\hline Propane/Liquefied Petroleum Gas & 1.151 \\
\hline Kerosene & 1.205 \\
\hline Wood and Pellets & 1.000 \\
\hline
\end{tabular}




\section{Appendix D: Variables Used in MLR Analysis}

This appendix includes tables summarizing the variables considered in the MLR analysis in Sections 3.4-3.5. NYSERDA and Town of Bedford were excluded from this analysis. Full data for the binary variables were data after filtering for reasonable energy saved range. The training data were randomly selected at $70 \%$ from the full data.

Table D-1. Categorical Variables

\begin{tabular}{|l|l|c|}
\hline \multicolumn{1}{|c|}{ Variable } & \multicolumn{1}{c|}{ Description } & $\begin{array}{c}\text { Number of } \\
\text { Categories }\end{array}$ \\
\hline GRANTEE & Letter Code for Each Grantee & 35 \\
\hline CENSUS_REGION & Standard Census Regions & 4 \\
\hline PRED_METHOD_CAT_2 & Prediction Method Categories & 5 \\
\hline
\end{tabular}

Table D-2. Numeric Variables

\begin{tabular}{|c|c|c|c|c|c|c|c|c|}
\hline Variable & Description & $\begin{array}{c}\text { Test } \\
\text { in } \\
\text { Model }\end{array}$ & Missing & $\begin{array}{l}0.5 \text { th } \\
\text { Pctl. }\end{array}$ & $\begin{array}{l}\text { 25th } \\
\text { Pctl. }\end{array}$ & Median & $\begin{array}{l}\text { 75th } \\
\text { Pctl. }\end{array}$ & $\begin{array}{l}\text { 99.5th } \\
\text { Pctl. }\end{array}$ \\
\hline RETROFIT_YR & $\begin{array}{l}\text { Year Project } \\
\text { Completed }\end{array}$ & Yes & 0 & 2010 & 2012 & 2012 & 2013 & 2013 \\
\hline FLOORAREA & $\begin{array}{l}\text { Floor Area } \\
\text { in Square } \\
\text { Feet }\end{array}$ & Yes & 9361 & 0 & 1300 & 1824 & 2500 & 6222 \\
\hline OCCUPANCY & Occupancy & No & 20853 & 0 & 2 & 2 & 3 & 7 \\
\hline $\begin{array}{l}\text { RETROFIT- } \\
\text { JOBHOURS }\end{array}$ & $\begin{array}{l}\text { Project Job } \\
\text { Hours }\end{array}$ & Yes & 4753 & 0 & 8 & 20 & 40 & 280 \\
\hline $\begin{array}{l}\text { RETROFIT- } \\
\text { INVOICEDCOST }\end{array}$ & $\begin{array}{l}\text { Project } \\
\text { Invoiced } \\
\text { Cost }\end{array}$ & Yes & 2356 & 0 & 1913 & 4735 & 9192 & 33942 \\
\hline $\begin{array}{l}\text { RETROFIT- } \\
\text { CUSTCONTRIB }\end{array}$ & $\begin{array}{l}\text { Customer } \\
\text { Contribution }\end{array}$ & No & 26785 & 0 & 0 & 581 & 4148 & 29861 \\
\hline BBSUBSIDY & $\begin{array}{l}\text { Better } \\
\text { Buildings } \\
\text { Subsidy }\end{array}$ & No & 25838 & 0 & 0 & 500 & 1600 & 14196 \\
\hline $\begin{array}{l}\text { TOTALRENEWABLE- } \\
\text { JOBHOURS }\end{array}$ & $\begin{array}{l}\text { Renewable } \\
\text { Project Job } \\
\text { Hours }\end{array}$ & No & 39726 & 0 & 0 & 0 & 0 & 104 \\
\hline $\begin{array}{l}\text { TOTALRENEWABLE- } \\
\text { INVOICEDCOST }\end{array}$ & $\begin{array}{l}\text { Renewable } \\
\text { Project } \\
\text { Invoiced } \\
\text { Cost } \\
\end{array}$ & No & 39672 & 0 & 0 & 0 & 0 & 30991 \\
\hline
\end{tabular}

Table D-3. Binary Variables for EEMs (Count Installed)

\begin{tabular}{|l|l|r|r|}
\hline \multicolumn{1}{|c|}{ Variable } & \multicolumn{1}{|c|}{ Description } & $\begin{array}{c}\text { Full } \\
\text { Data }\end{array}$ & \multicolumn{1}{c|}{$\begin{array}{c}\text { Training } \\
\text { Data }\end{array}$} \\
\hline B_INST_AC & Air Conditioner & 5702 & 4027 \\
\hline B_INST_AC_TUNE & AC Tune-up & 187 & 131 \\
\hline
\end{tabular}




\begin{tabular}{|c|c|c|c|}
\hline Variable & Description & $\begin{array}{l}\text { Full } \\
\text { Data }\end{array}$ & $\begin{array}{c}\text { Training } \\
\text { Data }\end{array}$ \\
\hline B_INST_AIR_SEALING & Air Sealing & 28930 & 20302 \\
\hline B_INST_BOILER & Boiler & 1350 & 1003 \\
\hline B_INST_CLTH_WASH & Clothes Washer & 945 & 665 \\
\hline B_INST_DISHWASHER & Dishwasher & 205 & 140 \\
\hline B_INST_DOORS & Doors & 186 & 128 \\
\hline B_INST_DUCT_INSUL & Duct Insulation & 4654 & 3277 \\
\hline B_INST_DUCT_SEALING & Duct Sealing & 8200 & 5765 \\
\hline B_INST_DHW_INSUL & Hot Water Insulation (tank/pipe) & 10616 & 7509 \\
\hline B_INST_FIREPLACE_INSERT & Fireplace Insert & 22 & 16 \\
\hline B_INST_FREEZER & Freezer & 19 & 15 \\
\hline B_INST_FURNACE & Furnace & 9435 & 6602 \\
\hline B_INST_FURNACE_TUNE & Furnace Tune-up & 1606 & 1154 \\
\hline B_INST_HEAT_PUMP & Heat Pump & 4125 & 2938 \\
\hline B_INST_HVAC_TUNE & HVAC Tune-up & 384 & 270 \\
\hline B_INST_HVAC_UPGRADE & HVAC Upgrade & 341 & 236 \\
\hline B_INST_INSUL_ATTIC & Insulation in Attic & 25963 & 18263 \\
\hline B_INST_INSUL_FLR_FND & Insulation in Floor or Foundation & 8487 & 5954 \\
\hline B_INST_INSUL_WALL & Insulation in Walls & 8661 & 6108 \\
\hline B_INST_LIGHTING & Lighting & 13065 & 9232 \\
\hline B_INST_LOWFLOW & Low-Flow Aerators & 9615 & 6795 \\
\hline B_INST_OTHER & Other & 186 & 137 \\
\hline B_INST_PCKG_UNIT_HT & Packaged Unit Heating & 2 & 1 \\
\hline B_INST_PRGM_TSTAT & Programmable Thermostat & 5454 & 3844 \\
\hline B_INST_REFRIG & Refrigerator & 1012 & 718 \\
\hline B_INST_SOLAR_PV & Solar PV & 72 & 52 \\
\hline B_INST_SOLAR_THERMAL & Solar Thermal & 95 & 64 \\
\hline B_INST_VENT_SYS & Ventilation System & 3557 & 2526 \\
\hline B_INST_WATER_CONSERV & Water Conservation & 1252 & 856 \\
\hline B_INST_WATER_HEATER & Water Heater & 11495 & 8102 \\
\hline B_INST_WINDOWS & Windows & 4876 & 3432 \\
\hline B_INST_WOOD_STOVE & Wood Stove & 29 & 17 \\
\hline B_INST_WTHR_STRPNG & Weather Stripping & 457 & 318 \\
\hline B_INST_THERMO_VLV & Thermostatic Valve & 378 & 270 \\
\hline B_INST_INSUL_BSMT & Insulation in Basement & 284 & 207 \\
\hline B_INST_RAD_BARRIER & Radiant Barrier & 230 & 165 \\
\hline B_INST_HEALTH_SAFETY & Health and Safety & 1374 & 959 \\
\hline B_INST_INSUL_OTHER & Insulation Other Locations & 707 & 503 \\
\hline B_INST_CHIMNEY_LINER & Chimney Liner & 1154 & 813 \\
\hline B_INST_SMART_STRIPS & Smart Strips & 738 & 511 \\
\hline
\end{tabular}


Table D-4. Additional Binary Variables (Counts)

\begin{tabular}{|c|c|c|c|}
\hline Variable & Description & $\begin{array}{l}\text { Full } \\
\text { Data }\end{array}$ & $\begin{array}{l}\text { Trainin } \\
\text { g Data }\end{array}$ \\
\hline LOANAMOUNT_LISTED & Loan amount listed & 8053 & 5670 \\
\hline LOAN_OBTAINED & Loan amount listed or approval date listed & 8078 & 5683 \\
\hline LOANAPPLICATIONREJECTED & Loan application rejected & 33 & 24 \\
\hline AUDIT_BPI_CERT & Auditor was BPI certified & 18052 & 12724 \\
\hline AUDIT_OTHER_CERT & Auditor was certified but not BPI certified & 2204 & 1533 \\
\hline CONTRACT_BPI_CERT & Contractor was BPI certified & 26153 & 18332 \\
\hline CONTRACT_OTHER_CERT & $\begin{array}{l}\text { Contractor was certified but not BPI } \\
\text { certified }\end{array}$ & 3289 & 2353 \\
\hline INST_ELECT_SAVINGS_LISTED & Electricity savings listed & 41421 & 29203 \\
\hline INST_NG_SAVINGS_LISTED & Natural gas savings listed & 33012 & 23210 \\
\hline INST_OTHER_SAVINGS_LISTED & Other fuel type savings listed & 6535 & 4626 \\
\hline YEARBUILT_UNKNOWN & Year built is unknown & 13368 & 9421 \\
\hline YEARBUILT_PRE_1950 & Year built is before 1950 & 12271 & 8666 \\
\hline YEARBUILT_1950_1959 & Year built is 1950 to 1959 & 6258 & 4420 \\
\hline YEARBUILT_1960_1969 & Year built is 1960 to 1969 & 3877 & 2712 \\
\hline YEARBUILT_1970_1979 & Year built is 1970 to 1979 & 3893 & 2732 \\
\hline YEARBUILT_1980_1989 & Year built is 1980 to 1989 & 3213 & 2247 \\
\hline YEARBUILT_1990_1999 & Year built is 1990 to 1999 & 2878 & 2063 \\
\hline YEARBUILT_POST_2000 & Year built is 2000 or after & 1750 & 1204 \\
\hline $\begin{array}{l}\text { RENEWABLEINVOICEDCOST_LISTE } \\
\text { D }\end{array}$ & Renewable invoiced cost is reported & 268 & 203 \\
\hline CUSTOMERCONTRIBUTION_LISTED & Customer contribution for audit is reported & 8408 & 6025 \\
\hline SUBSIDY_LISTED & Subsidy for audit is reported & 8175 & 5818 \\
\hline OTHERFUNDS_LISTED & Other funds for audit is reported & 5879 & 4208 \\
\hline RETROFITCUSTCONTRIB_LISTED & $\begin{array}{l}\text { Customer contribution for project is } \\
\text { reported }\end{array}$ & 11270 & 7988 \\
\hline BBSUBSIDY_LISTED & $\begin{array}{l}\text { Better Buildings subsidy for project is } \\
\text { reported }\end{array}$ & 14171 & 9996 \\
\hline TAXCREDIT_LISTED & Tax credit for project is reported & 1260 & 873 \\
\hline REASON_COMFORT & Reason for upgrade is comfort & 217 & 162 \\
\hline REASON_SAVINGS & Reason for upgrade is savings & 428 & 310 \\
\hline REASON_ENVIRONMENT & Reason for upgrade is environment & 22 & 14 \\
\hline REASON_COMMUNITY & Reason for upgrade is community & 23 & 15 \\
\hline REASON_HEALTH & Reason for upgrade is health & 3 & 2 \\
\hline LOWINCOME_TRUE & Project for low income occupant reported & 3205 & 2229 \\
\hline
\end{tabular}




\section{Appendix E: Energy Saved Distributions}

This appendix includes distribution graphs of estimated energy saved for the combinations listed in Table 1 of Section 2. Table E-1 is the same as Table 1 (duplicated here for convenience). Savings units plotted in the distribution graphs are in source MMBtu/year.

Table E-1. Ten Most Frequent Combinations of Measures

\begin{tabular}{|c|c|c|c|c|c|c|c|c|c|c|c|c|c|c|c|}
\hline 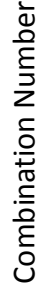 & 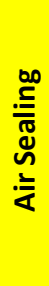 & 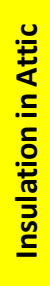 & 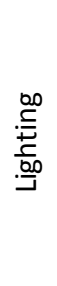 & 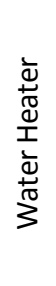 & 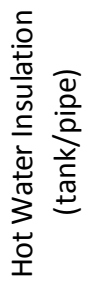 & $\begin{array}{l}0 \\
\frac{0}{0} \\
\frac{\pi}{0} \\
\frac{0}{0} \\
\pi \\
3 \\
0 \\
\frac{4}{4} \\
3 \\
0\end{array}$ & \begin{tabular}{l}
$\stackrel{8}{\sigma}$ \\
\multirow{0}{*}{}
\end{tabular} & 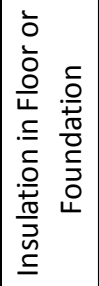 & 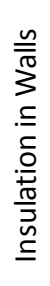 & 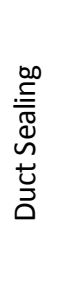 & 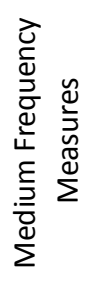 & 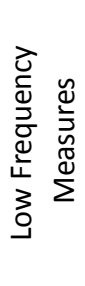 & 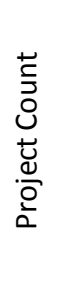 & 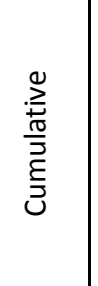 & 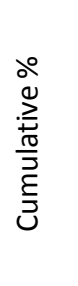 \\
\hline 1 & 0 & 0 & 0 & 0 & 0 & 0 & 0 & 0 & 0 & 0 & 1 & 0 & 3689 & 3689 & $7 \%$ \\
\hline 2 & 1 & 1 & 0 & 0 & 0 & 0 & 0 & 0 & 0 & 0 & 0 & 0 & 3598 & 7287 & $15 \%$ \\
\hline 3 & 1 & 1 & 0 & 0 & 0 & 0 & 0 & 1 & 0 & 0 & 0 & 0 & 1964 & 9251 & $18 \%$ \\
\hline 4 & 1 & 1 & 0 & 0 & 0 & 0 & 1 & 0 & 0 & 1 & 1 & 0 & 1208 & 10459 & $21 \%$ \\
\hline 5 & 0 & 0 & 0 & 1 & 0 & 0 & 0 & 0 & 0 & 0 & 0 & 0 & 1109 & 11568 & $23 \%$ \\
\hline 6 & 0 & 1 & 0 & 0 & 0 & 0 & 0 & 0 & 0 & 0 & 0 & 0 & 1007 & 12575 & $25 \%$ \\
\hline 7 & 1 & 1 & 0 & 0 & 0 & 0 & 0 & 0 & 1 & 0 & 0 & 0 & 978 & 13553 & $27 \%$ \\
\hline 8 & 0 & 0 & 1 & 0 & 1 & 1 & 0 & 0 & 0 & 0 & 0 & 0 & 954 & 14507 & $29 \%$ \\
\hline 9 & 0 & 0 & 1 & 1 & 1 & 1 & 1 & 0 & 0 & 0 & 1 & 0 & 935 & 15442 & $31 \%$ \\
\hline 10 & 1 & 0 & 0 & 0 & 0 & 0 & 0 & 0 & 0 & 0 & 0 & 0 & 931 & 16373 & $33 \%$ \\
\hline
\end{tabular}

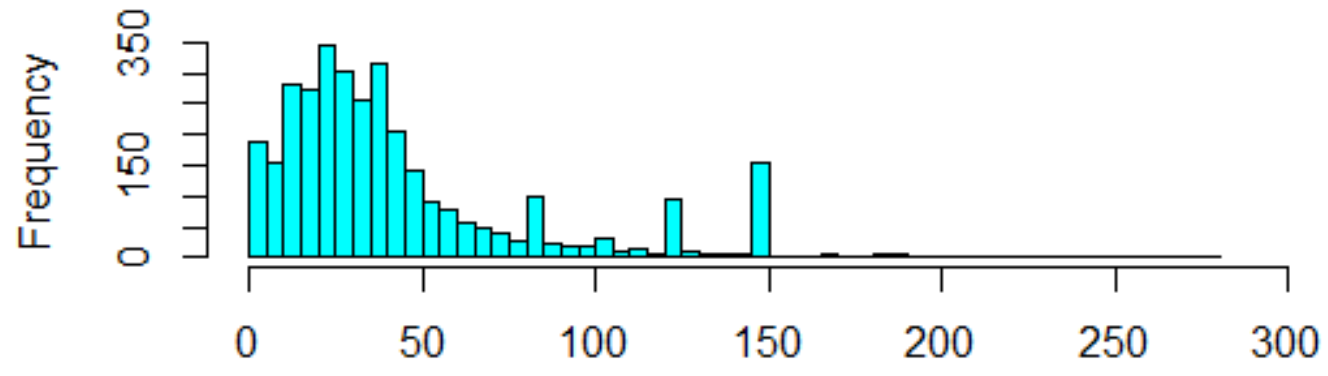

Combination 1

(a) 


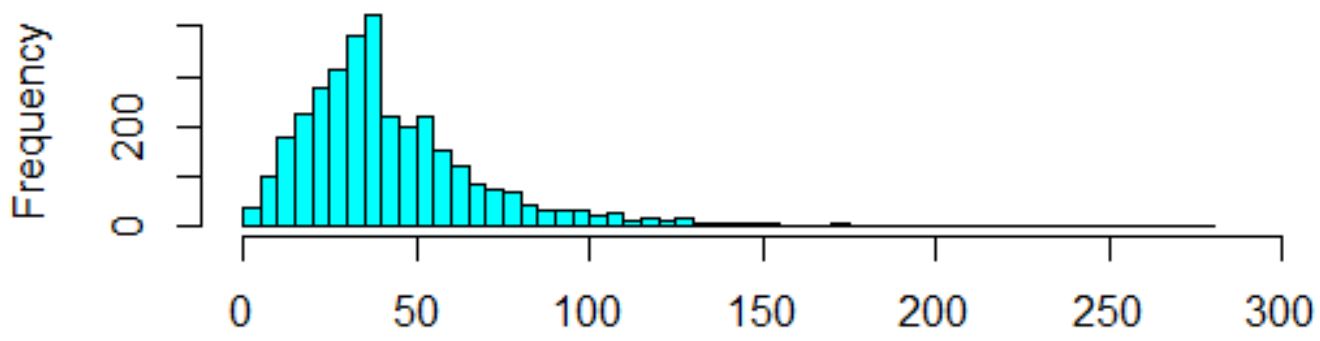

Combination 2

(b)

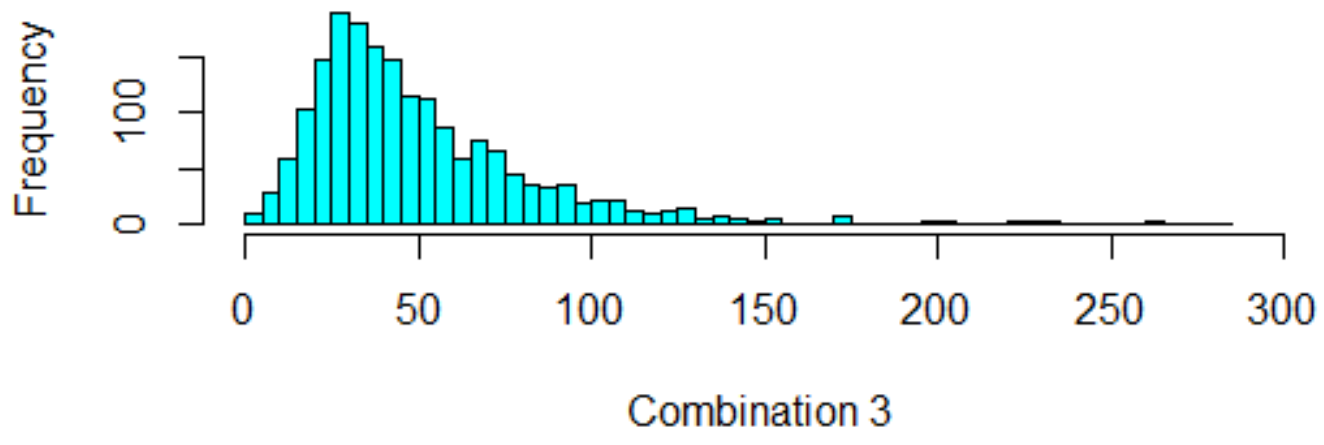

(c)

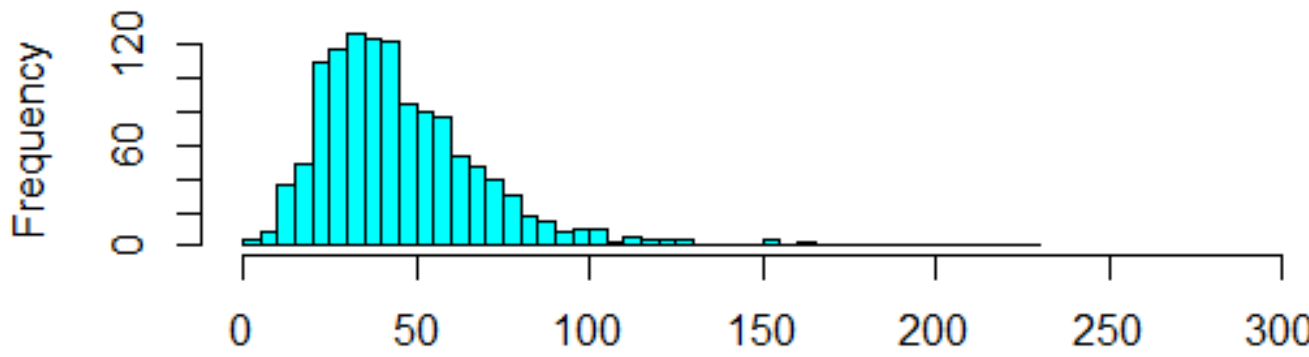

Combination 4

(d) 


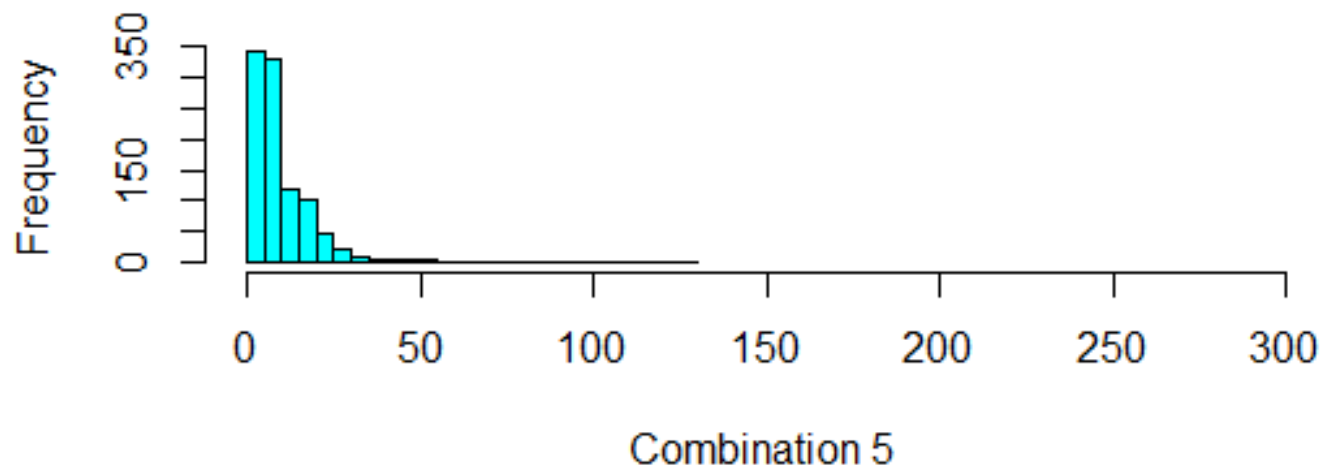

(e)

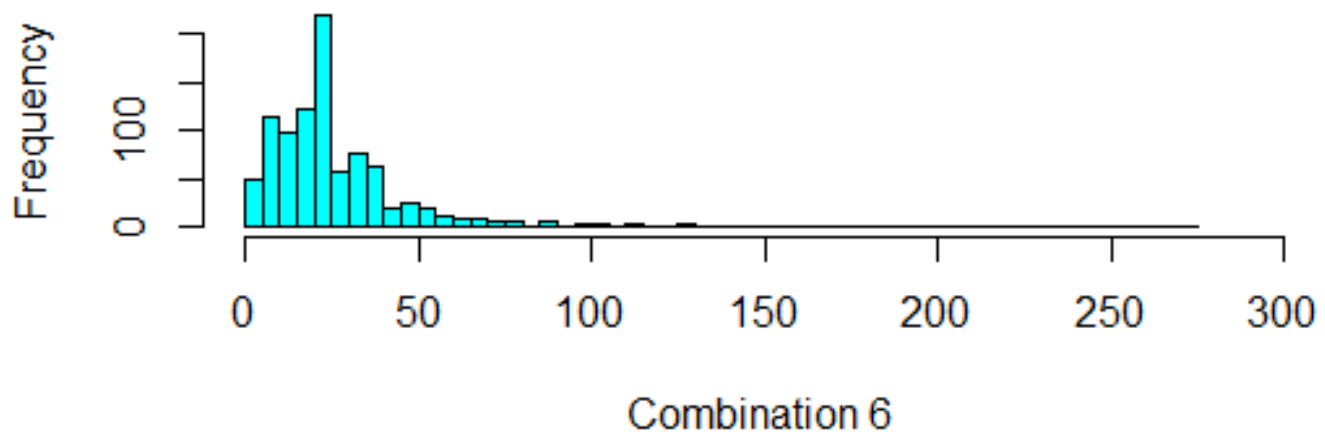

(f)

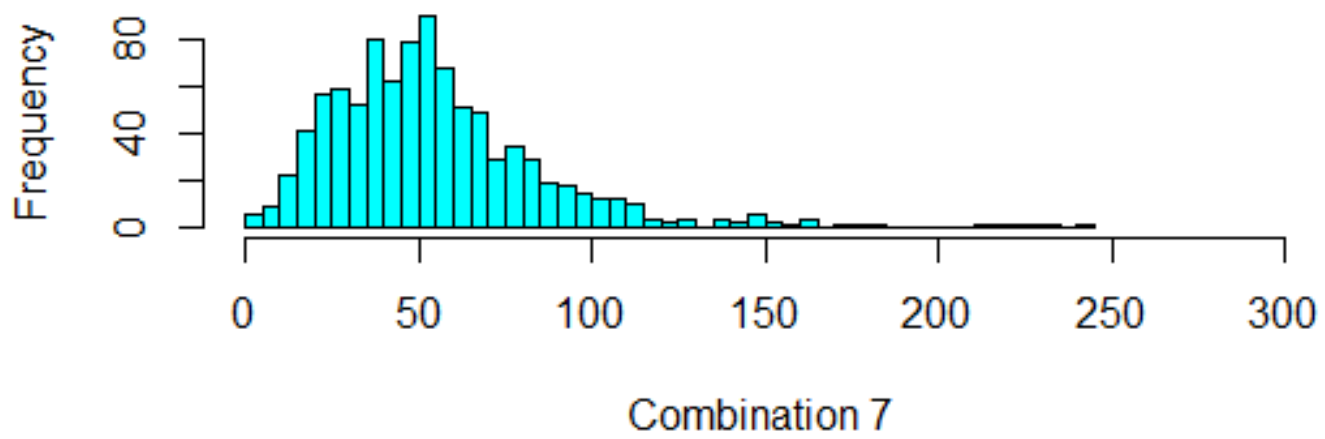

$(\mathrm{g})$ 


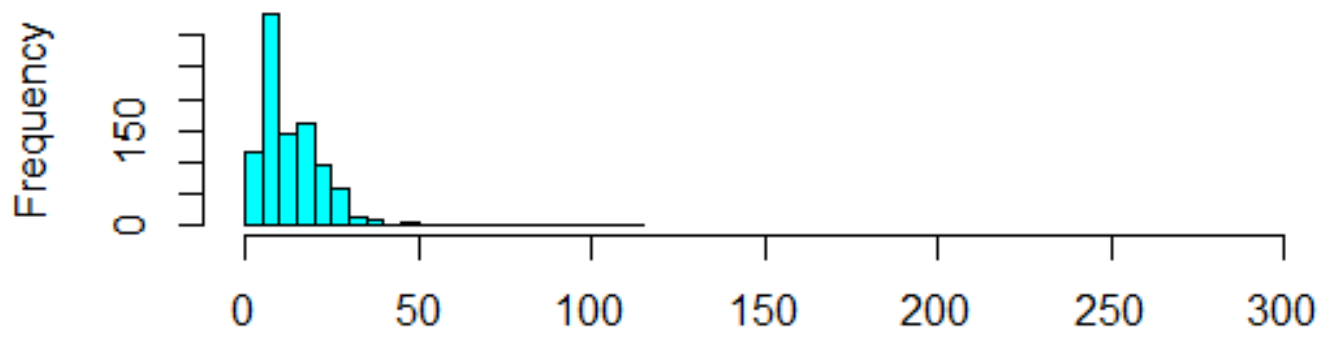

Combination 8

(h)

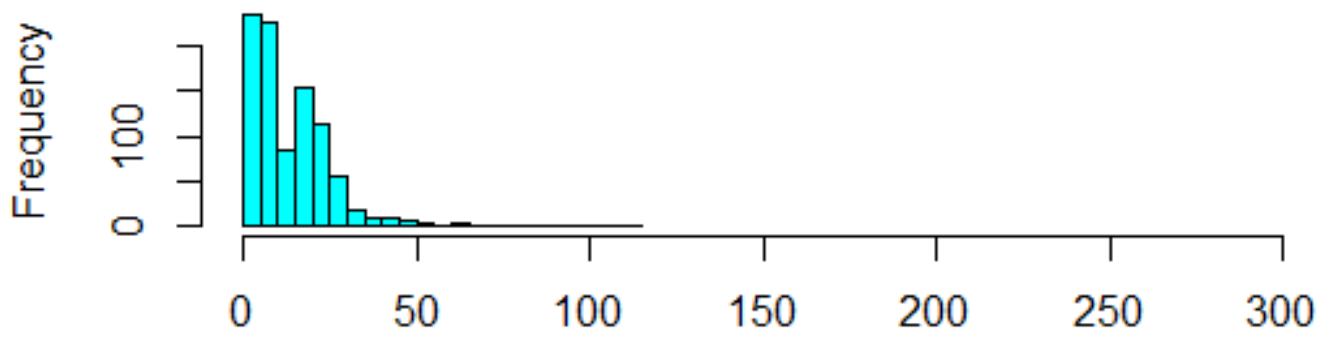

Combination 9

(i)

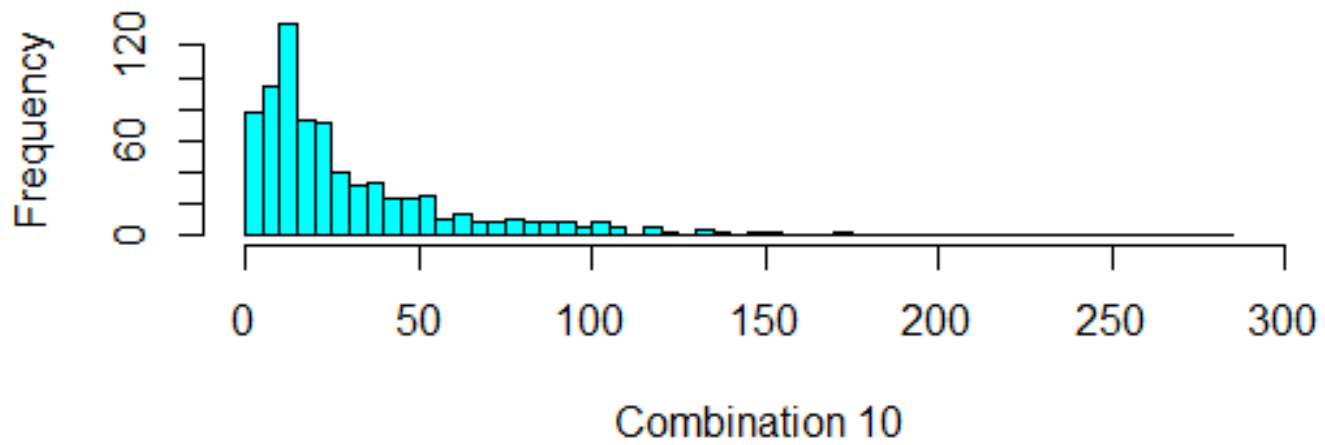

(j)

Figure E-1. Distributions of estimated energy saved for EEM combinations. Savings units are in source MMBtu. 